\title{
Knowledge Sharing Strategies for Smart Architectural Development: facilitating interdisciplinary collaborative design.
}

by

Eric Wolfe

A thesis submitted to the Faculty of Graduate and Postdoctoral Affairs in partial fulfillment of the requirements for the degree of

Master of Design

in the

School of Industrial Design

Carleton University

Ottawa, Ontario

(C) 2021, Eric Wolfe 


\section{Abstract}

The emergence of smart building technologies designed to detect and respond to changes in the built environment have inspired architects to consider the relationship between occupants and responsive environments (Di Christina, 2001; Walter, 2015). Presently, architectural project teams have grown to incorporate specialized technologists to help integrate sensing, actuation, and data collection into the architectural program, yet differences in disciplinary understanding of technologies and design processes (Bektas, 2013) often lead to the failure of smart architectural features (Meagher, 2014) and prevent smart buildings from achieving the full scope of established project objectives.

This research presents an inquiry into how collaboration and knowledge sharing might be best facilitated among interdisciplinary smart architecture project team members through a series of design charrettes and card sorting exercises hosted using online collaboration board tools. Results demonstrate that while online collaboration platforms allowed for a rapid exchange, evolution, and refinement of design ideas - that knowledge sharing and acquisition were mitigated by the knowledge sharing habits of charrette team members and a lack of familiarity with collaboration board tools. Recommendations are made surrounding the organizational approach and implementation of knowledge sharing strategies to overcome interdisciplinary knowledge gaps, improve collaborative efficiency, and generate informed responses to smart architectural design problems.

Keywords: smart architecture, smart technology, knowledge sharing, interdisciplinary collaboration 


\section{Acknowledgements}

First and foremost, thank you to Brock the consultant, Robyn the editor, and to the rest of my family for their love, patience, and support.

I would also like to extend my thanks to my research supervisor Stephen Field and co-supervisor Ali Arya for their insight and expertise regarding all things design and technology. Your collective enthusiasm and interest in my work were instrumental in helping me push forward during my studies.

I am especially grateful to the Faculty of Industrial Design at Carleton for providing me with an opportunity to explore design from another point of view during a transitional period in my studies. Thanks must also be given to my professors and colleagues for countless hours of discussion and camaraderie. Your perspectives and input have enriched my experience and broadened my understanding of the world of design.

Finally, a special thank you to those who completed surveys and participated in online design charrettes and card sorting sessions. Your willingness to share your time and expertise has made this study possible. 


\section{Table of Contents}

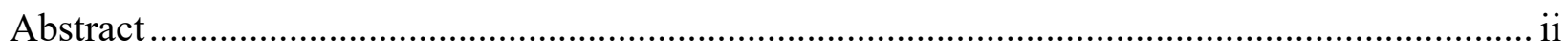

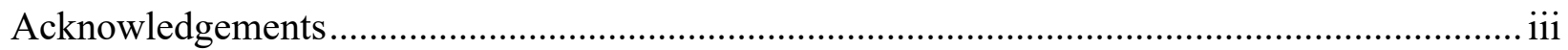

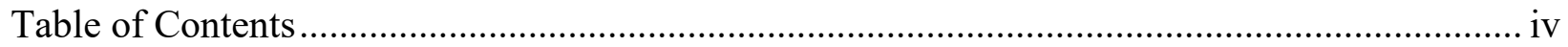

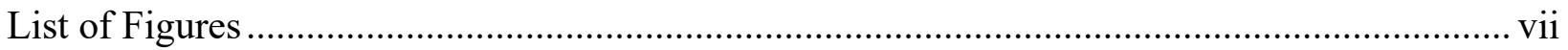

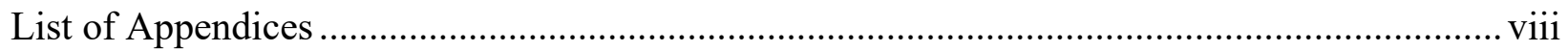

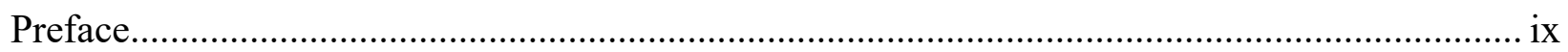

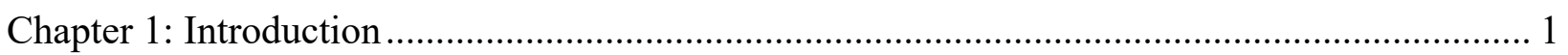

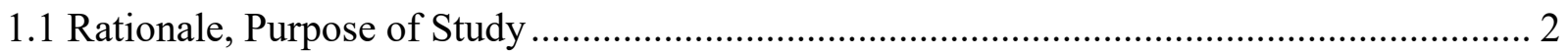

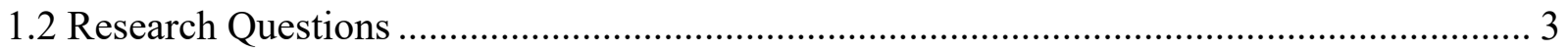

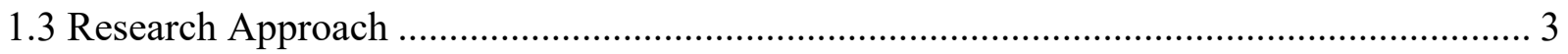

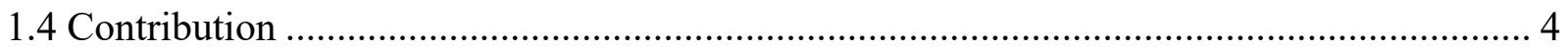

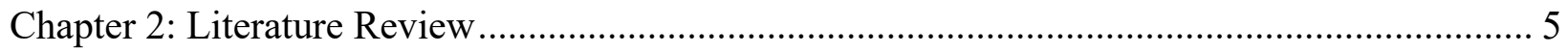

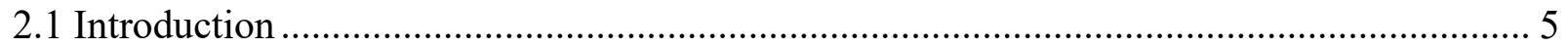

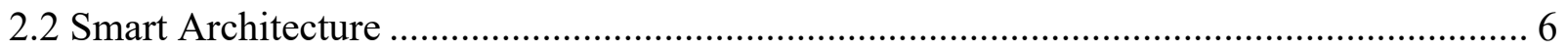

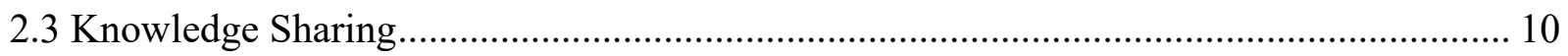

2.4 Barriers to Knowledge Sharing Among Smart Architecture Project Collaborators ............ 12

2.5 Knowledge Sharing Strategies Employed by Smart Architecture Project Collaborators ... 14

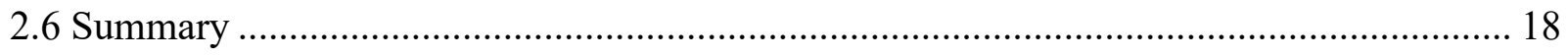

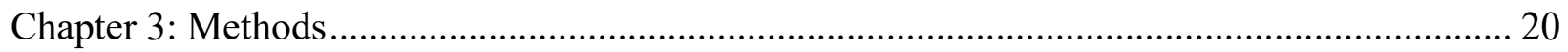

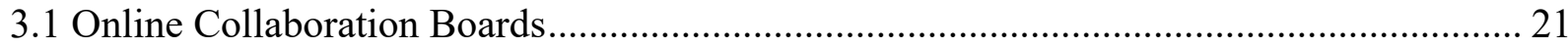

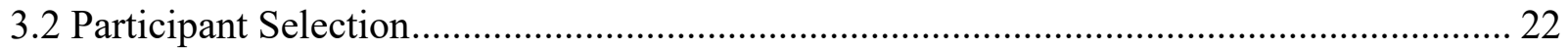

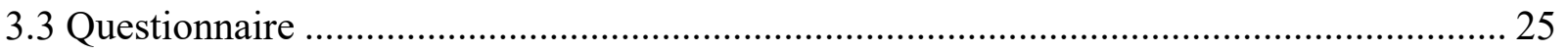

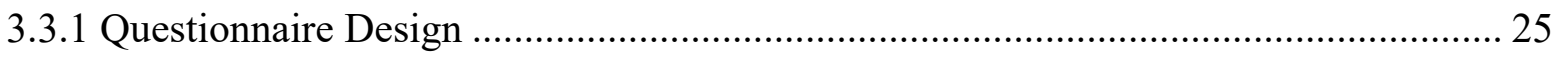


3.3.2 Questionnaire Data Collection.................................................................................... 25

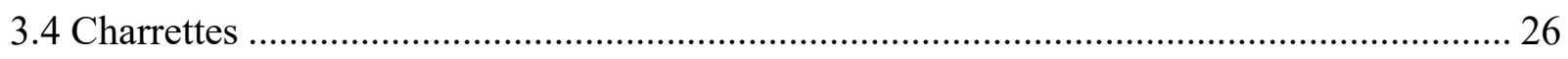

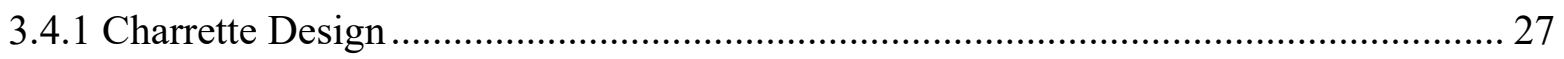

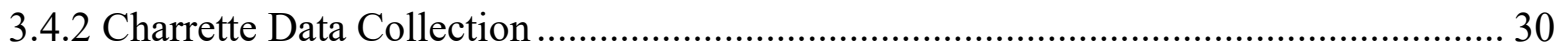

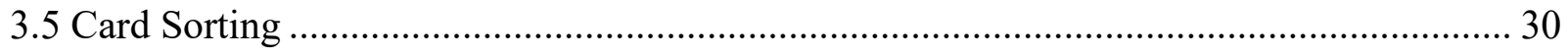

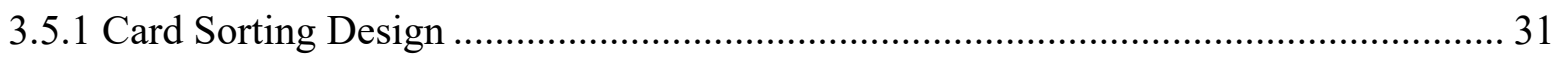

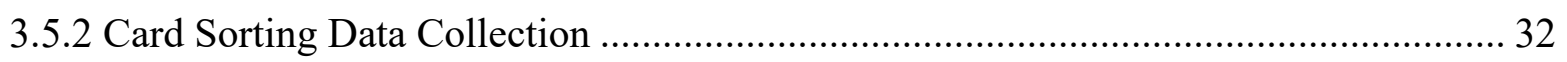

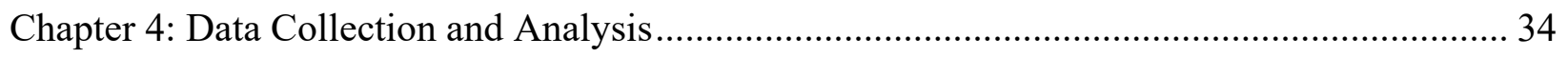

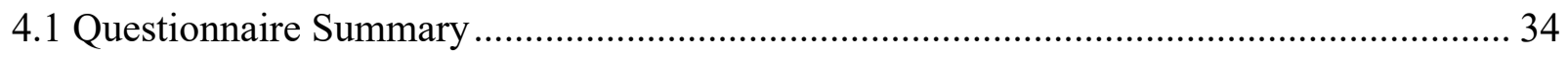

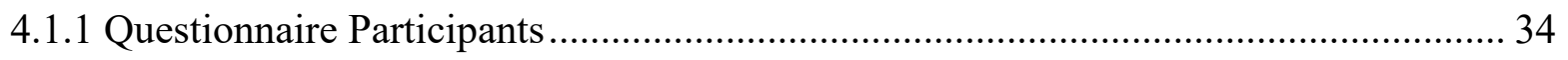

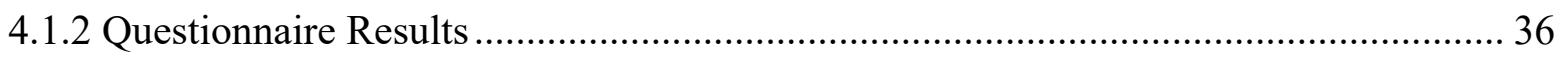

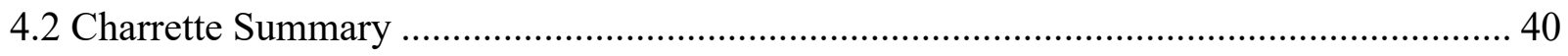

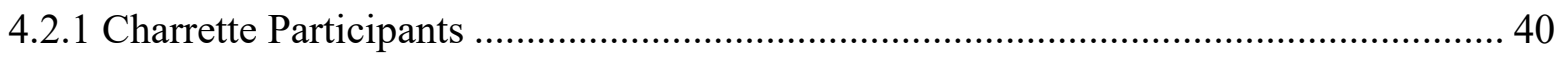

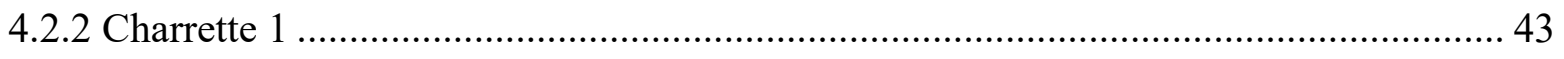

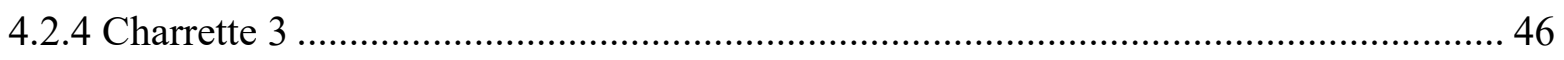

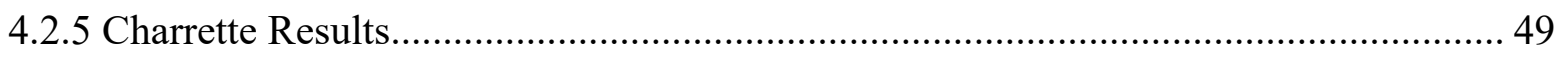

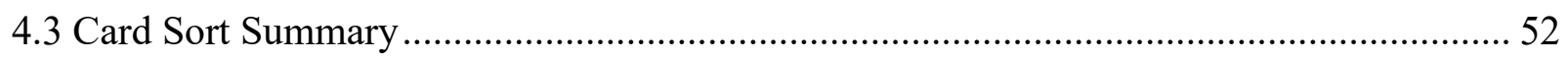

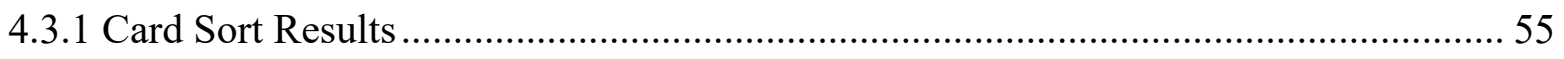

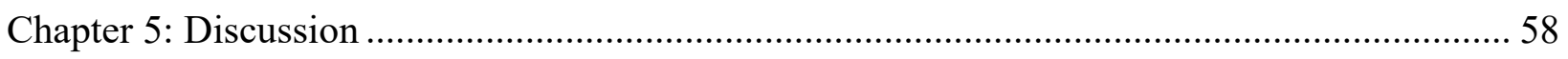

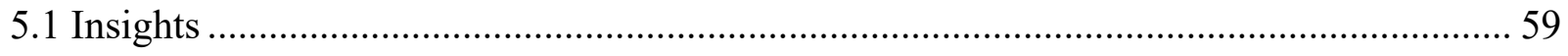

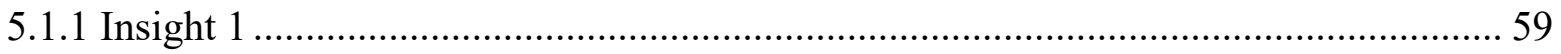

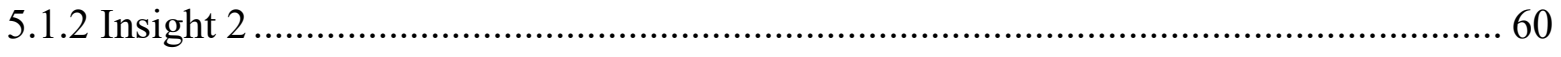

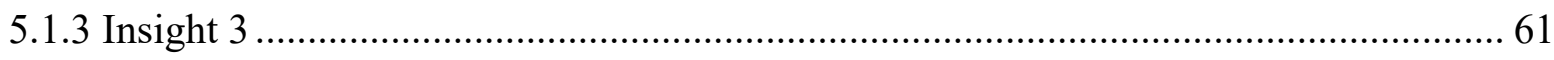

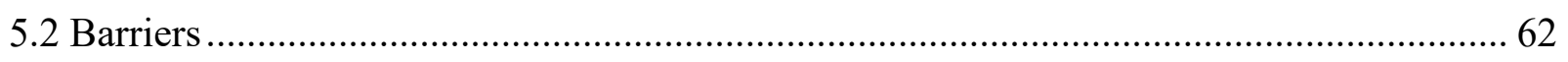

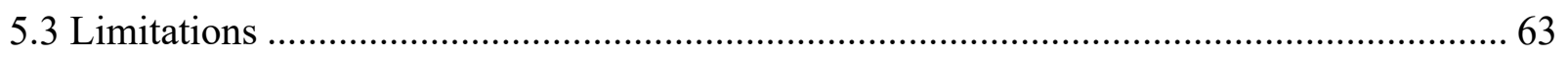




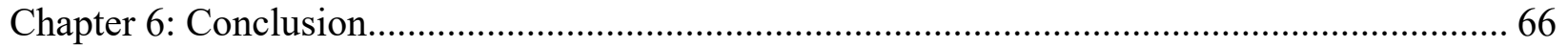

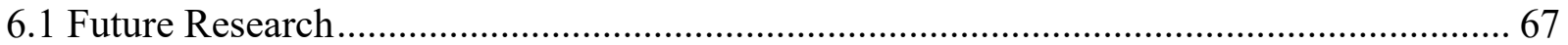

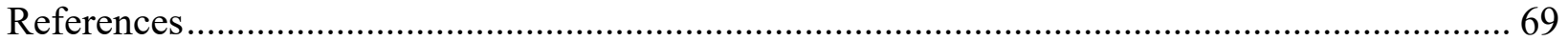




\section{List of Figures}

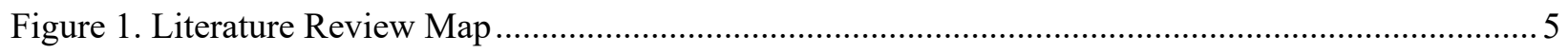

Figure 2. Arab World Institute Southern Façade (Fessy) ................................................................ 6

Figure 3. Mechanical Failure of Shutter Mechanism (Meagher, 2015) .................................................. 7

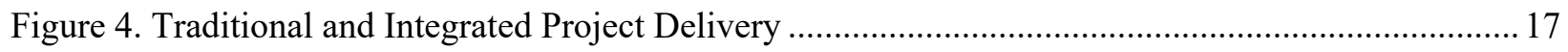

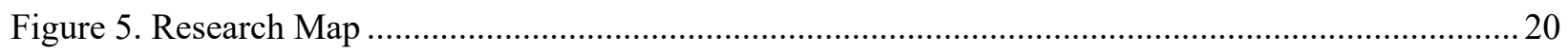

Figure 6. Interaction between smart architecture project team members ............................................ 23

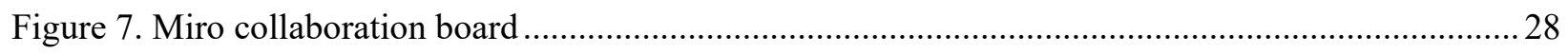

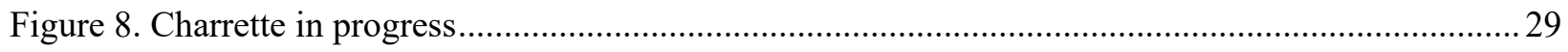

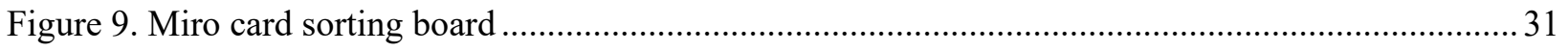

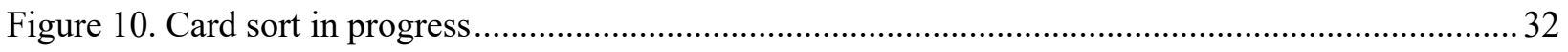

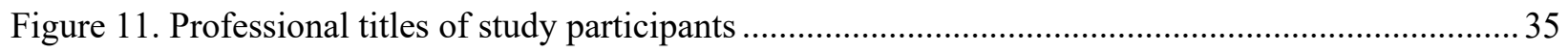

Figure 12. Professional experience level of study participants .......................................................... 35

Figure 13. Knowledge sharing strategies encountered by Team 1 ..................................................... 36

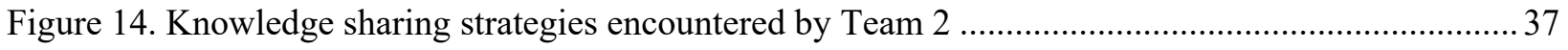

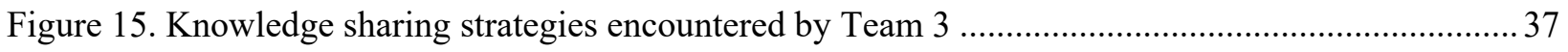

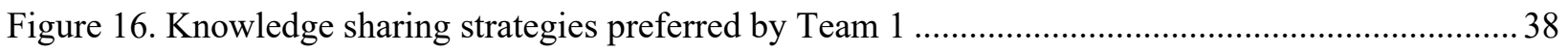

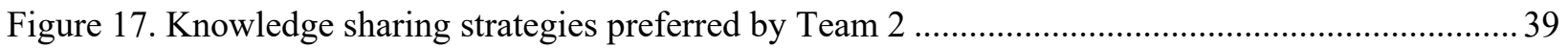

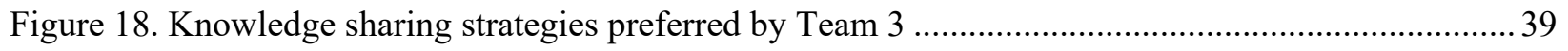

Figure 19. Composition of Charrette and Card Sorting Teams ......................................................... 42

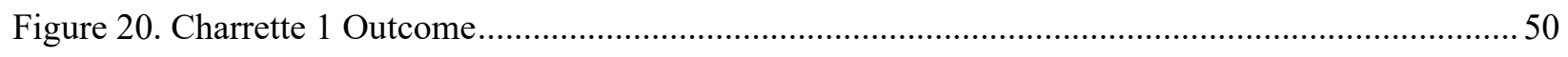

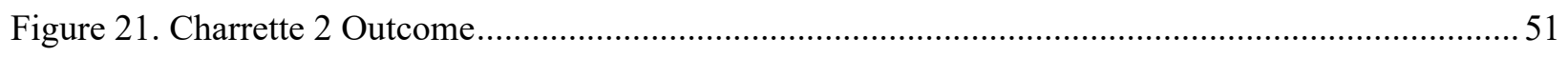

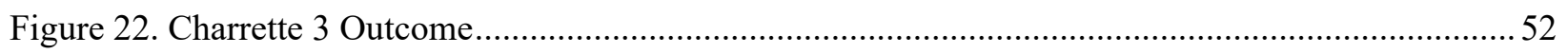

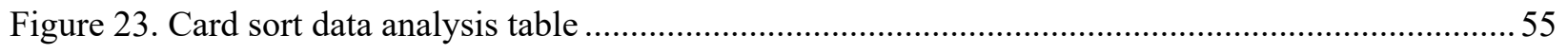




\section{List of Appendices}

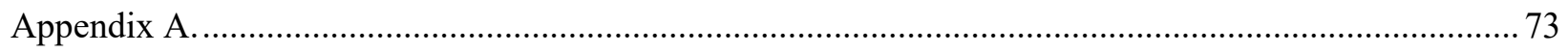

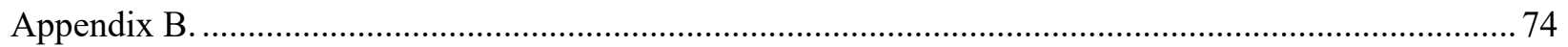

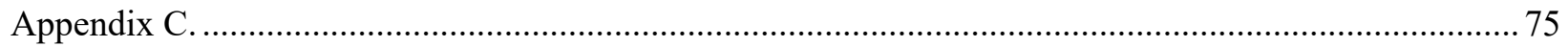

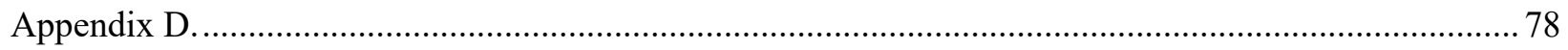

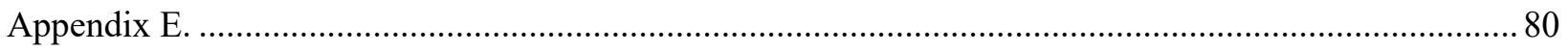

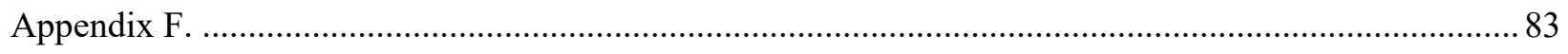

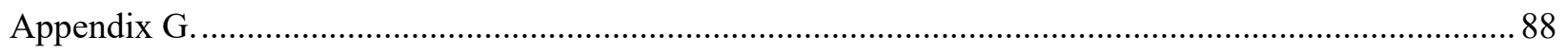

Appendix H.

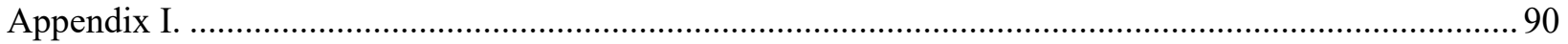

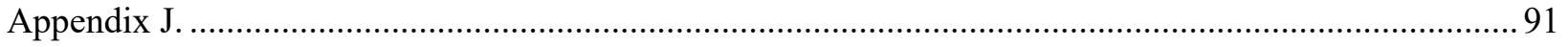

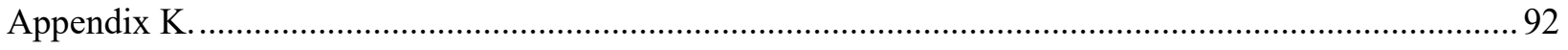

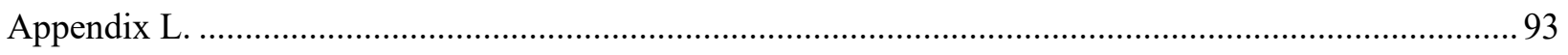

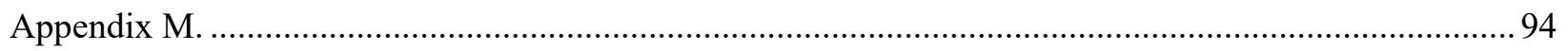




\section{Preface}

Throughout my undergraduate studies in architecture, lectures celebrating the achievements of newly completed smart buildings endeared a then impressionable young architecture student towards what might be possible at the intersection of technology, occupant, and space.

In the years since, however, it has come to light that many of the preeminent examples of smart building design shown to my graduating class have since faltered and ultimately failed to achieve the full scope of occupant satisfaction and energy efficiency goals they had set out to attain. Due to the deterioration and eventual discontinuation of integrated building systems essential to their operation, occupants of smart buildings have been left without many amenities that built environments are responsible for providing.

My ongoing studies with Carleton's School of Industrial Design have broadened my understanding of architecture as a complex interdisciplinary collaborative practice and continue to inform my research into how the opportunities presented by smart technologies might be best leveraged at the spatial and building scale.

The emergent challenges associated with the integration of smart technologies into the built environment have prompted architectural project teams to broaden their range of expertise while simultaneously finding ways to integrate new participants and information into existing disciplinary practices. The disconnect between the purported benefits of technologically augmented architecture and the struggle to design and ensure the continued performance of smart building features forms the basis for this study. 


\section{Chapter 1: Introduction}

Due to the breadth and depth of knowledge required to successfully coordinate all technological and architectural dimensions of smart architecture projects, there is a need for the implementation of knowledge sharing strategies to facilitate collaboration amongst smart architectural project team members.

Senagala (2006) defines smart architecture as a "blend of passive and active technological and architectural strategies that harness computationally networked, globally connected, complexadaptive and real-time responsiveness so as to form a coevolutionary whole with the inhabitant." This synthesis of architecture and technology culminates in the development of smart buildings capable of sensing changes in the built environment and regulating heating, ventilation, air conditioning (HVAC), and lighting systems to achieve occupant experience and building performance criteria (Walter, 2015; Sinopoli 2016). Building projects of this nature require the collective expertise of a broad range of disciplinary collaborators (Ghaffarianhoseini et al., 2016). Due to an incomplete knowledge of current developments within smart technology fields, architectural project teams will elect to collaborate alongside specialized technologists to ensure that building performance goals are achieved (Sinopoli, 2016).

While second nature for building industry professionals, smart architecture projects present the challenge of familiarizing new disciplinary participants with architectural design principles and processes. To overcome these challenges, knowledge sharing strategies are commonly employed to ensure that gaps in project team understanding are filled (Gluch, Johansson, \& Räisänen., 2013). If unaddressed, gaps in knowledge of the capabilities and limitations of smart systems 
have the potential to translate themselves into decreased building performance and reduced longevity of smart enabled building features and services (Meagher 2014).

\subsection{Rationale, Purpose of Study}

This research investigates the role that online collaboration board tools might play in facilitating knowledge sharing and collaborative design between interdisciplinary smart architectural project team members.

Due to their inability to fully manage the design and incorporation of smart building systems into architectural projects, individual project stakeholders must rely upon one another to provide disciplinary expertise (Shen et al. 2010). While interdisciplinary project teams help increase the likelihood that all project goals can be met, they struggle if not all members are accustomed to working within the context of an architectural project and its associated collaborators, processes, deliverables, and schedules (Olsen \& Namara 2014).

The hypothesis tested through this study anticipates that online collaboration boards will facilitate knowledge sharing and help smart architectural project teams overcome the challenges associated with smart architectural design. Insights obtained through this research will expand upon the body of knowledge that exists surrounding architectural knowledge sharing and will provide an example of how knowledge sharing strategies might be best applied to smart architecture projects. 


\subsection{Research Questions}

This research asks:

How can smart architectural project teams employ online collaboration boards to facilitate interdisciplinary knowledge sharing and collaborative design?

This research will also look to address questions regarding:

How does the introduction of new collaborators, knowledge, and technologies influence the design processes and outcomes of smart architectural projects?

How gaps in knowledge and knowledge sharing experience between smart architectural project teams influence the outcomes of smart architectural projects?

\subsection{Research Approach}

To answer these research questions, this study collects complementary data sets from interdisciplinary groups of participants using a mixed method approach.

The study begins with a review of existing literature surrounding interdisciplinarity and collaboration in architectural project work and of knowledge sharing and its associated strategies. Following the literature review, the mixed method approach developed for this study employs a combination of questionnaires, online design charrettes, and card sorting exercises to draw upon the experience of participants within architectural, engineering, and building automation domains to obtain a series of quantitative and qualitative datasets. After gauging participant's prior experiences with knowledge sharing through the preliminary questionnaire, online design charrettes place interdisciplinary teams of participants within a simulated project 
environment to investigate the effectiveness of online visual collaboration platforms as knowledge sharing tools. Last, online card sorting exercises help facilitate participant team discussions surrounding experiences in sharing, acquiring, and implementing new disciplinary knowledge throughout both the design charrettes and professional practice.

Both online charrette and card sorting proceedings are video and audio recorded to allow for both concurrent note-taking and post-analysis of participant interaction through the online visual collaboration platform.

\subsection{Contribution}

Through the conduction of online design charrettes, this research replicates project scenarios and challenges that might be encountered by interdisciplinary smart architectural project teams. As groups of participants work together to share and implement disciplinary knowledge throughout the charrettes, insights are generated regarding knowledge gaps that exist between smart architecture project collaborators. These insights will contribute to the existing body of research surrounding architectural knowledge sharing and help develop guidelines for smart architectural project teams looking to overcome the difficulties associated with the integration of new disciplinary knowledge and project collaborators. 


\section{Chapter 2: Literature Review}

\subsection{Introduction}

A review of the literature surrounding smart architecture and collaboration was prompted by the desire to understand the difficulties experienced by smart architecture project teams in their pursuit of achieving the vision of sensory-equipped, interactive built environments. The body of literature assembled in this review is composed of accounts of architectural development processes and analyses of completed smart architecture projects built from the perspective of architects, engineers, technologists, researchers, and critics. Prompted by the emphasis placed upon collaborative approaches to smart architectural design within the literature, the review expanded to include the body of work surrounding knowledge sharing and associated strategies as indicated by figure 1 below.

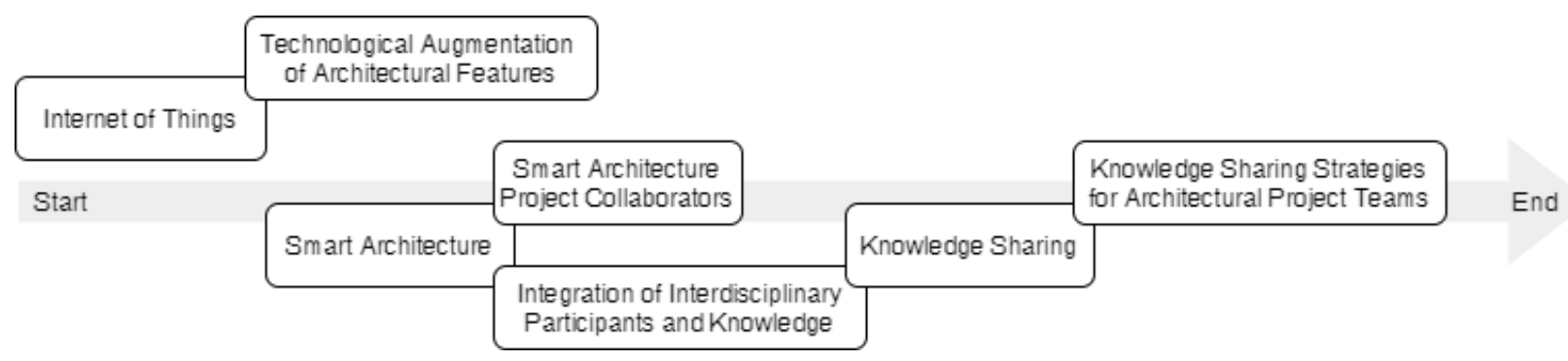

Figure 1. Literature Review Map

An expansion of the scope of the review revealed how knowledge sharing strategies might allow smart architecture project collaborators to produce better design solutions together. 


\subsection{Smart Architecture}

Within the fields of architecture and design, the introduction of smart technologies built to detect and react to events or changes within the built environment (Walter, 2015) have inspired designers to consider the relationships that might be shared between occupants and responsive environments (Di Christina, 2001). Meagher (2015) has identified a number of early examples of responsive architecture to illustrate the ways in which responsive features allow buildings to respond to changes in interior and exterior environments. Among them is the Arab World Institute which features an array of photosensitive shutters along its southern façade, allowing it to automatically adjust the level of light filtration into adjacent interior spaces.

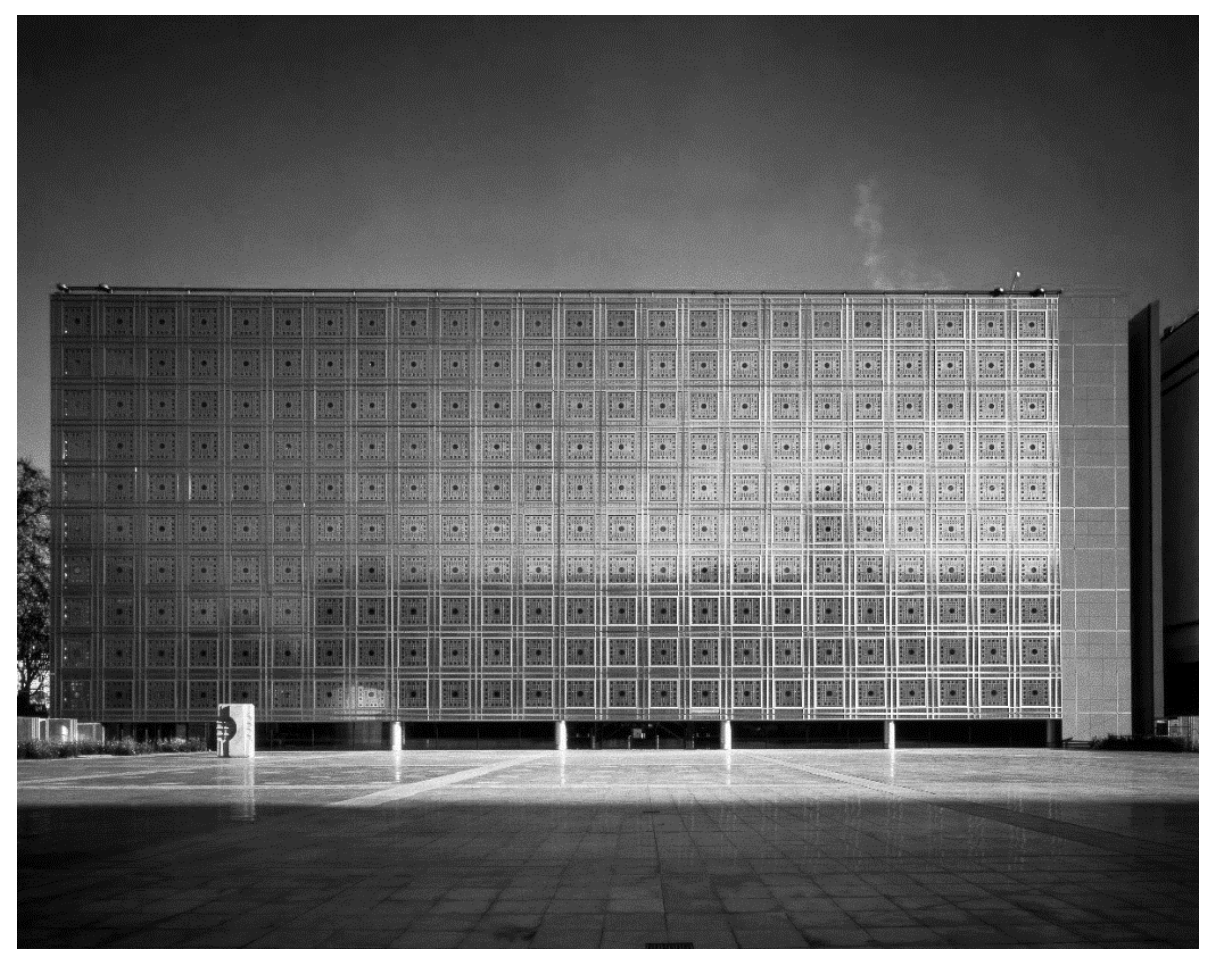

Figure 2. Arab World Institute Southern Façade (Fessy)

Given the mechanical failure and decommissioning of this system just six years following its implementation Meagher suggests that contemporary architecture teams must thoroughly 
consider the longevity and maintainability of responsive building features if they are to be successful.

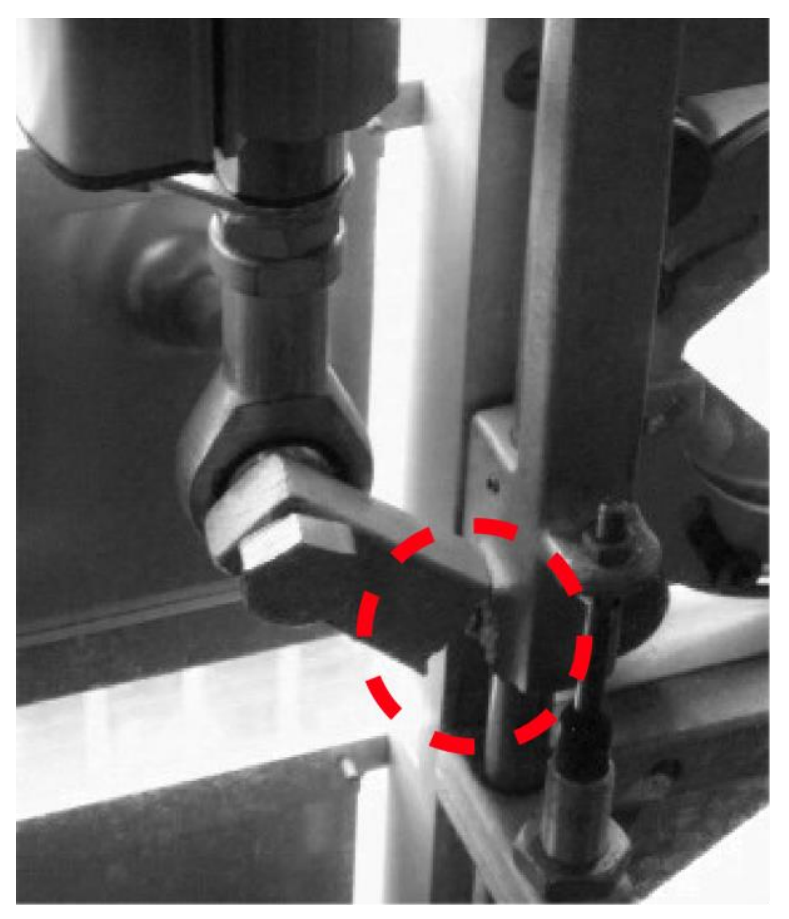

Figure 3. Mechanical Failure of Shutter Mechanism (Meagher, 2015)

Networks of smart technologies are referred to collectively within the fields of ubiquitous computing and ambient intelligence as the Internet of Things (IoT) and alongside people and information, are said to form a socio-technical ensemble (Shin, 2014). Through radio-frequency identification, infrared, and global positioning systems, IoT technologies are able to generate, access, transmit, process, and apply information to respond to and control environmental elements such as light, heat, power, and sound (2014).

Following the evolution of the internet from a means of connecting end-user devices to one another towards interconnecting networks of smart technologies capable of providing services (Miorandi 2012), research and progress within ubiquitous computing and ambient intelligence domains have shifted focus from initial goals of reducing the perceptual qualities of smart 
technologies (Weiser, 1991) towards improving the abilities of smart technologies to successfully embed themselves into both spaces and routines (Tolmie, Pycock, Diggins, MacLean, \& Karsenty, 2002). In more recent tears, research has been conducted to improve the rate at which smart technologies are able to reliably identify and respond to the needs of spatial occupants (Augusto, 2007), and to enhance building services and offer greater operational efficiency (Sinopoli, 2016). The concept of responsive architecture can be traced to the work of architect Nicholas Negroponte (1970) whose works describe "architecture machines" which "integrate local computing power into built spaces and structures."

\subsubsection{Concepts}

As technological capabilities have evolved over time, so too have our understandings and descriptions of smart architecture. Since Negroponte's early conception of responsive architecture, terminologies used to help define and describe technologically augmented architecture have both emerged and fallen out of favor, and remaining terminologies may hold different meaning now compared to when they first came into use (Wigginton \& Harris, 2002; Wong, Li, \& Wang, 2005). MacKnight (2018) suggests that "smart" refers to the interconnectedness of architectural devices in communication with one another and "intelligence" as "an extended function of smartness and ability to learn." Ghaffarianhoseini et al. (2016) have documented changes in descriptions of intelligent architecture over time from their early focus on occupant comfort and efficient use of building resources through to the expansion of the description to include consideration for user interaction with smart building features (Wigginton \& Harris, 2002; Wong, Li, \& Wang, 2005).

As subsets of intelligent architecture, distinctions between responsive and interactive architecture have been drawn by Krakowski (2008), and Knapp (2013) who describe responsive architecture 
as architecture that gathers information and responds yet lacks the agency to change its behavior in response to the explicit desires of the occupant. Conversely, Knapp describes interactive architecture as one that gives both architecture and occupant the agency to alter the environment through an array of smart sensors and a user interface. To consolidate each of these related topics, Senagala (2006) provides a conceptual framework for understanding kinetic, responsive, and adaptive architecture, and intelligent buildings as "complex adaptive systems." Further, smart environments, buildings, and architecture are respectively distinguished from one another as; "user and device supporting platform; physical artefact comprised of materials, users, and systems; and collective area of knowledge, artefacts, and systems that surround the culture of building" (Senagala, 2006).

\subsubsection{Challenges}

Apprehension among architects, engineers, and building owners (Glynn, 2014) surrounding the value, reliability, and security of smart architecture and a lack of empirical evidence supporting the deliverance of reported benefits (Ratti \& Claudel, 2014) (Ghaffarianhoseini et al., 2016) constitute primary barriers to the design and implementation of smart technologies within the built environment. To provide value to building owners, the high cost of sensors, actuators, and building management systems alongside operational and monitoring costs associated with smart architecture must be offset by an improvement in energy consumption and occupant related costs

- the latter including healthcare, productivity, and building tenant retention (Clements-Croome 2014, 2015). In their empirical study of intelligent building façades in warm climates, findings in Ochoa and Capeluto (2008) suggest that a higher degree of building performance and in turn energy savings can be achieved when passive design strategies such as light shelves, overhangs, 
and shades are combined with active smart features to combat humidity and thermal massing when compared to passive or active strategies used independently from one another.

Meagher (2014) addresses the problem of reliability and obsolescence through a reframing of Brand's (1995) theory of high and low architecture. Compared to high architecture which aspires to permanence, low architecture is said to anticipate and embrace the eventual decay, obsolescence, and replacement of materials over time. In Meagher's assessment, technologies used to create smart architecture both require regular maintenance and become obsolete over time and thus exhibit the qualities of a hybrid architecture, occupying a space somewhere between the high and low. A hybrid approach to smart architecture design, according to Meagher, would anticipate regular maintenance and plan for the eventual obsolescence and replacement of building technologies.

\subsection{Knowledge Sharing}

Knowledge sharing exists conceptually within the fields of knowledge management and organizational learning and finds its origins in Nonaka et al. (1995). These fields concern themselves with the processes surrounding knowledge creation and sharing alongside the subsequent translation of acquired knowledge into improved organizational performance.

Bektas (2013) delineates between the practice of sharing tacit and explicit knowledge but nevertheless describes each knowledge dimension as interdependent. Tacit knowledge is understood as the sum total of knowledge and experience gained by individuals and by extension organizations through education, training, and practice. Described as innately personal, this knowledge dimension is difficult to communicate and share and was characterized in initial writings on knowledge sharing as "knowledge not yet articulated" (Nonaka, 1994). 
Comparatively, explicit knowledge is described as the more readily communicable of both knowledge dimensions. Transferred to tangible material from tacit knowledge by individuals, explicit knowledge may be stored within knowledge databases and transferred to others (Bektas, 2013).

\subsubsection{Architectural Knowledge Sharing}

In their analysis of knowledge sharing among energy-efficient building project collaborators, Gluch, Johansson, and Räisänen frame learning and knowing as "dynamic activities that take place in situated contexts and practices" and describe knowledge as "embedded in the processes, methods and tools of a practice as well as in the people that carry out the practice" (2013). Through the process of knowledge sharing, project collaborators beyond the boundaries of a particular discipline are able to learn and apply disciplinary knowledge to improve project outcomes.

Within architectural practice, knowledge is generated and preserved by participants through the creation of sketches, drafts, and digital models (Bektas, 2013) and tends not to travel beyond disciplinary boundaries due to complexity (Gluch et al., 2013). In the case of smart architecture, research suggests that innovation in building technology be met with an evolution in architectural design processes, strategies, and tools (Aksamija, 2016) to facilitate knowledge sharing and interdisciplinary collaborative design (Gluch et al., 2013). 


\subsection{Barriers to Knowledge Sharing Among Smart Architecture Project Collaborators}

Through her investigation into the knowledge sharing behaviors of large-scale interdisciplinary architectural project teams, Bektas (2013) has identified and categorized a number of barriers encountered by project collaborators. This study will make use of the nomenclature provided by Bektas to classify and discuss these barriers.

\subsubsection{Complexity}

Many of the difficulties encountered by smart architecture project collaborators engaged in knowledge sharing can be attributed to the complexity inherent to designing smart architecture itself. Complexity necessitates the subdivision of project labor into disciplinary groupings and tasks to be completed in parallel alongside one another. These disciplinary processes are informed by unique perspectives, consist of particular and at times fragmented approaches and methodologies (Shen et al., 2010), and may themselves be employed to uphold a set of unique disciplinary goals (Gluch et al., 2013). As smart architecture project collaborators each produce work to deliver to both clients and one another, relationships between disciplines may become strained if project goals and strategies are uncoordinated or unclear (Bektas, 2013).

\subsubsection{Temporariness}

Due in large part to their complexity, smart architecture design projects have the potential to last for several years. Despite lengthy project timelines, knowledge sharing among smart architecture project collaborators may be impeded by the perception that relationships with other organizational collaborators are temporary. The resultant lack of motivation among collaborators to invest and engage in knowledge sharing with one another may leave individual organizations 
with a lack of essential project knowledge if insights are not captured and retained for future reference (Bektas, 2013).

\subsubsection{Uniqueness}

The perceived uniqueness of smart architecture projects may also impede knowledge sharing between project collaborators. Unique project components such as building location, classification, client, and stakeholder groups may distract collaborators from recognizing the universal benefits of implementing knowledge sharing strategies to capture and retain project knowledge. Bektas (2013) suggests that challenges associated with the division of labor, adherence to project schedule and budget, consistent communication among stakeholders, changes in scope, and development of a shared project narrative and culture each constitute generic problem areas within architectural development. Thus, the establishment of knowledge sharing strategies may help organizations capture and retain valuable information that may be used in future project work.

\subsubsection{Awareness}

Smart architecture project collaborators each make use of a set of disciplinary tools in order to externalize knowledge and complete tasks. Among disciplinary smart architecture project collaborators, awareness of the capabilities of their own and other disciplinary tools is nonuniform and may obscure design opportunities and constraints (Bektas, 2013). The apparent absence of purpose-built knowledge sharing tools aligned with the needs of smart architecture project collaborators (Gluch et al., 2013), alongside the investment of time required to learn them explains the reluctance among smart architecture project collaborators to engage with or follow the development of new knowledge sharing tools (Bektas 2013). 


\subsection{Knowledge Sharing Strategies Employed by Smart Architecture Project Collaborators}

Written accounts detailing the design processes of smart technologies and environments have indicated that while interdisciplinary teams of project stakeholders are being assembled (Sinopoli, 2016) (Aksamija, 2016), it remains unclear which design methods or knowledge sharing strategies are employed and when and to what degree stakeholders from smart technology domains are involved in the design process.

Through an investigation of knowledge sharing among large-scale building project collaborators, Bektas (2013) has identified and gathered insights regarding the employment of setting, tool, social, and procedure-based knowledge sharing strategies. This study will make use of the nomenclature provided by Bektas to discuss each approach.

\subsubsection{Physical Settings, Co-Location, and Workgroups}

Architectural project teams may choose to make use of physical settings to help ease communication and interaction among interdisciplinary collaborators. Setting-based strategies may include shared workspaces, workgroups, or pilot projects (Gluch et al., 2013) and may be employed continuously or periodically among project stakeholders over the duration of a project. It is suggested that these strategies perform the social function responsible for "stimulating interaction, lowering barriers, enhancing productivity and relationships, and promoting a shared culture" (Bektas, 2013) among project collaborators.

If setting-based strategies are to succeed, Bektas suggests that flexible spaces for formal and informal interaction and focus be planned, that actions which take place within them are 
clarified, and that project team members be given a hand in their design. The occupational characteristics of shared workspace participants, roles, purposes, and outcomes of setting-based strategies should also be considered and clarified prior to their implementation (2013).

\subsubsection{Knowledge and Building Management Tools}

Within the context of architectural development, tools exist to fulfill the needs of project team interaction and discussion (Gluch et al., 2013; Laing, 2019). Bektas (2013) draws a distinction between information technology (IT) based and non-IT based tools used by architectural collaborators to share knowledge noting differences in the level of expertise required to participate and the nature of information exchanged through each.

Bektas classifies CAD modeling programs, information repositories, and project intranets as ITbased tools that provide collaborators with channels to externalize, implement, and share explicit knowledge. Choosing to use IT-based tools to facilitate distributed collaboration amongst design team members, however, may introduce challenges affecting the overall quality of design decisions. Hammond's (2001) hypothesis regarding distributed collaboration speculates that quality of communication among collaborators becomes affected in two ways; the efficiency of information transferred becomes mitigated by the medium through which it travels, and communication processes are altered to accommodate a lack of social presence vital to the formation of working relationships. Findings in Hammond et al. (2005) suggest that distributed collaboration may also result in increased mental workload compared to face-to-face alternatives as well as a decreased 'design space,' referring to the total amount of time spent and number of design issues and alternatives considered by the design team. Distributed design teams were also found to be less likely to interact with one another until faced with a critical design problem, and upon the discovery of which would spend more time communicating concepts to one another 
while generating fewer overall solutions compared to teams collaborating face-to-face (Hammond et al., 2005).

Brainstorming, training sessions, and both formal and informal meetings are classified as non-ITbased tools, as collaborators may exchange tacit and explicit knowledge free from the constraints often presented by IT-based tools (Hammond et al., 2005). Bektas (2013) notes that if IT-based tools are to be used, that they be introduced to project collaborators prior to the commencement of building projects through pilot testing and feedback sessions to determine the usefulness, potentials, constraints, and overall commitment level of participants. In this study, non-IT-based tools are classified as procedures following the distinction outlined in Bektas (2013).

\subsubsection{Social Practices}

The function of social practices employed throughout architectural project lifecycles are to allow for the formation of project-specific sub-cultures (Bektas, 2013) among collaborators with different backgrounds (Gluch et al., 2013) for the purpose of "leveraging a collective understanding to solve design problems" (Bektas 2013). Among architectural design project interviewees, Bektas (2013) identified that social practice-based strategies and shared activities were the most likely to help build relationships, trust, commitment, and establish a knowledge sharing culture between collaborators. Once these objectives have been met, participants believe that "social practices become knowledge sharing practices" (Bektas, 2013) as collaborators become more inclined to prevent misunderstandings about design solutions, ideas, roles, and responsibilities amongst one another. 


\subsubsection{Procedures}

Knowledge sharing procedures can often be the missing link between collaborators engaged in the use of knowledge sharing strategies. Bektas (2013) describes procedures as a set of regulations that define and regulate "knowledge sharing, interaction, planning of physical settings, use and evaluation of tools, and responsibilities of participating disciplines."

Regulations defining the responsibilities and organization of collaborators are often referred to as project delivery strategies, some of which aim to generate as much overlap and opportunity for collaboration between building owners, contractors, architects, and engineers as possible (Hughes, Champion, \& Murdoch, 2015). To this end, an integrated project delivery strategy ensures that all parties involved in smart architectural projects take part in defining the degree to which smart technology, services, and data will play in the overall building program and control scheme (Sinopoli, 2016).

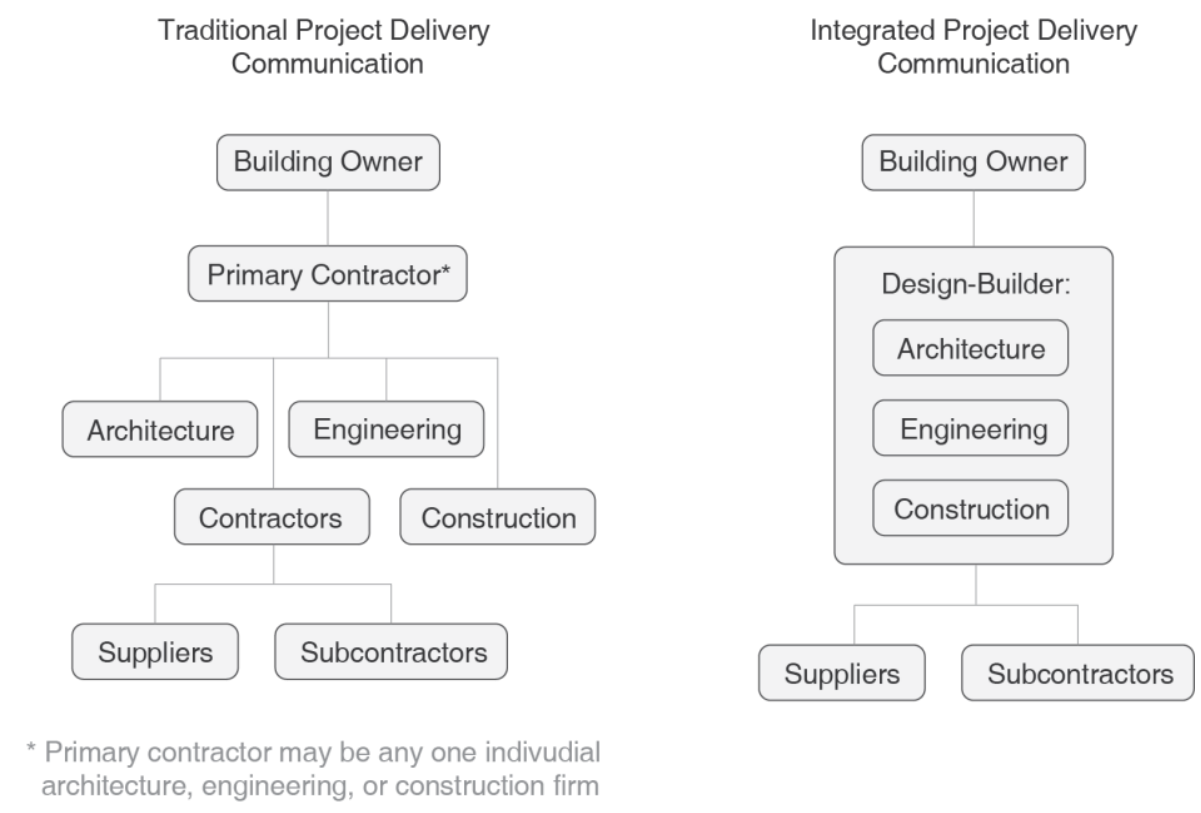

Figure 4. Traditional and Integrated Project Delivery 
While the establishment of procedures may help architectural project teams formalize actions and legal boundaries, procedures do not always ensure the establishment of social bonds and may also limit the freedom of collaborators to experiment if they are too strict (Bektas, 2013).

\subsubsection{Deliberate and Emergent Strategies}

Strategies adopted by architectural project teams may diverge from original procedures due to changing project conditions or collaborators. Top-down deliberate strategies implemented by project managers may fail or be less effective if they do not accommodate bottom-up strategies that emerge to meet an unforeseen need. While emergent strategies were found to have a higher potential to promote knowledge sharing among project collaborators, Bektas (2013) found that these strategies were less likely to be recognized and adopted by all participants.

\subsection{Summary}

Literature review has identified a number of factors affecting the transfer of knowledge between interdisciplinary smart architecture project team members. Alongside project complexity, the perception that relationships with collaborators are temporary and that design challenges are unique and will not be encountered in the future constitute the primary barriers to the sharing and capturing of architectural project knowledge. Given knowledge gaps between disciplinary building industry collaborators and the consequences associated with the failure of technologically augmented architectural features, there is an apparent need for the implementation of strategies to facilitate knowledge sharing between smart architectural project team members.

While the literature on architectural knowledge sharing and collaboration prescribes a number of strategies to overcome knowledge gaps between project team members, it has not explored how 
knowledge sharing strategies might be applied to smart architectural project challenges. The research that follows seeks to discern how online collaboration board tools might be implemented to facilitate knowledge sharing and collaborative design between smart architectural project teams and new disciplinary participants. 


\section{Chapter 3: Methods}

This research seeks to understand how smart architectural project team members conceptualize and engage in interdisciplinary knowledge sharing using online collaboration board tools. To gain a greater understanding of the research problem, a mixed method approach (see fig. 5) was developed to generate and collect complementary sets of data using interdisciplinary groups of building industry participants.

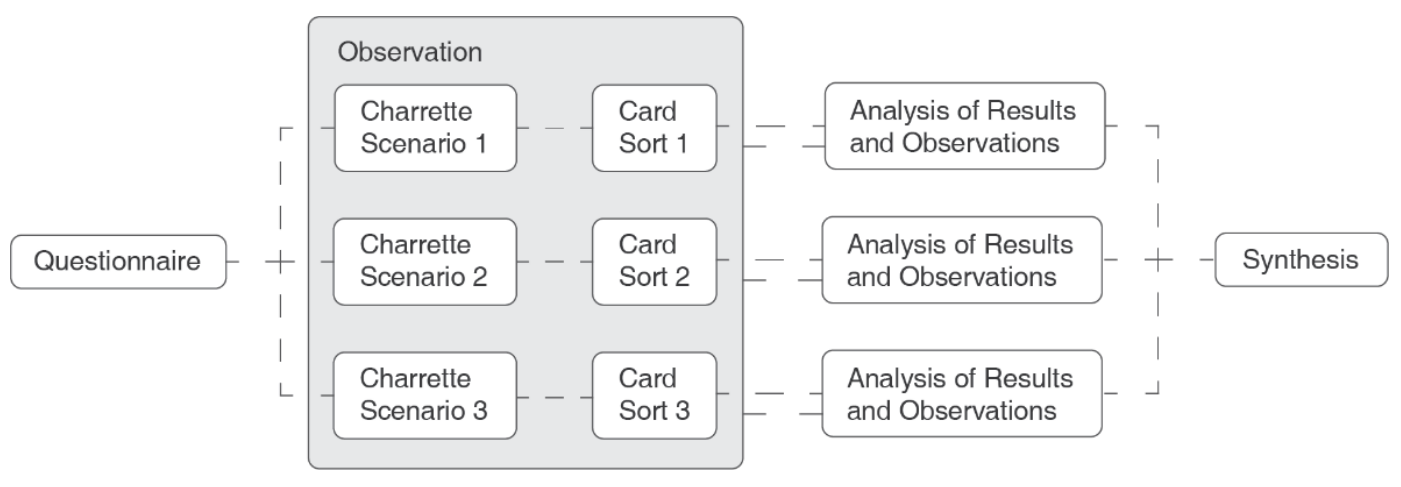

Figure 5. Research Map

As an introduction to the study and research topic, participants completed preliminary questionnaires that recorded prior experiences with and attitudes towards knowledge sharing strategies. From questionnaire respondents, three interdisciplinary teams of participants were assembled from architectural, engineering, contractor, and building automation domains. Teams then participated in two successive qualitative methods each: online design charrettes and card sorting sessions. Methods employed throughout this study were selected and designed to simulate smart architectural project environments, allow participants the opportunity to share and implement disciplinary knowledge, and to share experiences with and build consensus surrounding knowledge sharing strategies. 
Video and audio data generated by charrette and card sorting proceeding were recorded using OBS Studio, an open-source video capturing tool. Recording research methods for post-analysis allowed the researcher to supplement recorded data with observational data recorded live as participants worked to share, acquire, and implement disciplinary knowledge. Alongside responses to design briefs and accounts of collaboration and knowledge sharing, questionnaire and card sorting data are used to draw connections between charrette outcomes and knowledge sharing experience, attitudes, approaches of charrette teams. This research approach was derived from the method employed by Cross (2011) where qualitative observations of collaborative design activities were used to examine designers' abilities to collectively formulate and adhere to design strategies throughout timed design exercises.

\subsection{Online Collaboration Boards}

Charrette and card sorting methods were administered remotely and hosted online using Miro, an online whiteboard developed to facilitate real-time distributed collaboration. Using Miro, project teams are able to host and document the results of online meetings, workshops, and brainstorming sessions as well as collectively annotate and modify shared files. While alternatives such as Mural, Conceptboard, Ziteboard, and Stormboard may have been used, free access to Miro was provided by Carleton University. In order to provide each participant team with their own charrette and card sorting boards complete with briefs, architectural drawings, and card sorting decks, a solution featuring unlimited board creation and image and file hosting was required. 


\subsection{Participant Selection}

The criteria for participant selection consisted of a professional designation and five years of experience within one of the architectural, contractor, civil, electrical, or mechanical engineering, or building automation technology domains. Each domain selected to participate in this study represents a critical component of a smart architectural project team. This criteria ensured that those recruited had a high level of domain-specific expertise and would be able to contribute valuable insights during interdisciplinary design charrettes. This approach to participant selection draws upon the Delphi method wherein groups of subject matter experts are consulted to both build a consensus surrounding and generate possible solutions to a research problem (Hsu \& Sandford 2007). Approaching recruitment in this way resulted in the formation of highly knowledgeable, experienced, and diverse teams of participants representative of project collaborators that might be assembled to design smart architecture.

Brought together and shared recurrently, differentiated knowledge among project team members enables the formation of problem-solving approaches no individual domain may envision alone (Newell, \& Huang 2005). Figure 6 illustrates the interaction between project team members as they work to share knowledge with one another in order to generate design solutions. 


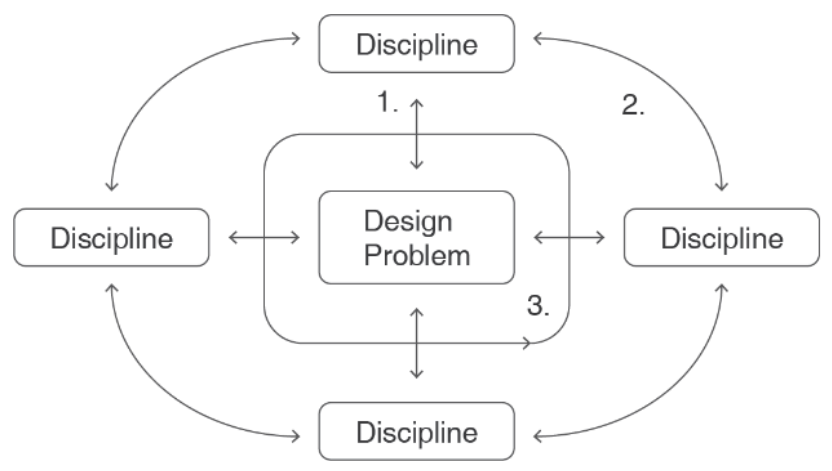

1. Discipline / Design Problem

2. Discipline / Discipline

3. Discipline / Team

Figure 6. Interaction between smart architecture project team members

(Adapted from Robin et al. 2007, p.189)

Sinopoli (2010) identifies the architect as the principal link between the client, building owner, and assembled project team. The project architects and associated firms work to externalize knowledge through the development of the facility program and the completion of design drawings coordinating building technology systems, wiring, and end-user devices with building finishes, millwork, and furnishings (Bektas, 2013). These tasks are facilitated by the architect's education and training which allows them to approach the unique aesthetic, functional, environmental, cultural, and economic facets of a project using spatial reasoning and representation skills trained through open-ended, multi-method problem-solving exercises.

While responsible for the analysis of building code and writing of material specifications, the architect is not commonly trained to the same depth of technical building systems expertise as other project team members. Thus, disciplinary knowledge from engineering and information technology domains are required to fully satisfy the technical dimensions of each building project (Olsen \& Namara, 2014).

Building technology systems include heating, ventilation, air conditioning (HVAC), electrical, lighting, networking, and in the case of a smart building project, automation (Sinopoli, 2016). 
These systems are designed in collaboration with teams of civil, mechanical, and electrical engineers whose in-depth understanding of materials, systems, and processes, and the possibilities they afford, has been obtained through highly technical education, training, and experience (Bektas, 2013). Engineering programs provide opportunities for students to engage in open-ended problem-solving and design, however practitioners note that the isolated, deterministic approach to problem solving often emphasized by course curricula has made the transition to working professionally alongside other disciplines in a collaborative capacity a challenge (Olsen \& Namara, 2014).

Sinopoli (2016), Olsen, and Namara (2014) note the importance of collaboration alongside professionals within information technology domains during project conception and development phases and suggest that such approaches may result in better project outcomes. Presently, Sinopoli (2016) suggests that the value and capabilities of newer building technologies are often overlooked by architectural project teams who favor and select legacy designs and systems for building projects prior to consultation with those from information technology domains. Because the shared experience of architectural project team members may be inadequate or even irrelevant (Cross, 1982), professionals from technology domains provide a critical up-to-date understanding of building technology systems and how data collection combined with smart features might be used to improve building performance (Sinopoli, 2016). When involved during project conception, technologists alongside project contractors responsible for managing trades, materials, and technology vendors (Sinopoli, 2016) help ensure that such smart features are well integrated into building technology systems and will reliably support the proposed building program. A minimum of three participants were drawn from each of the identified domains in order to act as representatives on each of the three charrette and card 
sorting teams. Recruitment relied on accessing industry professionals known to the advisors or to the researcher (see Appendix A for recruitment email).

\subsection{Questionnaire}

Prior to conducting charrette activities, participants were asked to complete a preliminary questionnaire to gauge prior project experience and awareness of knowledge sharing strategies. (see Appendix D for questionnaire).

\subsubsection{Questionnaire Design}

The questionnaire was delivered through Qualtrics, an online survey platform, and was composed of four questions. Respondents were asked to select a provided domain that best described their area of expertise and to indicate how many years of professional experience they had accumulated within the indicated domain. An open field was provided to allow respondents to indicate a domain not listed by the questionnaire. Responses assisted the research team in ensuring that participants met the inclusion criteria and in ensuring an even distribution of participants from each domain in the charrette and card sorting sessions.

A short briefing on knowledge sharing was given prior to questions three and four. The briefing outlined and classified strategies commonly used by interdisciplinary design teams and was included to help respondents understand terminology and identify any prior personal experiences or preferences in relation to knowledge sharing or knowledge sharing strategies.

\subsubsection{Questionnaire Data Collection}

Questionnaire data served to inform the researcher of prior participant experience and preference with respect to knowledge sharing and knowledge sharing strategies. Responses to 
questionnaires were organized according to discipline in order to analyze the relative level of familiarity with and attitudes towards knowledge sharing and knowledge sharing strategies.

\subsection{Charrettes}

The charrette method finds its origins in the traditions of the École des Beaux-Arts in France where the Faculty of Architecture would issue challenging projects to its students to complete within a limited time frame. As the strictly enforced deadline drew near a pushcart or charrette was sent through the studio to collect the students' final pieces of work for critique (Roggema 2014). The culture of intensive collaborative work is still familiar to professionals working within the design disciplines to generate solutions to task, interaction, and experience-based problems. Likewise, the charrette tradition lives on through the practice of holding multiple day on-site workshops attended by interdisciplinary groups of stakeholders, and involving visual collaboration techniques such as diagramming, sketching, and low-fidelity prototyping (Lennertz \& Lutzenhiser, 2006) (Curedale, 2012, 2013). Through the sharing of disciplinary ideas, values, and experience through visual collaborative means, charrettes have the ability to help project teams generate new knowledge and project visions (Sutton \& Kemp, 2006) but also have the potential to introduce complication and interpersonal conflict by requiring collective problem solving (Cross \& Cross, 1995).

As a research tool, Sutton and Kemp (2006) suggest that the regimented timelines of charrettes allow researchers to engage communities of participants in creative problem-solving activities that provide both parties with tangible results. In this way, design is used as a method of inquiry and allows researchers the opportunity to experiment with charrette variables and the integration 
of different collaboration strategies while gauging the collaborative abilities of interdisciplinary groups of participants.

Charrette project teams were assembled from remote locations using Microsoft Teams, an online video conferencing program, and Miro, an online digital whiteboard. Once connected, each project team was introduced to any knowledge sharing strategies to be used throughout the charrette and were provided with a brief detailing the charrette objective and deliverables. Teams were then able to work collaboratively to produce a response to the design brief using Miro to record notes, annotated diagrams, or sketches over a period of 30 minutes (see Appendix F for charrette briefs).

\subsubsection{Charrette Design}

Charrette briefs delivered to design teams outlined the call for the design and implementation of a smart shading system into one of three building scenarios. Architectural shading systems are used to manage solar heat gain and glare to achieve optimal interior temperatures and light level and can be provided using a variety of building components and devices. Within the context of this charrette, participants were asked to employ and automate one of these strategies to dynamically regulate building temperature and light level across multiple building units. Charrette briefs were designed to provide charrette teams with a defined user group, occupancy type, location, climate, and orientation, and performance criteria to help inform design decisions. 


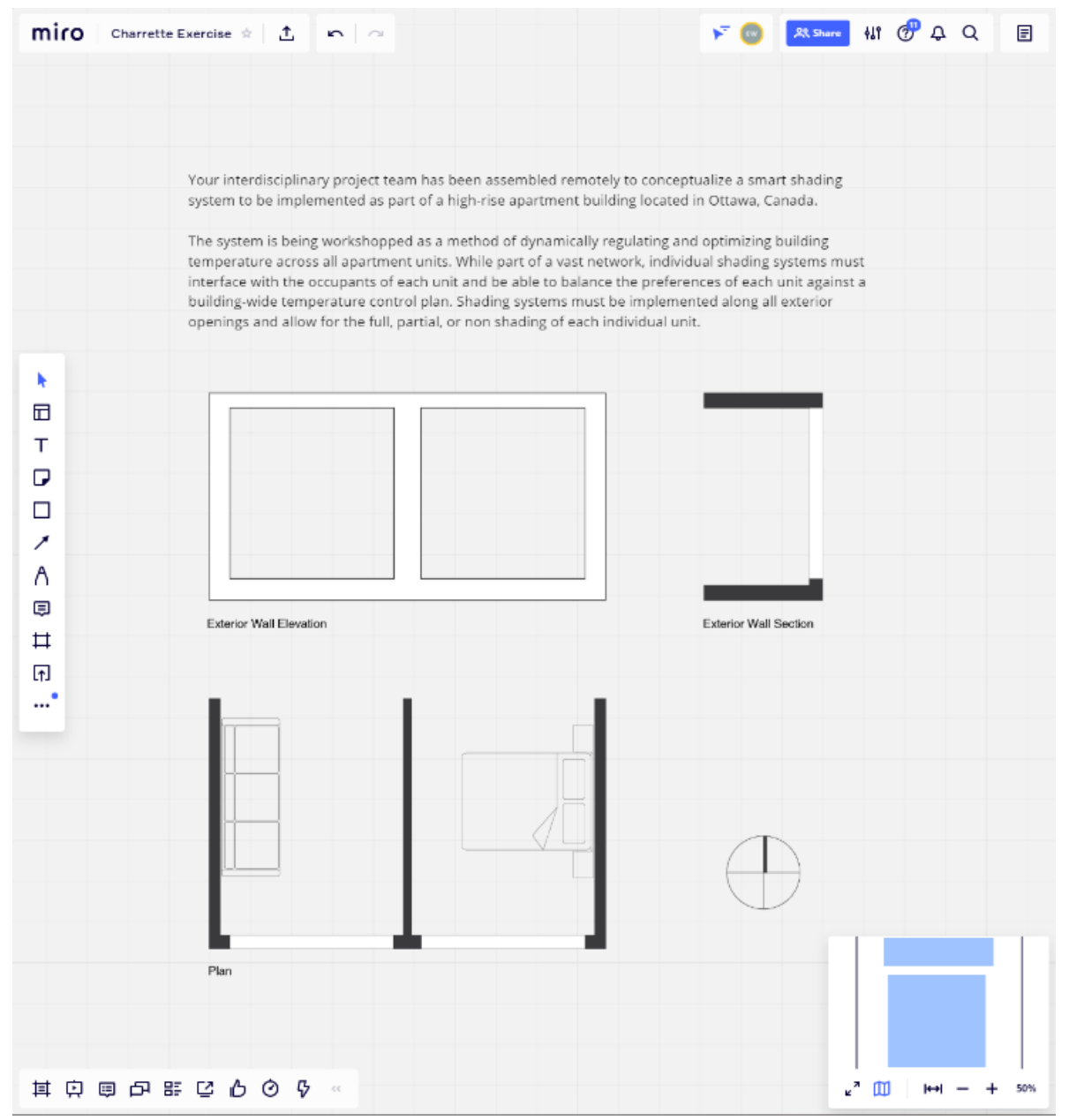

Figure 7. Miro collaboration board

As members of the design team assembled online to participate in the charrette, a short introduction and verbal briefing was given by the moderator to familiarize participants with each other and the goal of the exercise, and to provide clarification if necessary prior to commencement. Finally, participants were advised to monitor and structure their time effectively as they worked towards generating a response to the brief over the 30-minute duration of the charrette. 


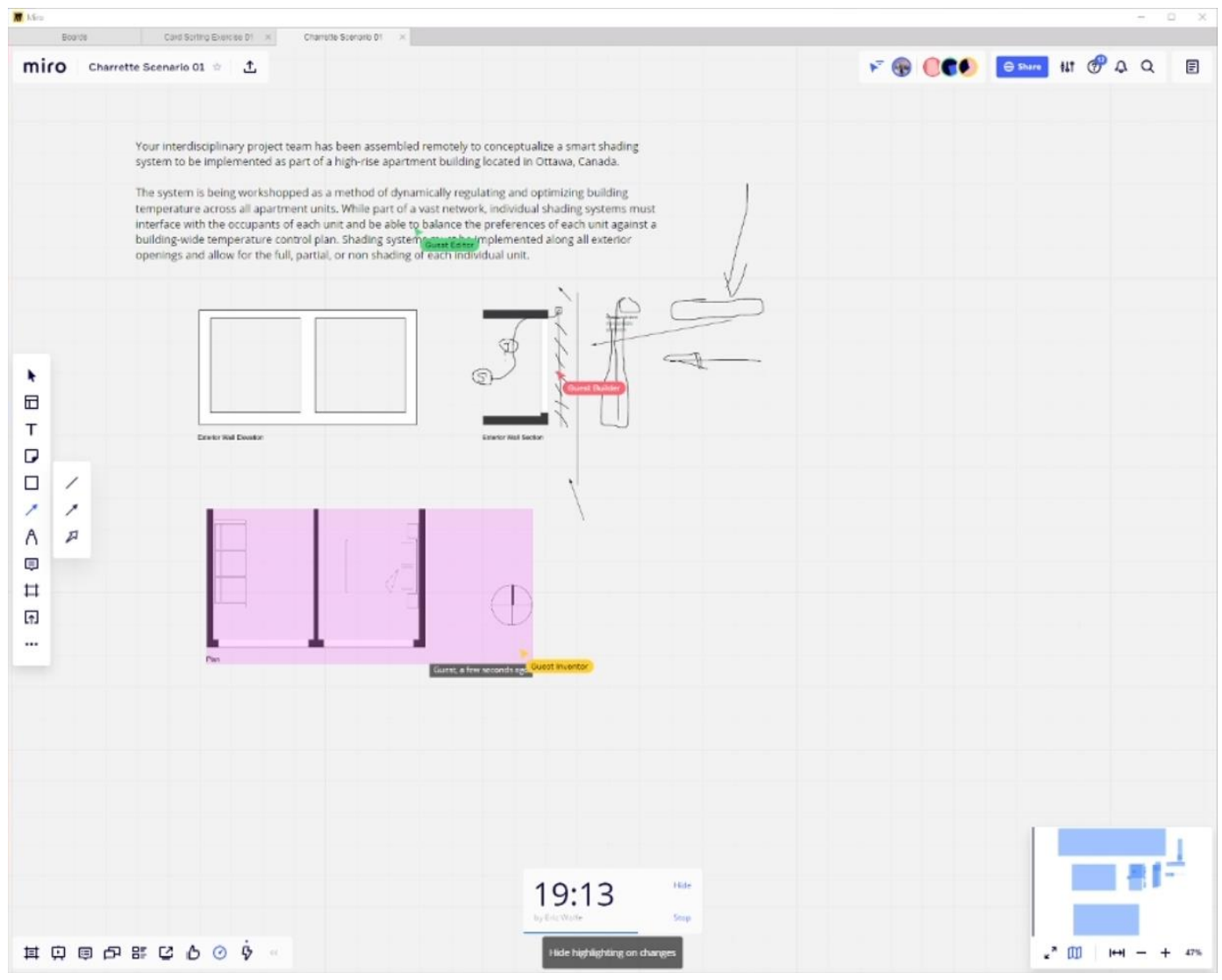

Figure 8. Charrette in progress

Online tools were used to simulate typical physical tools such as whiteboards, work surfaces, sticky notes, pens, pencils, markers, and paper commonly made available to a charrette team assembled in the same physical location. Design briefs were presented to charrette teams on the Miro online workspace and were supplemented by a verbal briefing outlining knowledge sharing strategies and goals to be upheld throughout the charrette (see Appendix F for charrette brief and tutorial). At the end of each session, charrette teams were asked to present their responses to the design brief to the researcher. 


\subsubsection{Charrette Data Collection}

Charrette video and audio data were recorded using OBS Studio to allow the researcher to transcribe interactions between project team members and capture the formation and evolution of design ideas, key points of discussion, and instances of knowledge sharing that occurred.

\subsection{Card Sorting}

Following each charrette, card sorting sessions were held to learn how participants conceptualize and evaluate their experience with and perception of knowledge sharing strategies used throughout the charrette and in professional practice. In a card sort, participants are presented with a set of items displayed on cards and are then asked to sort the items into categories created based on similarity or adherence to a certain criteria. In an open card sort, the creation of categories is left to the participants, but may stem from ideas or suggestions given to them by the research team. As suggested by Spencer (2009), open card sorting creates the conditions for valuable discussion to take place between participants and generate insights that may be more valuable to researchers than the outcomes of the card sorting sessions themselves. For the purposes of this research, an open card sort will also allow interdisciplinary teams to make sense of the charrette exercise and provide them with an opportunity to arrive at a consensus regarding concepts associated with knowledge sharing strategies (see Appendix I for card sorting deck). 


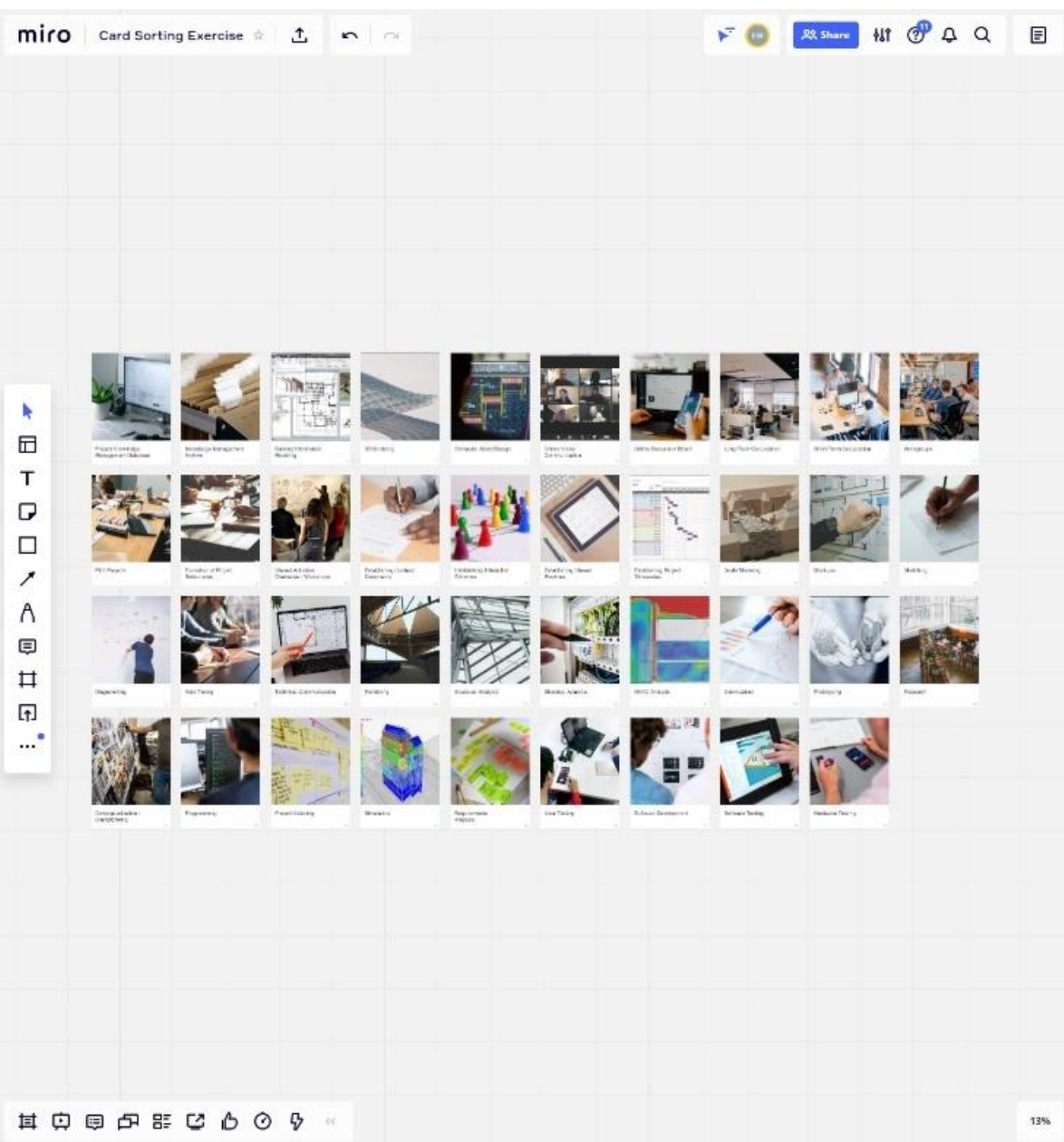

Figure 9. Miro card sorting board

\subsubsection{Card Sorting Design}

Prior to the card sorting session, participants were given a briefing that explained the principles and goals of the card sorting activity. Participants were then given a set of cards representing examples of specific knowledge sharing strategies, tools, settings, social practices, and procedures, and examples of artefacts created through the employment of those strategies which included models, mock-ups, sketches, notes, and diagrams. During the process, participants were asked to think about these items within the context of key steps they might take throughout a collaborative design process as they sorted them into categories. After having completed the card 
sorting activity, participants were debriefed and asked to describe the groupings that were made and provide a brief explanation to rationalize the content within each grouping.

\subsubsection{Card Sorting Data Collection}

Card sorting video and audio data were recorded using OBS Studio to allow for transcription and post-analysis. Recording card sorting activities also allowed the researcher to record observational data as participants formed categories and subsequently discussed the categorization of each item.

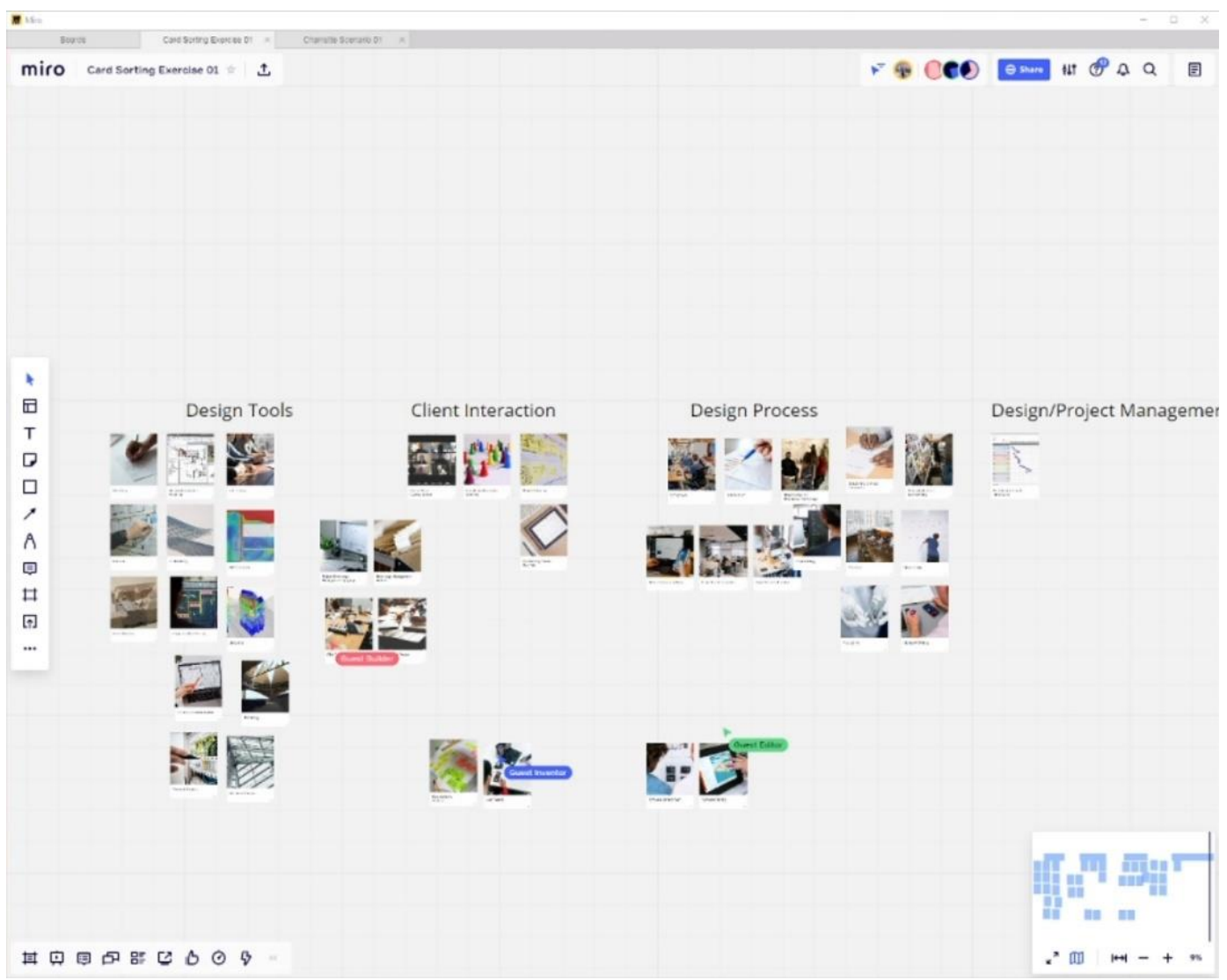

Figure 10. Card sort in progress

A number of different sorting categories were possible using the card sorting deck designed for this study, including the use of strategies by project stage, use of strategies in response to a 
particular type of design problem, strategies typically employed by or between specific disciplinary user groups, or the perceived effectiveness of strategies. Following each card sort, the categories created by participants, cards sorted within those categories, and how participants described and rationalized the sorting of cards into said categories were recorded. Alongside the recorded discussions held by participants surrounding these choices, data obtained through card sorting provided the researcher with a final point of reference against which insights from literature review other methods employed in this study might be compared. 


\section{Chapter 4: Data Collection and Analysis}

\subsection{Questionnaire Summary}

Questionnaire responses were collected online between November 2020 and March 2021. The questionnaire contained 4 questions and took an average of less than 5 minutes to complete. After having completed the questionnaire, respondents were thanked for their time and notified both that their responses had been recorded and that they would be contacted shortly to arrange a date and time for the online charrette to take place.

\subsubsection{Questionnaire Participants}

Once participants confirmed their willingness to take part in the online charrettes and card sorting sessions, participants were invited via email to both read and sign the study consent form and access the online questionnaire via a clickable link. Those invited to participate were professionals from architectural, engineering, or information technology domains with interdisciplinary building industry experience. Recruitment sought a balance between building project stakeholder groups so as to ensure an equal representation of disciplines throughout charrette and card sorting proceedings. Professional designations of participants were recorded by the questionnaire and are indicated in Figure 11. 


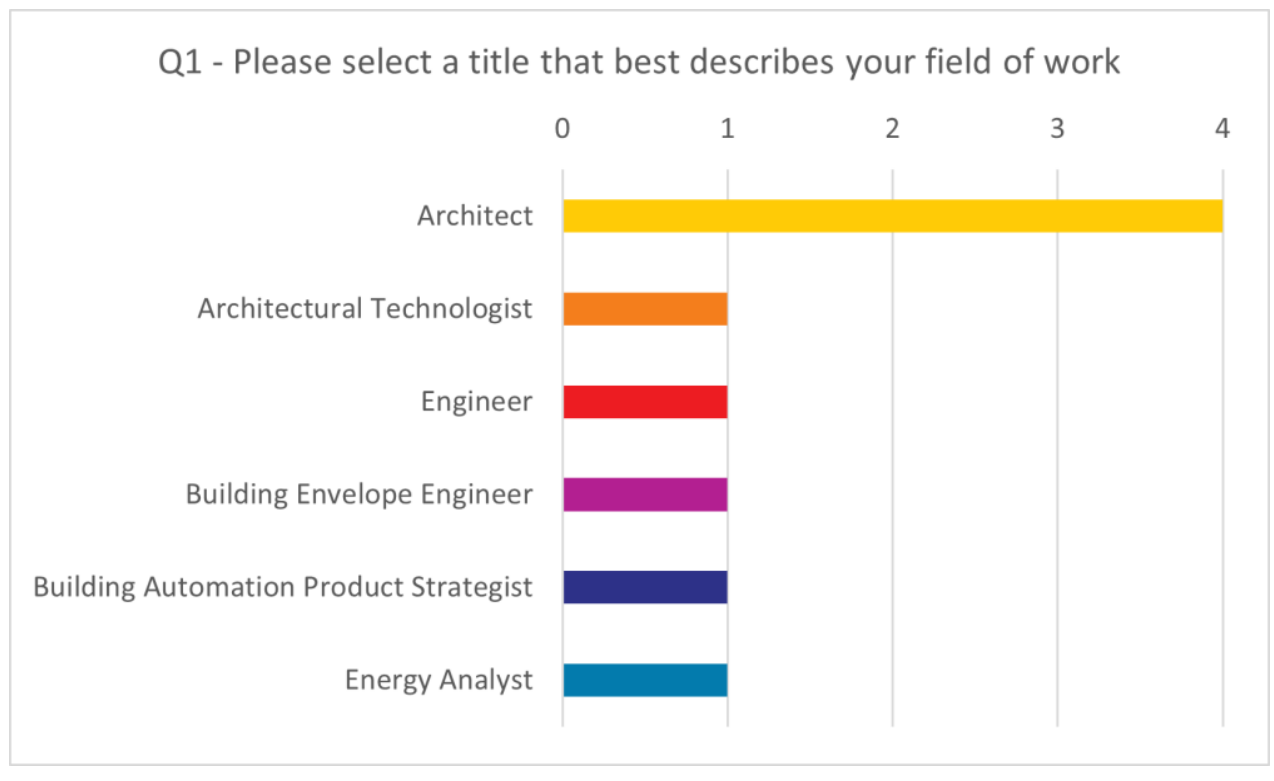

Figure 11. Professional titles of study participants

Recruitment also sought participants with five years of professional experience within their designated field. Participant experience level, indicated on Figure 12, increased the likelihood that participants had encountered a number of different knowledge sharing strategies within and between disciplines.

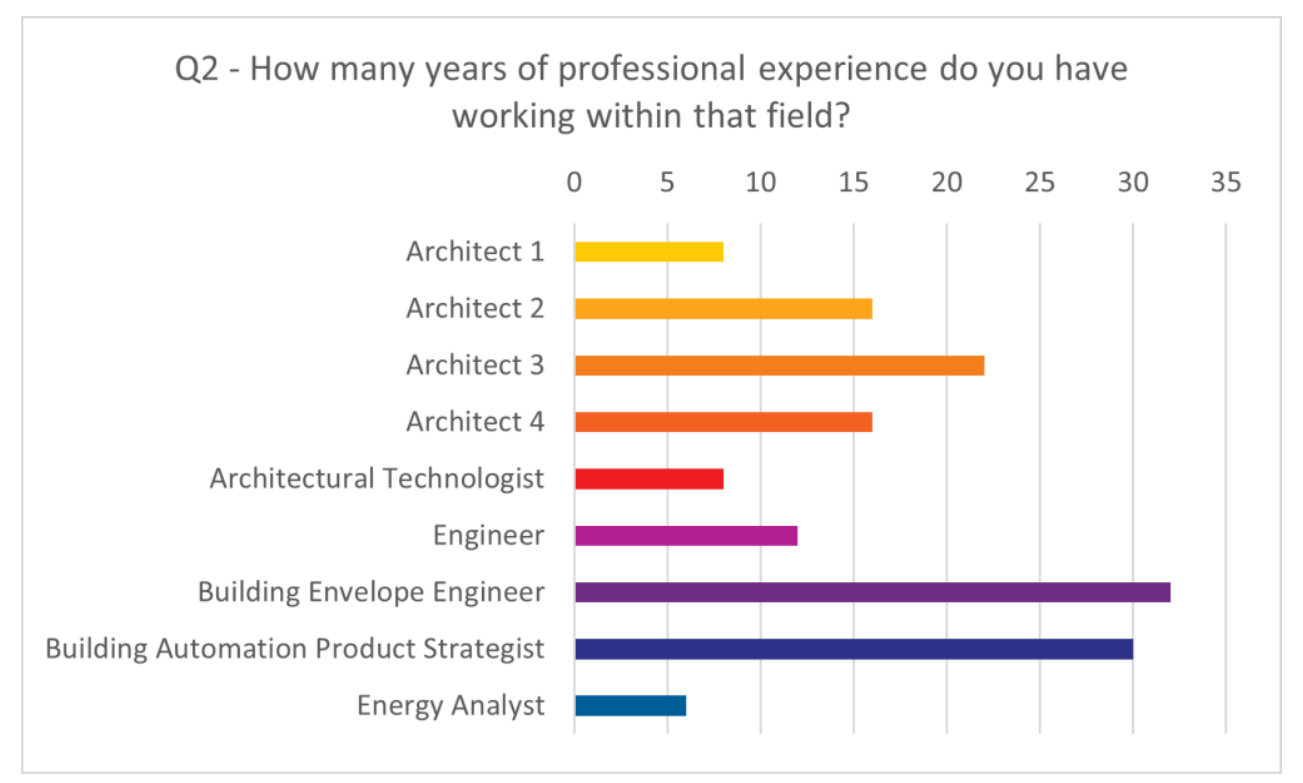

Figure 12. Professional experience level of study participants 


\subsubsection{Questionnaire Results}

Questionnaire Q3 (Figures 13, 14, 15) indicates the total number of knowledge sharing strategies encountered by participant teams. When individual participants selected "other," they were prompted to enter any other knowledge sharing strategies they had encountered in the open text field provided.

Strategies indicated in the open field by one participant from team 1 included design team meetings and regular standard communications, while two participants from Team 3 indicated having encountered Revizto, a 3D interactive BIM collaboration software platform, and cloudbased live review of project documents. No other knowledge sharing strategies were indicated by participant team 2 .

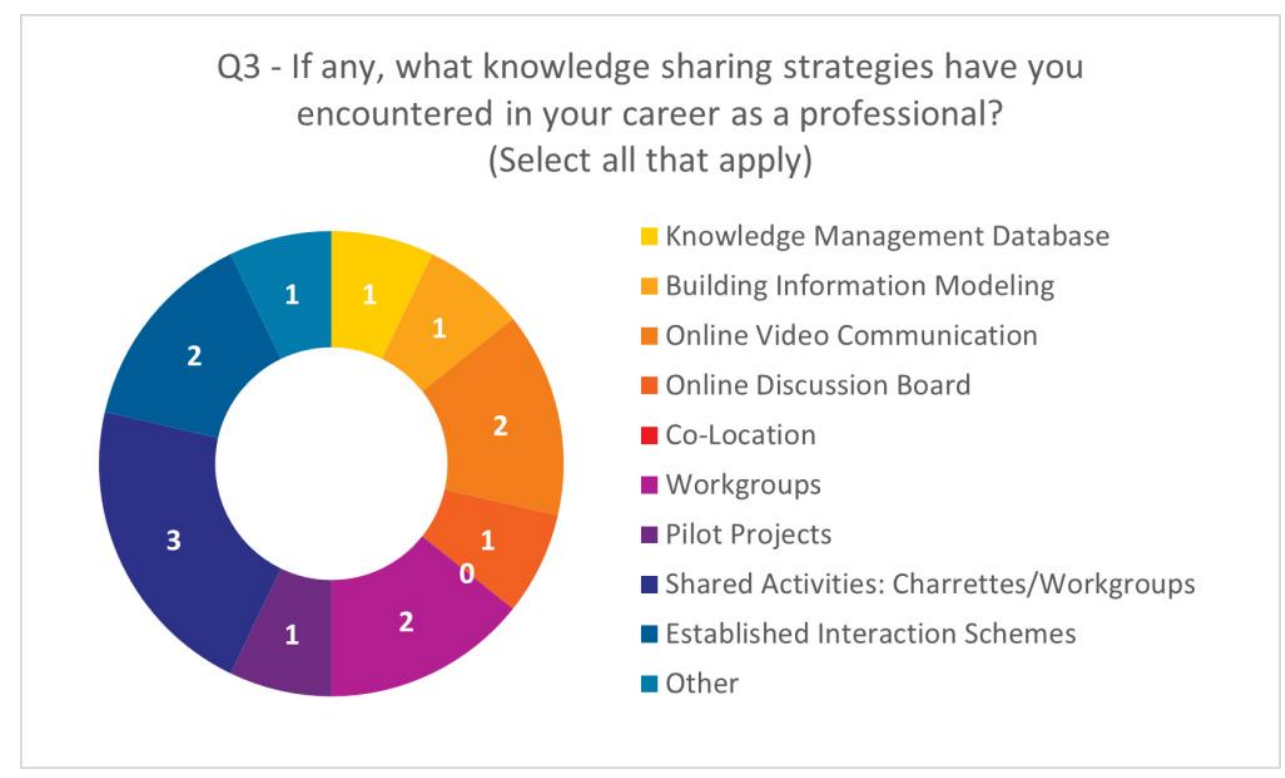

Figure 13. Knowledge sharing strategies encountered by Team 1 


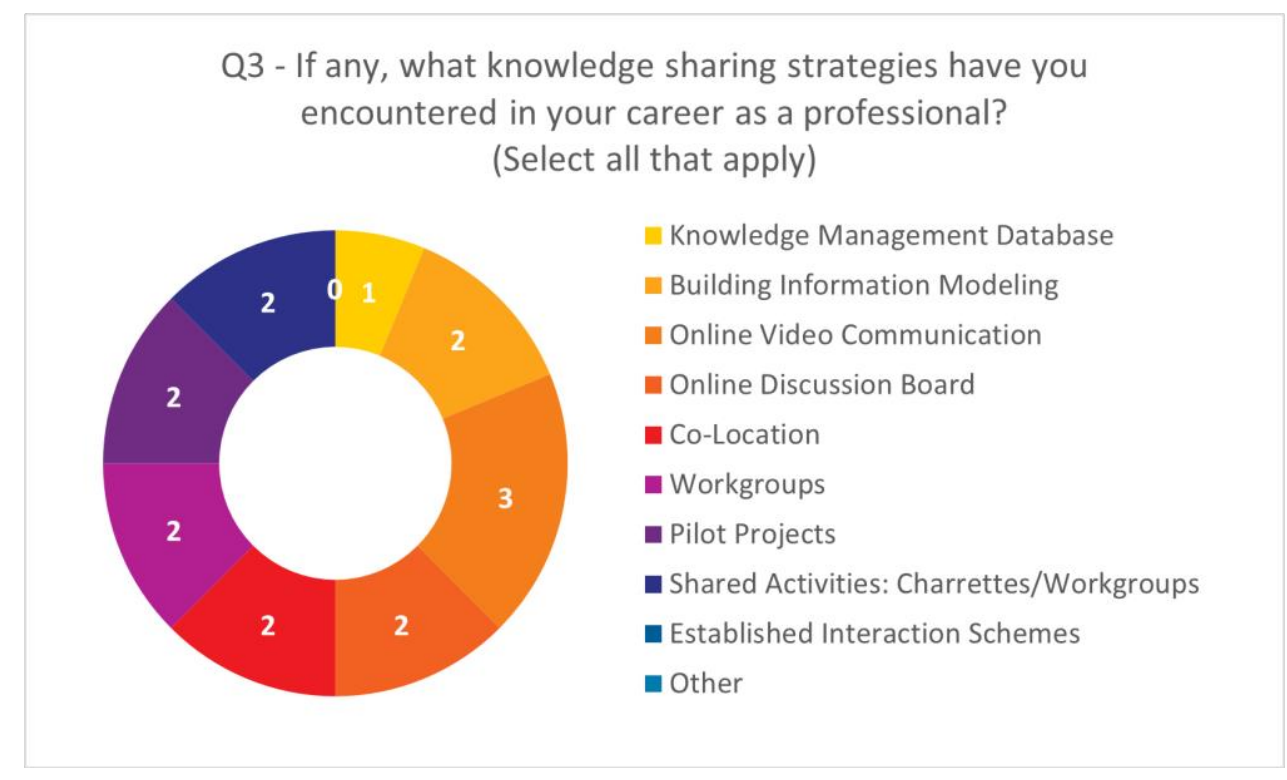

Figure 14. Knowledge sharing strategies encountered by Team 2

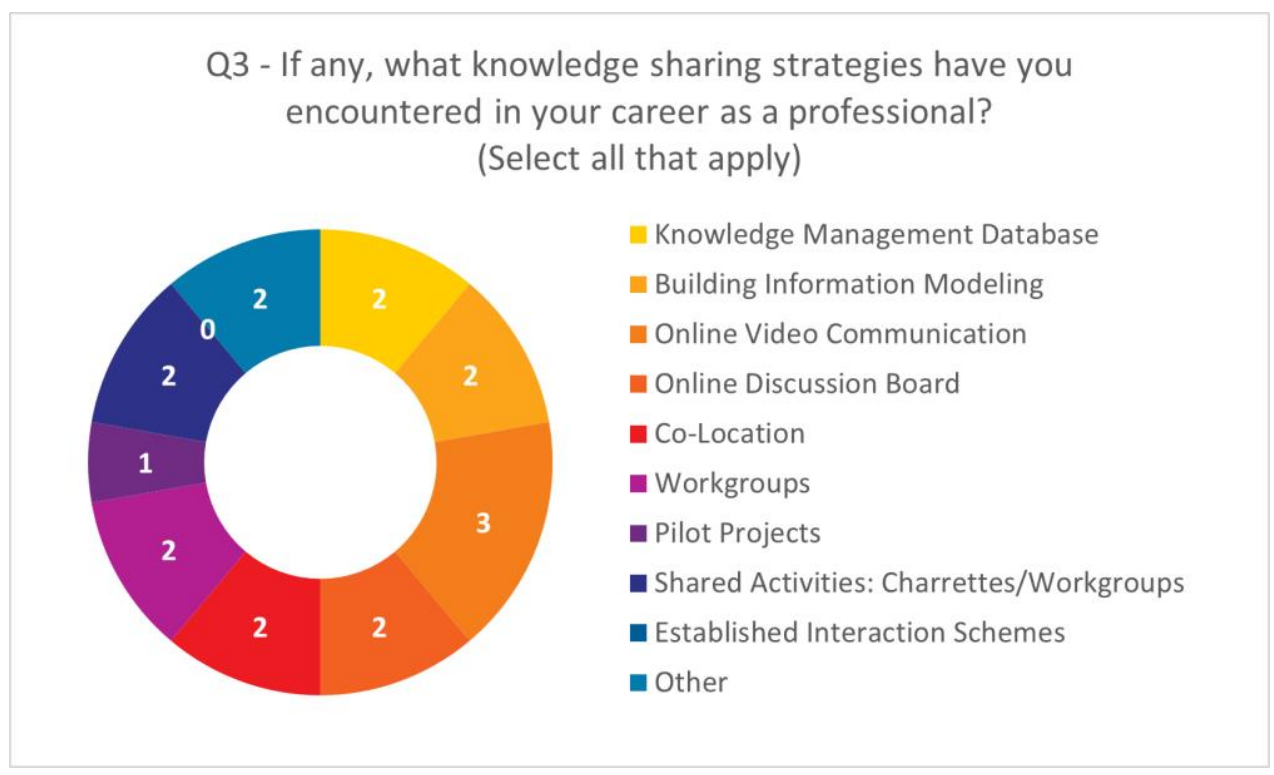

Figure 15. Knowledge sharing strategies encountered by Team 3

Responses to questionnaire Q3 indicate the relative experience levels of participant teams with knowledge sharing strategies commonly employed throughout the architectural design process. Among participant teams, only participants from team 1 had not encountered co-location, while only participant team 3 had not encountered enstablished interaction schemes. 
Questionnaire Q4 (Figures 16, 17, 18) indicates knowledge sharing strategies preferred by participants when working alongside other disciplinary collaborators. When participants selected "other", they were they were prompted to enter any other preferred knowledge sharing in the open text field provided.

Strategies indicated in the open field by one participant from team 1 included design team meetings and regular standard communications while two participants from Team 3 indicated a preference for phone calls and cloud-based live review of project documents No other knowledge sharing strategies were indicated by participant team 2 .

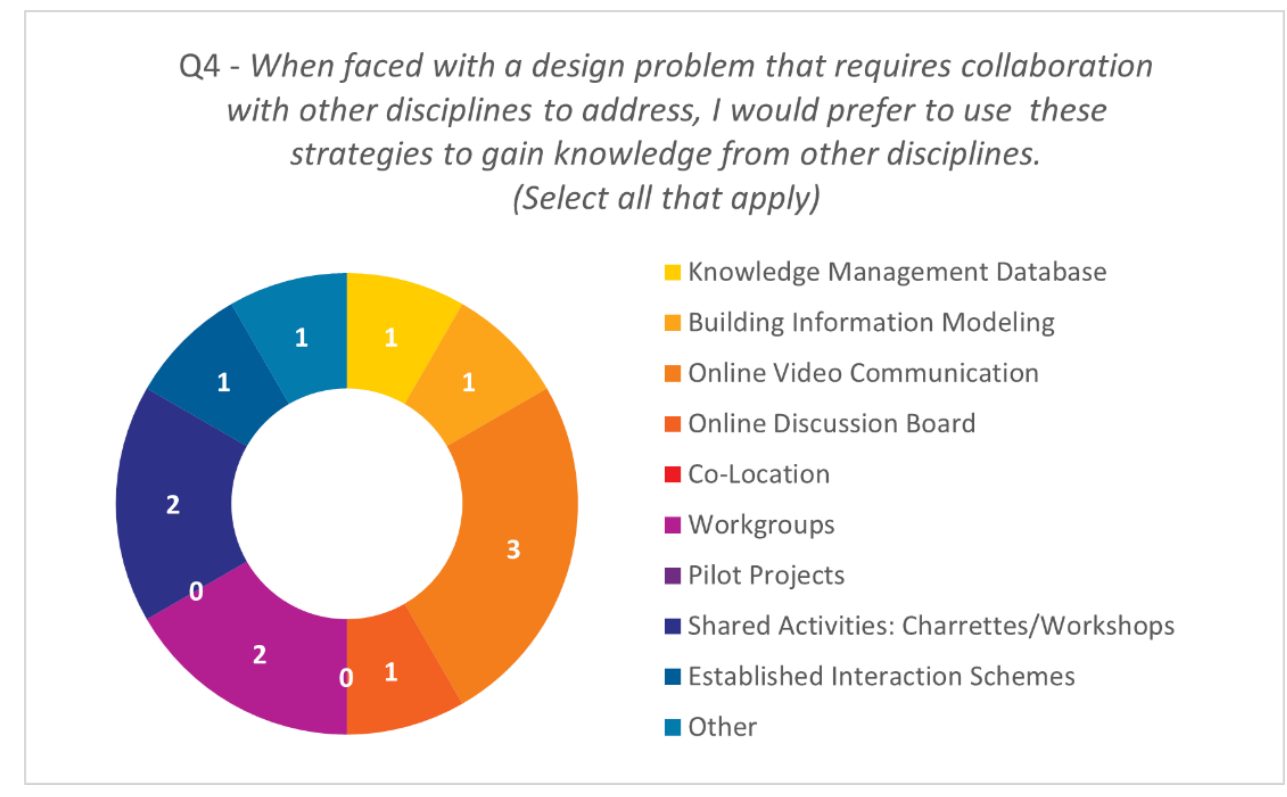

Figure 16. Knowledge sharing strategies preferred by Team 1 
Q4 - When faced with a design problem that requires collaboration with other disciplines to address, I would prefer to use these strategies to gain knowledge from other disciplines. (Select all that apply)
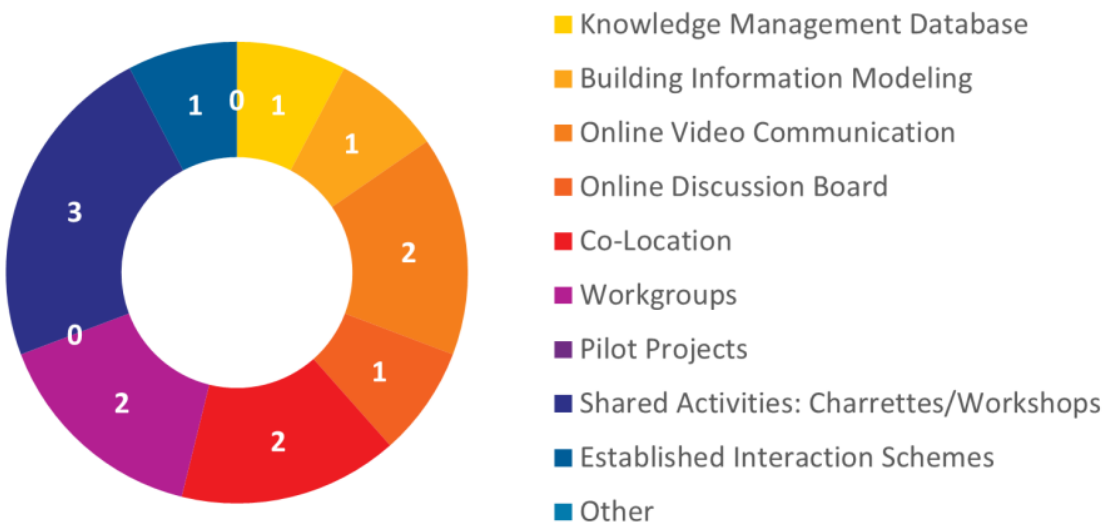

Figure 17. Knowledge sharing strategies preferred by Team 2

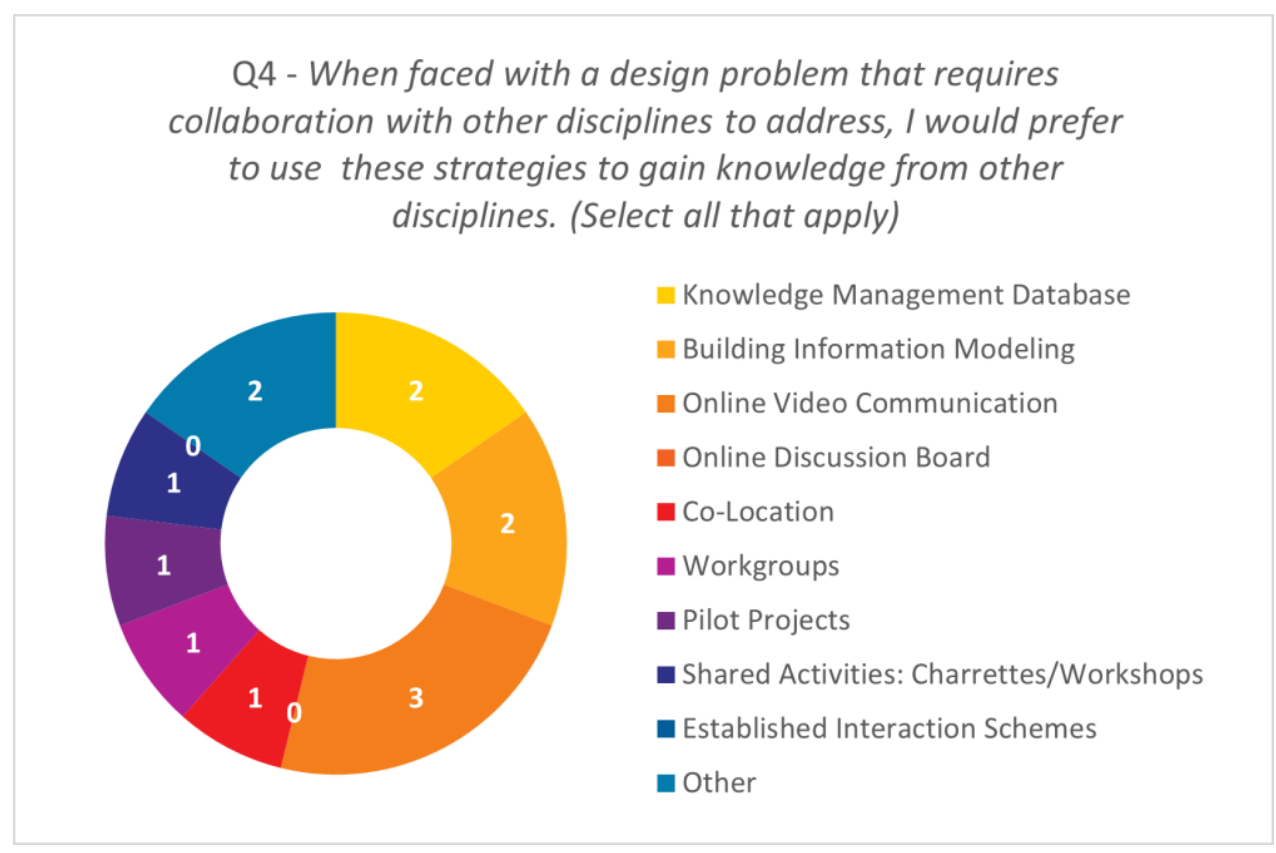

Figure 18. Knowledge sharing strategies preferred by Team 3

Responses to questionnaire Q4 indicate the relative preferences of participant teams with respect to the knowledge sharing strategies commonly employed throughout the architectural design 
process. Among participant teams, both participants from teams 1 and 2 had not indicated a preference for pilot projects, participants from team 1 had not indicated a preference for colocation, and participants from team 3 had not indicated a preference for established interaction schemes.

\subsection{Charrette Summary}

Summaries of design charrettes are composed of a chronological recounting of charrette proceedings and are supplemented with observational analysis recorded by the researcher while the charrettes took place.

\subsubsection{Charrette Participants}

After having responded to questionnaires, participants were sorted into charrette teams according to their self-identified field of expertise. Charrette teams were formed in a way that included at most one participant with architectural, engineering, contractor, or building automation technology experience.

Charrette team 1 consisted of:

- Participant A: an architect for an award-winning integrated architecture and interior design firm specializing in design innovation, project delivery, planning, advisory services, and visual communications. Participant A has 8 years of professional experience and a specialization in educational facility design.

- Participant B: a building envelope engineer and vice president for a global integrated multi-sector architecture and engineering firm. Participant B's 32 years of professional experience also includes roles as a contractor, consultant, developer, and facility owner. 
- Participant C: an energy analyst and policy consultant with 6 years of professional experience currently working with a leading Canadian building technology company offering IoT HVAC energy monitoring and control solutions for multi-unit residential buildings.

Charrette team 2 consisted of:

- Participant D: a project architect for a collaborative design studio known for innovative work in commercial, institutional, recreational, and educational sectors across Canada. Participant D's 16 years of professional experience includes building code research, architectural space planning, and program resolution.

- Participant E: an architect working with one of the largest integrated development services, design and construction firms in Western Canada. Participant $\mathrm{E}$ has 22 years of professional experience and specialization in commercial, industrial and retail projects.

- Participant F: an electrical engineer currently working with one of the world's leading transportation and infrastructure, property and buildings, environment, and power and energy services consulting firms. Their 12 years of professional experience includes positions as a proposal manager and senior digital solutions and smart infrastructure consultant for buildings, campuses, and smart cities.

Charrette team 3 consisted of:

- Participant G: an architect and education and recreation studio lead with 16 years of professional experience working for an award-winning integrated architecture and interior design firm specializing in design innovation, project delivery, planning, advisory services, and visual communications. 
- Participant H: a building information modeling and virtual design and construction coordinator for one of North America's most collaborative and innovative commercial builders. Participant H's 8 years of professional experience also includes positions as an architectural technologist.

- Participant I: a product strategy manager working with an award-winning global market leader in open protocol building automation systems. Their 30 years of professional experience also includes positions as president. CEO, general, and business development manager within the building systems and energy management industries.

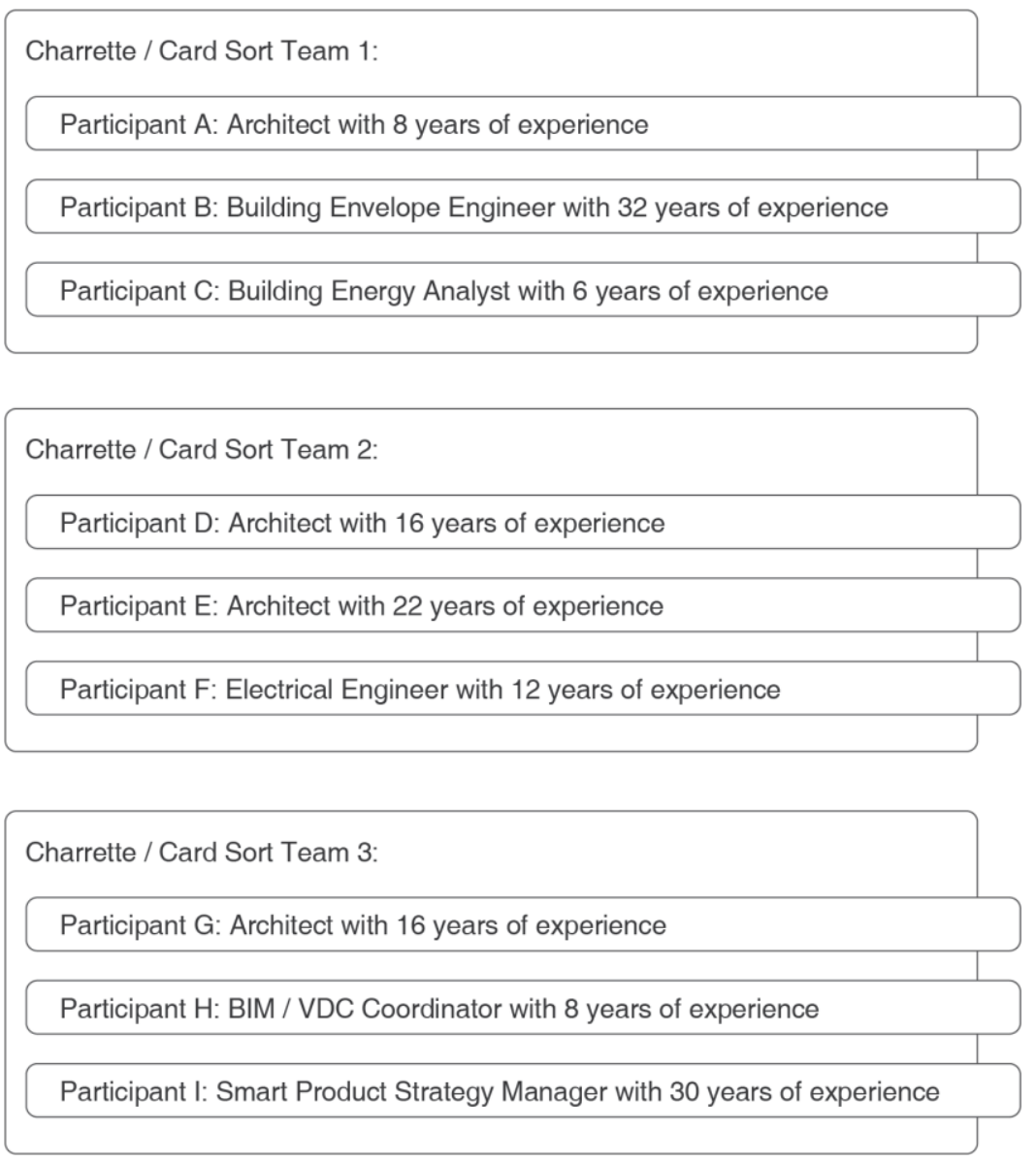

Figure 19. Composition of Charrette and Card Sorting Teams 


\subsubsection{Charrette 1}

After some time was spent familiarizing themselves with the locations and functionality of tools on the online collaboration board, participants of charrette 1 elected to begin the exercise by extracting sets of requirements desired qualities and requirements from the charrette brief. Participant B (building envelope engineer) defined the solution as one that must be able to minimize solar heat gain and unwanted glare while being resistant to the local climate and produced a visual of a smart louver system on the exterior of a wall section drawing provided alongside the brief. Participant C (energy analyst) clarified that the purpose of the louvers would be to help regulate internal building temperatures against heat gain due to HVAC systems and solar radiation. Participant B confirmed that locating louvers inside the building would help with glare, but not temperature, but also noted that in a northern climate exterior louvers may not be a viable solution. Participant B began documenting desired qualities on the board by listing freeze resistance and maintainability. With reference to freeze resistance, participant A (architect) proposed a dual layer wall which would provide a uniform appearance on the outside of the building and serve to house and protect the smart louver system from the exterior climate. Participant B added that venting the dual layer wall or 'double skin' would allow hot air to be expelled from the system, but that an interior opening would be required to allow for natural ventilation and the maintenance of dampers. Participants A and B recognized a similarity between their proposed solution and their knowledge of a strategy employed in an existing project, the Manitoba Hydro Building in Winnipeg.

Participant $\mathrm{C}$ inquired as to whether or not the smart louver system would be connected to a building wide control plan or if the building manager would be responsible for manually overriding the system in response to a change in temperature. Participant B answered that since 
the building was residential that each unit should be able to override a setting if they wish, but that if left unattended could result in over or underheating. Participant B and C agreed that the final control plan would need to balance tenant overrides against the building management system.

Before committing fully to the smart louver solution, Participant B considered alternative solutions beginning with a rolling shutter design. Participant A included auto fritting and electrostatic tinting solutions. Both alternatives were ultimately outruled as neither would satisfy the requirement for partial shading.

After identifying that the typical building opening provided was south-facing, participant B noted that sunshine would not enter the interior space until the winter months at which point it would be desirable. Thus, the group considered the use of an awning unless all building openings were to be treated with the same shading solution to ensure a consistency of aesthetic. After 17 minutes and 8 seconds had elapsed, charrette team 1 considered their response to be complete.

When asked about the team's problem-solving approach and response to the brief, participant B of charrette team 1 explained that the group's process was informed by their collective understanding of current state-of-the-art technologies and knowledge of existing projects featuring similar solutions. Further, their response to the brief would uphold a certain aesthetic quality, respond to the expected risks presented by the project climate, and ensure the long-term operability of the smart system.

Participant $\mathrm{C}$ of charrette team 1 was unable to join participants $\mathrm{A}$ and $\mathrm{B}$ on the video portion of the Microsoft Teams call. 


\subsubsection{Charrette 2}

After participants of charrette 2 paused to familiarize themselves with the brief and collaboration board layout, participant E (architect) questioned whether all aspects of the brief could be answered unless the group delegated responsibilities and tasks amongst themselves. Participant F (electrical engineer) answered that the group should begin by condensing the brief using a sticky note. Participants D (architect) and E brainstormed possible design solutions while $\mathrm{F}$ assumed responsibility for capturing them using another sticky note. Among the proposed solutions were animated louver systems and roller blinds combined with ambient light and temperature sensors. Participant E questioned whether a louver solution would be best implemented on the exterior or within the interior of the building façade while participant D considered the location of interior temperature sensors. Participants D and E agreed on a south-facing exterior louver system where smart control would allow optimal louver angles for passive solar gain and shading to be found.

After the louver system was selected, participant $\mathrm{D}$ called upon participant $\mathrm{F}$ to help determine how the louvers might be controlled and automated. Participant F searched for a symbol tool to help create diagrams and annotate drawings and resorted to the use of hand drawn symbols and text boxes with help from the rest of the team. Participants all commented that this exercise was challenging due to their unfamiliarity with the tools available on the collaboration board with participant D remarking that the Miro "was not the same as a good old piece of sketch paper." After three minutes of searching, participant $\mathrm{F}$ was able to locate and place a Wi-Fi symbol on the board.

Four minutes prior to the time limit, participant D indicated that the group should spend some time defining the rules that governed how occupant overrides would be accommodated by the building management system. Participants D and E discussed the possibility of a minimum or 
maximum range of operability available to occupants but requested input from team members with engineering experience. Participant F was inclined to go along with the solution proposed by participant $\mathrm{E}$ who also recommended that the solution also feature operable windows.

Insufficient time was left in the exercise to depict the location of operable windows on any of the provided drawings so a note was made using the sticky note tool.

When asked about the team's problem-solving approach and response to the brief, participant $\mathrm{E}$ of charrette team 2 explained that the groups' process could not begin until they had first come to a complete understanding of the design problem. After having come to an understanding, the team was able to discuss how passive shading systems might be connected to building management systems and augmented by smart technology. Participant $\mathrm{F}$ while demonstrating using the produced diagram outlined the relationship between interior temperature sensors and the building management system through to the automated louver system. With reference to another note made on the collaboration board, participant $\mathrm{F}$ explained the rules that would dictate the relationship between the smart louvers and building HVAC systems to ensure that optimal temperatures would be maintained. Finally, participant $\mathrm{E}$ added that operable windows were a last-minute consideration to improve building ventilation and airflow.

Throughout the exercise, the charrette team required clarification on the operation of collaboration board tools, the scale of drawings, and the charrette objective. The charrette timer was paused during these intervals.

\subsubsection{Charrette 3}

Participants of charrette 3 began the exercise by discussing how each member would be able to help the team respond to the brief. Participant I (building automation product strategist) noted that 
they would be able to help specify components or controls that might be required to devise a smart system but would be happy to defer sketching and annotation duties to participants $\mathrm{G}$ (architect) and H (BIM and VDC coordinator) who had experience working with architectural drawings.

Participant I listed an inventory of required components that included sensing elements, signal transmitters, and an automated blind. Participant I also raised questions surrounding how blinds would be powered and offered local battery, solar, or integration with the building electrical grid as possibilities. Finally, participant I indicated that the team would need to define how blinds would respond locally to changes in the environment to maintain a building wide temperature control plan. Participant $\mathrm{H}$ added that the control plan would need to account for occupants wanting to override the control plan in order to change spatial lighting conditions.

Shortly after discussions surrounding shading solutions and implementations began, the team opened a sticky note to document possible shading solutions. While participants $\mathrm{H}$ and I reflected upon the mechanical benefits of a simple interior rolling shade solution, participant $\mathrm{G}$ added that the group should also consider an exterior shading system such as a fixed shading screen or automated venetian louver. From a temperature control standpoint, participant G noted that when combined with an interior shading system, that exterior shading systems had been shown to be 50-60\% more effective than interior shading systems alone. In response, participant I suggested that the scale of implementation, whether it be solely at certain openings, across all openings, or across the entirety of a building's façade would help guide their decision-making process. Participant $\mathrm{G}$ remarked that it would be expensive but that implementing automated exterior and interior blinds across all openings would satisfy the requirements of the brief. 
Given the possibility of even greater stability and temperature control, participants also considered the use of a dynamic shading system housed within the cavity created between the walls of a double-skinned building façade. Participant $\mathrm{G}$ noted that a similar solution had been successfully implemented throughout the façade of the Manitoba Hydro Centre in Winnipeg. Participant I remarked that the cavity might also be used as a ventilation shaft when combined with operable interior windows while $\mathrm{H}$ indicated that without planning for access points that the double-skin façade might present challenges for operation and maintenance teams. After ten minutes had elapsed the team documented the ideas that they had generated thus far using a bulleted list on the collaboration board. Upon participant H's request for a preferred option, G advocated for the stability of the double skin solution while I maintained that an interior blind solution would be the easiest to maintain and modify despite not fulfilling all of the requirements presented in the brief.

Regardless of the chosen shading solution, participant I suggested that the team spend time discussing the location of sensing and user interfacing elements. Participant $\mathrm{G}$ suggested that interior photocell resistors be used to measure and control interior light level while participant I offered that it might instead be controlled by an algorithm balancing the typical building heat loads against predicted weather data. Participant $\mathrm{H}$ also suggested the use of occupancy sensors to provide the building management system with additional data to regulate the operation of the shading system. Participant I briefly touched on the feasibility of predictive heating and cooling plans but the strategy was discarded as the building was to be occupied at all times.

With four minutes remaining, the team considered the concepts they had generated and documented on the collaboration board. Participant $\mathrm{H}$ mentioned that although the brief did not mention cost, that the interior blind system appeared to be the most realistic solution. While 
drawing a blind along the opening of the building section, participant $G$ maintained that if temperature control was a priority that the most efficient way to mitigate solar heat gain would be through an exterior shade. Thus, a combined automated blind and exterior louver system was proposed.

When asked about the team's problem-solving approach and response to the brief participant $G$ of charrette team 3 began by reiterating that their approach was informed by an understanding of interior and exterior shading and the effectiveness of similar solutions implemented in existing projects. Participant I added that while they were not familiar with the technologies used in the aforementioned project that they would be interested in learning more. With reference to the team's process, participant I mentioned that the exercise allowed the group to generate ideas and expand upon them through valuable discussions informed by years of professional experience. Participant $\mathrm{H}$ concluded that the exercise demonstrated that problems such as these cannot be viewed in isolation as smart systems must tie into multiple other building utilities.

\subsubsection{Charrette Results}

Of the charrettes conducted in this study, charrette 1 was the only one considered complete by participants before the 30 minutes allotted for the exercise had elapsed. The collaborative process was led largely by participant B (building envelope engineer), who was the one to interpret the charrette brief, outline a list of required components for the proposed design, and present the team's response upon completion. Participant A (architect) worked together with participant B to generate an inventory of possible smart shading solutions while participant C (energy analyst) entered the conversation to discuss how smart shading systems would be monitored and integrated into the building wide temperature control plan. With these facets of the design left unexplored, participant $\mathrm{C}$ had a limited opportunity to contribute to the proposed design. 


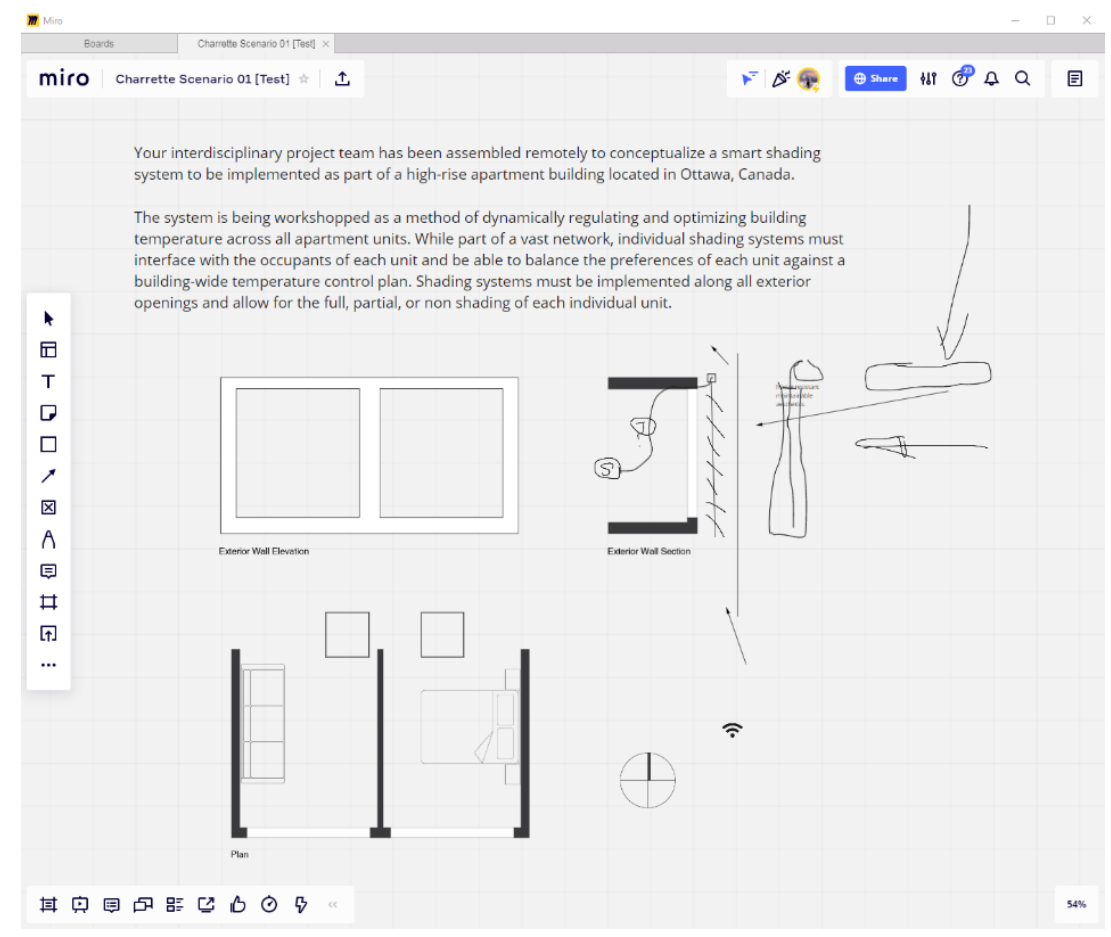

Figure 20. Charrette 1 Outcome

Among participant groups, participants of charrette 2 experienced the most difficulty with the operation of collaboration board tools and interpretation of the design brief. These factors led to the only charrette where participants were not able to fully represent the extent of design ideas on the collaboration board within the time allotted for the exercise. The outcome of this charrette may have been further influenced by the role assumed by participant $\mathrm{F}$ (engineer), who documented knowledge externalized by participants D (architect) and E (architect). While capturing knowledge, participant $\mathrm{F}$ was less likely to respond to questions from other participants asking them to share disciplinary knowledge themselves. Technical dimensions of the design solution governing the functionality and relationship between the smart shading and building management systems were underdeveloped during the charrette but were summarized afterwards by participant $\mathrm{F}$ who presented the proposed design. 


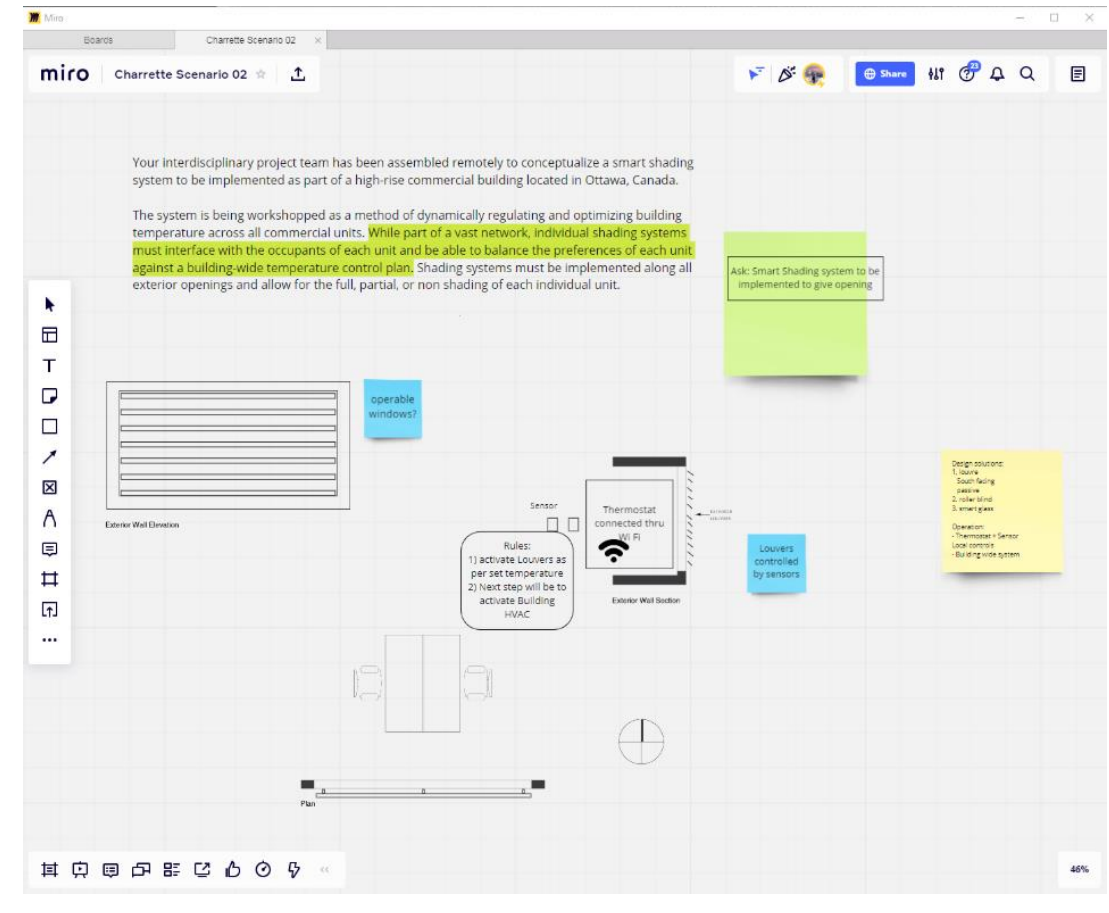

Figure 21. Charrette 2 Outcome

Participants of charrette 3 were the most likely among charrette teams to capture knowledge throughout the exercise. This approach was led by participant I (building automation product strategist), who set a precedent for concurrent disciplinary knowledge sharing and selfdocumentation in relation to the challenges issued by the charrette brief. Participants $G$ (architect) and $\mathrm{H}$ (BIM/VDC coordinator) were then able to concurrently share and fill in identified knowledge gaps. A healthy debate between building shading strategies was held between participants $\mathrm{G}$ and I, who spent the most time discussing possible shading strategies out of all charrette teams. The commitment to knowledge sharing between members of charrette team 3 continued after the conclusion of the study as participants were interested in learning more about previous projects and experience with technologies discussed throughout the charrette. 


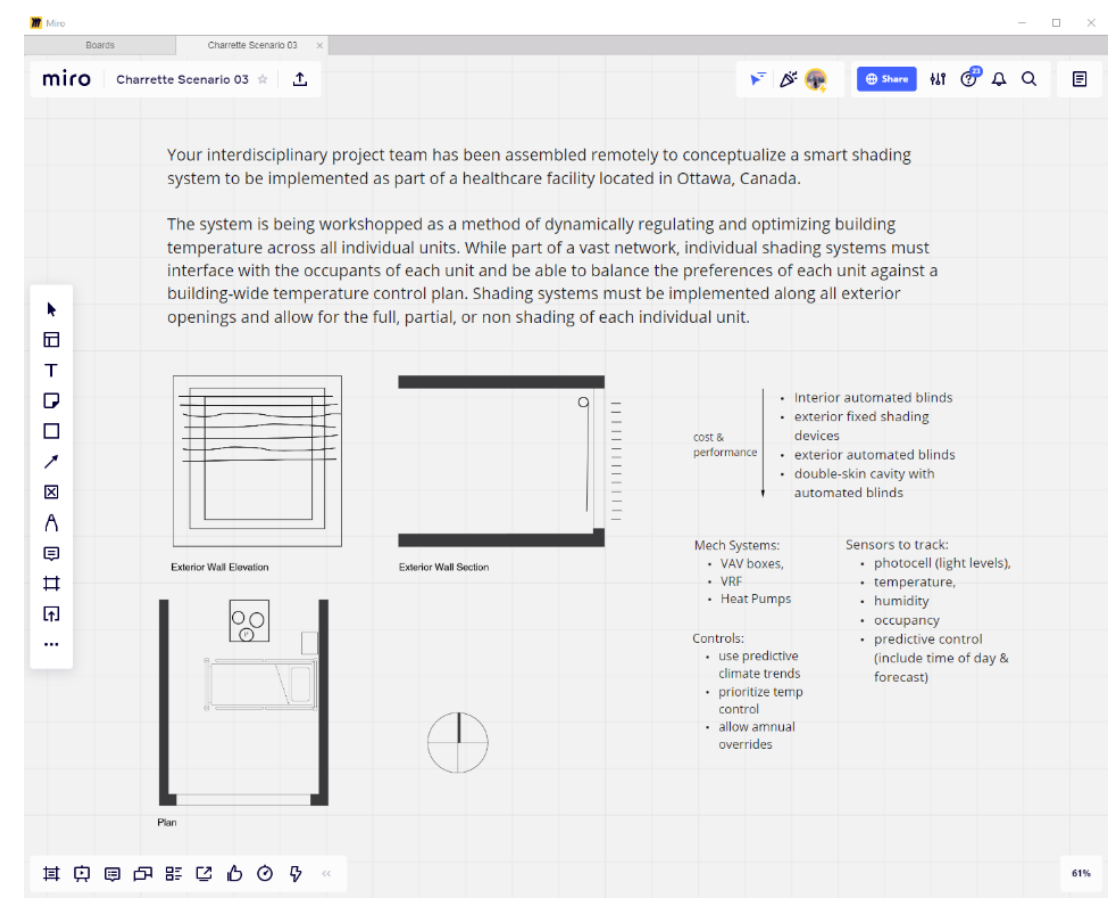

Figure 22. Charrette 3 Outcome

\subsection{Card Sort Summary}

After having completed and discussed their responses to the charrette brief, teams of participants were invited to participate in an online card sort held on another Miro collaboration board.

Following participant B's (engineer) suggestion, members of charrette team 1 began their sort by organizing cards into broad categories. Upon viewing cards depicting modeling techniques, participant A (architect) began sorting like cards into a "design tools" category while participant B began sorting items into a category labeled "client interaction." Participant C (energy analyst) suggested that a "research and analysis" category be created but no action was taken. The broad card sort yielded little discussion among participants regarding experience with processes or tools depicted on the cards. When the process was nearly complete, participants A and B agreed that the cards that had yet to be sorted could be grouped and sorted into a "project management" 
category. After the broad sort, participant B suggested that the "design process" category be subdivided as cards either had to do with the design of buildings or building management software. When asked about the team's card sorting process, Participant A explained that the group began by looking at the cards as a whole and created broad categories as they saw necessary then followed up and subdivided or refined categories if they appeared too large.

Participant E (architect) suggested that charrette team 2 begin their card sort by forming categories. Participant E proposed that cards be sorted by design stage while participant D proposed that cards might be sorted into categories based on the nature of the deliverable and offered "idea generation" and "document production" as examples. After a short deliberation period, participants agreed to sort cards according to design stage and began listing project phases to generate categories. The group then worked together to sort each individual card into a premade category. The remainder of the sort took place with little deliberation on the sorting of each individual card as participants were likely to agree with one another. Upon sorting "user testing" into the "post design" category however, participant D did remark that "it would be better if it happened earlier" indicating a desire for more research-based design. Shortly after beginning the sorting process, participants asked the researcher if cards might be duplicated and sorted into more than one category. When it was confirmed, participants came to the realization that a large number of cards fit into several categories and momentarily considered new methods of categorization. At this stage in the card sort, participant $\mathrm{F}$ (electrical engineer) indicated that they had another meeting to attend which led the remaining participants to sort the remaining cards into the existing organizational scheme. Participants D and E were uncertain how to categorize "software testing" and "hardware testing" and thus grouped both under "not applicable." When asked about the team's card sorting process, participant D explained that the 
group sorted items into categories based on a process that was mutually familiar among each team member. Participant D also noted that many cards may have been sorted into multiple categories but were sorted into design stages according to when they are typically first implemented.

Participant G (architect) of charrette team 3 began the team's card sort by expressing an inclination to categorize items according to their chronological appearance throughout a typical project lifecycle. While in agreement, participant I (building automation product strategist) noted that the categories devised for the sort would need to accommodate for a number of processes that may occur during more than one project stage. In response, participant H (BIM and VDC coordinator) suggested that a "collaboration/communication" category be made for items depicting mediums through which disciplines communicate with one another throughout the design process. Participant I emphasized the importance of cards sorted into the "collaboration / communication" category to capturing and maintaining project intent through all project phases when working with other disciplinary collaborators. When asked about the team's card sorting process, participant $\mathrm{G}$ indicated that the group instinctually sorted cards in chronological order according to a typical building project lifecycle while "collaboration / communication" and "project management" categories were created to contain items that occur perpetually through other categories. All participants were in agreement with participant G's comment that it would be easy to begin the sort again and sort items into different organizational schemes. 


\subsubsection{Card Sort Results}

Using the data analysis spreadsheet provided by Spencer (2009), open card sort data was recorded and plotted according to card and sort number (see Appendix L for card sort data analysis spreadsheet). Card numbers and names were entered into the first and second columns of the table while each subsequent column indicates the card's given category by each team of participants. An exploratory analysis of card sorting data was performed to compare and identify patterns between the composition of sorting reams, choices of organizational schemes, formation and naming of groups, sorting of cards into groups, and participant comments and discussion surrounding the items depicted on individual cards (See appendix M for exploratory analysis spreadsheet).

\begin{tabular}{|l|l|l|l|l|}
\hline Card no & Card name & Sort 1 & Sort 2 & Sort 3 \\
\hline 1 & $\begin{array}{l}\text { Project Knowledge } \\
\text { Management Database }\end{array}$ & Project Management & Schematic Design & Project Management \\
\hline 2 & $\begin{array}{l}\text { Knowledge } \\
\text { Management Archive }\end{array}$ & Project Management & Post-Construction & Project Management \\
\hline 3 & $\begin{array}{l}\text { Building Information } \\
\text { Modeling }\end{array}$ & Design Tools & Schematic Design & Detailed Design \\
\hline 4 & $\begin{array}{l}\text { 3D Modeling } \\
\text { Computer Aided } \\
\text { Design }\end{array}$ & Design Tools & $\begin{array}{l}\text { Design } \\
\text { Development }\end{array}$ & Detailed Design \\
\hline 5 & Design Tools & $\begin{array}{l}\text { Construction } \\
\text { Documents }\end{array}$ & Detailed Design \\
\hline
\end{tabular}

Figure 23. Card sort data analysis table

Sort 1 was done by participants A (architect), B (building envelope engineer), and C (energy analyst) from charrette team 1 . Cards in sort 1 were organized according to the (primary function) of each strategy or tool and into groupings labeled 'Client Interaction', 'Building Design Process', 'Design Tools', 'Software Design', and 'Project Management'. Sort 2 was done by participants D (architect), E (architect), and F (electrical engineer) from charrette team 2. Cards in sort 2 were organized according to the use of each strategy or tool by project stage and 
into groupings labeled 'Pre-Design', 'Concept Design', 'Schematic Design', 'Design development', 'Construction Documents', 'Contract Administration', and 'Post-Construction'. An 'Unsorted' category was also created. Sort 3 was done by participant G (architect), H (BIM/VDC coordinator), and I (building automation product strategist) from charrette team 3. Cards in sort 3 were organized according to use of tools or strategies by project stage and into groupings labeled 'Visioning', 'Detailed Design', and 'Prototyping and Testing' categories. 'Collaboration and Communication' and 'Project Management' groupings were also made. Exploratory analyses of card sorts revealed:

- 9/13 cards sorted into the 'Project Management' category in Sort 1 were in agreement with the 9 cards sorted into the 'Project Management' category in Sort 3

- $4 / 5$ cards sorted into the 'Client Interaction' category in Sort 1 were in agreement with the 11 cards sorted into the 'Collaboration and Communication' category in Sort 3

- 6/6 cards sorted into the 'Software Design' category in Sort 1 were in agreement with the 'Prototyping and Testing' category in Sort 3

- 5/7 cards sorted into the 'Design Development' category in Sort 2 were in agreement with the 8 cards sorted into the 'Detailed Design' category in Sort 3

- $3 / 3$ 'Unsorted' cards were in agreement with the 'Software Design Process' group in Sort 1 and the 'Prototyping and Testing' group in Sort 3

- 5/9 cards sorted into the 'Prototyping and Testing' category in sort 3 were in agreement with the 5 cards sorted into the 'Software Design Process' group in Sort 1

The card sorting exercise found a high level of disagreement and discussion surrounding card 36 'User Testing', which was sorted into 'Software Design Process' in sort 1, 'Post-Construction in sort 2, and 'Prototyping and Testing' in sort 3. During sort 2, participant D commented that "it 
would be better if it happened earlier", and during sort 3, participant I commented that "user testing typically happens after the design." While user involvement in the smart building design process is not investigated in this study, this finding is discussed further in Section 7. A high level of disagreement was also found with card 32 'Programming', which was sorted into 'Software Design Process' in sort 1, 'Pre-Design' in sort 2, and 'Prototyping and Testing' in sort 3 , which reflects the difference in interpretation of terminology between disciplinary participants. As an architect, 'Programming' may denote the act of preliminary space planning in response to client goals and requirements while as an engineer or building automation specialist, 'Programming' denotes the process of developing a set of instructions for a computer to perform. This finding is discussed further in Section 5. The emergence of the 'Unsorted' category in sort 2 suggests a gap in disciplinary understanding of software development as it applies to the development of building automation systems and smart architecture. This finding is discussed further in Section 5. 


\section{Chapter 5: Discussion}

This research sought to determine how online collaboration boards might be employed by smart architectural project teams to facilitate interdisciplinary knowledge sharing and collaborative design. Using a mixed method approach, this research also sought to identify how the outcomes of smart architectural projects might be influenced by the knowledge sharing approaches used by architectural project teams. Insights surrounding these research questions and hypotheses that expected online collaboration tools to facilitate architectural knowledge sharing and problem solving emerged from the analysis of charrette outcomes and were contextualized by participant team experiences with knowledge sharing obtained through questionnaires and card sorting.

Analyses of charrette outcomes encapsulate not only the responses to design briefs, but also the collaborative and knowledge sharing processes undergone by participant teams. Responses and interactions between participants were investigated through the lens of how the two were facilitated or hindered through the employment of online collaboration boards. In this way, insights regarding the affordances of online collaboration boards emerged from the documentation and review of charrette proceedings.

Insights discussed in this section are derived from accounts of how collaboration board tools were employed to externalize, capture, discover and fill in gaps in knowledge between design team members, as well as how they allowed individual disciplinary participants to enter and contribute to design processes and outcomes. When compared to responses to design briefs verbally presented to researchers following charrettes, traces of design processes and outcomes recorded by charrette participants on collaboration boards also serve as a measure of how 
effectively knowledge was shared, captured, and implemented by charrette teams using the collaboration period.

Questionnaire and card sorting data allow connections to be drawn between charrette outcomes and the knowledge sharing experience and approaches of charrette teams. Consensus surrounding design processes built through card sorting also allowed recommendations to be made to organizations surrounding the implementation of knowledge sharing strategies.

\subsection{Insights}

Analysis of questionnaire, charrette, and card sort outcomes resulted in the generation of the following insights into how smart architectural project teams might approach and implement knowledge sharing strategies to overcome interdisciplinary knowledge gaps and improve collaborative efficiency.

\subsubsection{Insight 1}

Online collaboration boards provided collaborators with knowledge sharing mindsets a platform to communicate and overcome knowledge gaps present between design team members.

Analysis of online design charrette proceedings suggest that participants with a proactive approach to knowledge sharing were able to promote a broader range of discussion surrounding possible design ideas and solutions amongst members of their charrette team. Participants with this approach regularly summarized their own disciplinary experience in relation to the design problem and were more likely to invite other collaborators to help fill in gaps in their own knowledge before discussing potential design solutions. Among charrette teams, this practice was exhibited most often by the most senior participants of charrettes 1 and 3 . Following their example, remaining participants of charrettes 1 and 3 were in turn more likely to disclose gaps in 
their own knowledge resulting in a higher degree of knowledge sharing and a broader range of discussion surrounding design ideas and solutions. Approaching collaboration in this way also allowed charrette teams to overcome barriers to architectural knowledge sharing associated with knowledge complexity and project uniqueness that had been identified within the literature (Gluch et al. 2013, Bektas 2013).

\subsubsection{Insight 2}

Online collaboration boards allowed participants to concurrently externalize and store knowledge that could in turn be accessed by other project team members.

Analysis of charrette proceedings suggest a connection between charrette outcomes and knowledge capturing approaches taken by charrette participants. While knowledge capturing represents an integral stage in the knowledge sharing process (Tan et al., 2010), outcomes of interdisciplinary collaborative design sessions may yield unsatisfactory results if participants become preoccupied with capturing knowledge verbalized by other collaborators.

Studies documenting knowledge exchange throughout large-scale interdisciplinary architectural projects have identified a number of factors influencing collaborators motivations to capture and retain project knowledge. Among them are perceptions that project challenges are unique and will not be encountered again, or that relationships between collaborators are temporary and are not worth committing to (Bektas, 2013). For these reasons, valuable project knowledge not captured by interdisciplinary architectural project team members may remain trapped within disciplinary boundaries (Gluch et al., 2013) and be unavailable to collaborators in the case of a recurring design problem. 
The effects of poor knowledge capturing practices surfaced throughout charrette 2, albeit because participants became preoccupied with capturing knowledge externalized by other charrette team members using collaboration board tools and as a result did not recognize when they were called upon to share knowledge themselves. Participants of charrette team 3 were able to circumvent these issues by routinely self-documenting as disciplinary concepts were shared through the use of bulleted lists and sketches on the collaboration board. Approaching knowledge sharing and capture in this way allowed non-subject matter experts efficient access to a visual inventory of disciplinary information, the confidence to offer design ideas, and the opportunity to enter into and contribute to the collaborative design process.

Alternatively, research suggests that organizations may choose to designate a participant as a project knowledge manager responsible for the capturing, organization, and management of design ideas generated during collaborative design processes (Tan et al., 2010).

\subsubsection{Insight 3}

Benefits of knowledge sharing tools designed to facilitate collaboration between groups of participants were mitigated by the experience levels of individual users with the tools themselves.

Analysis of charrette proceedings suggested a connection between charrette outcomes and participant familiarity with online collaboration board tools.

Members of charrette teams 1 and 2 routinely paused to locate and learn collaboration board tools, and as a consequence, charrette team 2 was unable to fully represent their response to the charrette brief within the 30 minutes allotted for the exercise. Charrette results align with the literature surrounding research into distributed collaboration conducted by Hammond (2001) which suggest a connection between unfamiliarity with collaboration platforms and decreased 
efficiency of information transfer between collaborators. Further research into distributed collaboration conducted by Hammond et al. (2005) suggested that increased mental workload associated with unfamiliarity resulted in fewer design issues and solutions considered by design team members.

For project teams looking to implement new knowledge sharing tools into existing processes, best results may be achieved if participants are first introduced to tools through pilot testing to increase the awareness level of tools alongside feedback sessions to determine the usefulness, constraints, and overall commitment level of participants (Bektas, 2013).

\subsection{Barriers}

Literature reviewed and data analyzed in this study indicate a number of barriers to be considered by smart architectural project teams planning to implement new disciplinary collaborators or knowledge sharing strategies into existing architectural design processes.

Charrette outcomes indicate that a lack of consideration for how knowledge is to be captured once it is shared can offset the benefits of bringing together interdisciplinary groups of participants. The results of charrettes 2 and 3 suggest that employing online collaboration boards may both facilitate the knowledge sharing habits and practices of some participants, while exacerbating the difficulties experienced by participants unfamiliar with collaborative design processes or collaboration board tools.

The gap in understanding of design methods and processes between building and technology industry members represents another significant barrier to interdisciplinary collaboration in smart architectural design. Throughout charrettes, a number of participants from technology industries indicated a lack of confidence surrounding their ability to meaningfully contribute and influence 
charrette design processes and outcomes. These incidents may reflect the extent to which professionals from smart building technology backgrounds are involved in smart architectural design processes any by extension exposed to architectural design methods or tools.

\subsection{Limitations}

Research methodologies devised for this study were originally selected prior to the COVID-19 pandemic and were altered to adhere with regulations set in place by the Carleton University Research Ethics Board to ensure the health and safety of all research participants. Prior to the restriction placed upon research involving direct interaction with participants, this study sought to assemble teams of interdisciplinary building industry participants for in-person charrettes to examine how knowledge sharing during design exploration phases might improve architectural project outcomes. Online collaboration boards were identified as a means through which charrettes might be administered remotely yet would require a re-imagining of the original research question and approach. As the outcomes of online charrettes would be tied to the abilities of participant teams to collaborate using these tools, the original research question was adjusted to reflect the shift in focus towards the examination of architectural knowledge sharing through online collaboration boards.

Recruitment was undertaken by the researcher and involved reaching out to known or researched architecture, engineering, technology, or integrated project delivery firms. At the time of recruitment, there may have been firms capable of providing suitable participants for the study that were not known by the researcher or that did not appear during the research process. This phase proved to be problematic amid the fatigue that developed towards online video communication in the midst of work-from-home orders issued by Canadian regional health 
authorities. Among participant demographics, technologists with relevant building automation experience proved to be difficult to connect with and recruit. Conversely, participants with architectural backgrounds were more likely to indicate an interest in the study, possibly due to their familiarity with the charrette format or research problem. Given the difficulties encountered during the recruitment process, this study features a smaller sample of participants. More definitive conclusions would require the conduction of additional online charrettes and card sorting sessions. Scheduling charrettes at a time mutually convenient for all disciplinary participant groups also proved to be a major challenge for the researcher during this study and resulted in numerous delays.

Charrettes conducted online during this study were shortened in order to accommodate participants with limited availability, however the condensed nature of charrette briefs and durations may have affected research outcomes. Participants routinely sought project information regarding total building square footage and rise, aesthetic direction, and general budget not provided by the brief to help guide group decision-making processes. Alongside a more comprehensive design brief, expanding the time allotted for charrettes may have resulted in a broader exploration of possible design solutions.

Collaboration between participants may have also been affected by the presence of the moderator during research proceedings. To mitigate the effects of observation on research outcomes, the moderator muted and disconnected themselves from the video portion of the Teams call during charrettes and card sorting sessions. However, participants were made aware that the moderator would be available to re-enter the call to answer any questions or provide assistance regarding the operation of collaboration board tools, thus re-introducing the observer effect. 
Throughout charrette proceedings, participants also asked if the online collaboration board toolset included a symbol library for diagramming. At the time of implementation, the researcher was not aware of such a tool, however one participant was able to locate a symbol library in a submenu entitled "wireframing library." Online collaboration boards may benefit from the use of generalized language to describe features as "wireframing" may not be understood by users without a background in user experience or web design. Had the library been easier to find, the feature may have been added to the default toolbar and included as part of the software demonstration given to participants prior to the commencement of the charrettes.

Among the methodologies employed in this study, open card sorting was selected to allow participants to discuss and build a group consensus surrounding their experiences with knowledge sharing strategies. Open card sorts generated less discussion amongst participants than expected, indicating that a closed card sort or other research method may have been more effective. Some confusion was generated during card sorting sessions by card number 32 "Programming" which depicted a source code editor meant to represent a stage in the building management software development process. Participants with a background in architecture interpreted the card according to their own disciplinary understanding of programming which denotes the act of preliminary space planning in response to the project goals and requirements outlined by the project client. To avoid confusion, two programming cards may have been made with different imagery to indicate a distinction between the two understandings. 


\section{Chapter 6: Conclusion}

This research was undertaken out of a desire to investigate the perceived disconnect between the capabilities and performance of today's technologically augmented smart buildings. Reviewing the literature surrounding smart architectural project development indicated that project teams struggle to bridge knowledge gaps and facilitate collaboration between themselves and new disciplinary collaborators (Bektas, 2013). Further review of the literature surrounding knowledge sharing led to the primary research question for this study, which asked how online collaboration board tools might be employed by smart architectural project teams to help facilitate knowledge sharing and interdisciplinary collaborative design.

By replicating architectural project scenarios using the charrette methodology and online collaboration board tools, teams of architects, engineers, contractors, and smart building technologists were observed as they worked to share and implement disciplinary knowledge to produce answers to charrette briefs. While charrette outcomes agreed with the hypothesis that online collaboration boards might facilitate knowledge sharing between interdisciplinary charrette team members, findings suggest that overcoming knowledge gaps between building industry participants may not be the sole factor to achieving desired project outcomes.

Observational analysis of research proceedings indicated that online collaboration boards enabled participants with a proactive approach to knowledge sharing and capturing to promote a broader range of discussion surrounding design ideas among design teams and result in stronger charrette outcomes. Conversely, a lack of familiarity among participants with design and knowledge sharing processes and tools were linked to lower levels of collaborative efficiency. 
In spite of the consequences associated with the misjudged implementation of smart building systems, research has identified that a considered approach to knowledge sharing taken by project collaborators can lead to more informed architectural design solutions and in turn better project outcomes. With a greater understanding of available knowledge sharing strategies and tools provided by this research, it is hoped that architectural project teams will gain the confidence to collaborate with and learn from new disciplines and are in turn able to take full advantage of the benefits of new smart building technologies.

\subsection{Future Research}

Prior to the restriction placed upon research involving direct interaction with participants, this study sought to assemble teams of interdisciplinary building industry participants for in-person charrettes to examine how knowledge sharing during design exploration phases might improve smart architectural project outcomes. Online collaboration boards were identified as a means through which charrettes might be administered remotely yet required a re-imagining of the original research question and approach. As the outcomes of online charrettes would be tied to the abilities of participant teams to collaborate using online collaboration board tools, the original research question was adjusted to reflect the shift in focus towards the examination of architectural knowledge sharing through online collaboration boards.

Once it is safe to resume on-campus research and interact with participant groups, online charrettes could be compared to in-person charrettes to gauge the difference in distributed and co-located collaboration and knowledge sharing between building industry participants. For a charrette to be conducted in-person, a suitable collaboration space would need to be selected and furnished with large tables, chairs, whiteboards, and materials including paper, sticky notes, 
pens, pencils, and markers. Card decks for card sorting exercises would also need to be printed to accommodate a physical sort. Charrette and card sorting proceedings would be video and audio recorded to allow the researcher to moderate the charrette, transcribe, and conduct post-analysis of research outcomes. Charrette briefs devised for this study were condensed to be completed within a 30-minute time frame by participants collaborating with one another through online collaboration boards. Conducting this exercise in-person may allow for alternative charrette structures and approaches to take place. When compared to the results of this research, smart architectural project teams might gain an understanding of how best to balance the use of physical setting and tool-based knowledge sharing strategies throughout the lifecycle of an architectural project.

This study does not investigate or discuss the role of the user in the smart building design process; however, research participants routinely indicated a desire for increased user testing and research within the architectural design process. Given the intention of smart buildings to automatically adjust interior conditions according to the environmental preferences of building occupants, future research into smart architectural design processes may look to recruit building occupants alongside building industry participants and examine how their inclusion influences charrette outcomes. 


\section{References}

Aksamija, A., \& Wiley InterScience (Online service). (2016). Integrating innovation in architecture: Design, methods and technology for progressive practice and research. West Sussex, United Kingdom.

Augustin, S., Coleman, C., \& ProQuest (Firm). (2012). The designer's guide to doing research: Applying knowledge to inform design. Hoboken, N.J: John Wiley and Sons.

Augusto, J. (2008). Ambient Intelligence: Basic Concepts and Applications. In Software and Data Technologies (Vol. 10, pp. 16-26). Springer Berlin Heidelberg.

Bektas, E. (2013). Knowledge Sharing Strategies for Large Complex Building Projects. $A+B E$ : Architecture and the Built Environment, (4), 1-332.

Cross, N. (2011). Design thinking : understanding how designers think and work (English ed.). Berg Publishers.

Cross, N. (1982). “Designerly ways of knowing.” Design studies 3(4): 221-227.

Cross, N., \& Cross, A. (1995). The Competitive Innovator. Creativity and Innovation Management, 4(3), 145-151.

Clements-Croome, D. (2014). Sustainable Intelligent Buildings for Better Health, Comfort and Well-Being. Report for Denzero Project.

Clements-Croome, D. (2014). Creative and Productive Workplaces: A Review. Intelligent Buildings International, 1-20.

Curedale, R. (2012). Design research methods : 150 ways to inform design (1st ed.). Topanga, CA: Design Community College.

Curedale, R. (2013). Design methods 1: 200 ways to apply design thinking (2nd ed.). Topanga, CA: Design Community College.

Di Cristina, G. (2001). AD: Architecture and science. Chichester: Wiley-Academy. 
Ghaffarianhoseini, A., Berardi, U., Berardi, U., Al Waer, H., Chang, S., Halawa, E., Clements Croome, D. (2016). What is an intelligent building? Analysis of recent interpretations from an international perspective. Architectural Science Review, 59(5), 338-357

Gluch, P., Johansson, K., \& Räisänen, C. (2013). Knowledge sharing and learning across community boundaries in an arena for energy efficient buildings. Journal of Cleaner Production, 48(C), 232-240.

Glynn, R. (2014). Animating architecture: Coupling High-Definition sensing with HighDefinition actuation. Architectural Design, 84(1), 100-105.

Hammond, J., Koubek, R. J., \& Harvey, C.M. (2001). Distributed collaboration for engineering design: A review and reappraisal. International Journal of Human Factors in Manufacturing, 11, 35-52.

Hammond, J., Harvey, C., Koubek, R., Compton, W., \& Darisipudi, A. (2005). Distributed Collaborative Design Teams: Media Effects on Design Processes. International Journal of Human-Computer Interaction, 18(2), 145-165.

Hsu, C. \& Sandford, B. (2007). The Delphi Technique: Making Sense of Consensus. Practical Assessment, Research \& Evaluation, 12(10), 1-8.

Knapp, P. (2013). Interactive Architecture. Retrieved from https://segd.org/interactivearchitecture

Krakowski, T. (2008). Interactive Architecture. Retrieved from https://segd.org/interactivearchitecture

Laing, R. (2019) Digital participation and collaboration in architectural design. Routledge.

Lennertz, W. R., \& Lutzenhiser, A. (2006). The charrette handbook: The essential guide for accelerated, collaborative community planning. Chicago, Ill: American Planning Association. MacKnight, P. (2018). The Learning Facade. ProQuest Dissertations Publishing. Meagher, M. (2014). Responsive architecture and the problem of obsolescence. Archnet-IJAR, 8(3), 95-104. 
Miorandi, D., Sicari, S., De Pellegrini, F., \& Chlamtac, I. (2012). Internet of things: Vision, applications and research challenges. Ad Hoc Networks, 10(7), 1497-1516.

Murdoch, J., Champion, R., \& Hughes, W. (2015). Construction contracts law and management. (5th ed.). Routledge.

Negroponte, N. (1970). The architecture machine; toward a more human environment. M. I. T. Press.

Newell, S., \& Huang, J. (2005). Knowledge integration processes and dynamics within the context of cross-functional projects. Management of Knowledge in Project Environments, 1939.

Nonaka, I. (1994). A dynamic theory of organizational knowledge creation. Organization science 5(1): 14-37.

Nonaka, I., \& Takeuchi, H. (1995). The knowledge-creating company : how Japanese companies create the dynamics of innovation. Oxford University Press.

Ochoa, C., \& Capeluto, I. (2008). Strategic decision-making for intelligent buildings:

Comparative impact of passive design strategies and active features in a hot climate. Building and Environment, 43(11), 1829-1839.

Olsen, C., \& Namara, S. M. (2014). Collaborations in architecture and engineering. New York, NY: Routledge.

Ratti, C., \& Claudel, M. (2014). The rise of the 'Invisible detail': Ubiquitous computing and the 'Minimum meaningful'. Architectural Design, 84(4), 86-91.

Robin, V., Rose, B., \& Girard, P. (2007). Modelling collaborative knowledge to support engineering design project manager. Computers in Industry 58(2): 188-198.

Roggema R. (2014) The Design Charrette. Springer, Dordrecht.

Senagala, M. (2006). Rethinking smart architecture: Some strategic design frameworks. International Journal of Architectural Computing, 4(3), 33-46.

Shen, W., Hao, Q., Mak, H., Neelamkavil, J., Xie, H., Dickinson, J., Thomas, R., Pardasani, A., \& Xue, H. (2010). Systems integration and collaboration in architecture, engineering, 
construction, and facilities management: A review. Advanced Engineering Informatics, 24(2), 196-207

Shin, D. (2014). A socio-technical framework for Internet-of-Things design: A human-centered design for the Internet of Things. Telematics and Informatics, 31(4), 519-531.

Sinopoli, J. (2016). Advanced technology for smart buildings. Boston: Artech House.

Sinopoli, J. (2010). Smart building systems for architects, owners, and builders.

Elsevier/Butterworth-Heinemann.

Spencer, D. (2009). Card sorting: Designing usable categories. Brooklyn, NY: Rosenfield Media

Sutton, S. E., \& Kemp, S. P. (2006). Integrating Social Science and Design Inquiry through Interdisciplinary Design Charrettes: An Approach to Participatory Community Problem Solving. American Journal of Community Psychology, 38(1/2), 125-139.

Tan, H.C., Anumba, C., Carrillo, P., Bouchlaghem, D., Kamara, J., \& Udeaja, C. (2010). Capture and Reuse of Project Knowledge in Construction. Wiley-Blackwell

Tolmie, P., Pycock, J., Diggins, T., MacLean, A., \& Karsenty, A. (2002). Unremarkable computing. 399-406.

Walter, G. (2015). Avoiding the "Internet of Misinformed Things." Design Management Review, 26(2), 36-43.

Weiser, M. (1991) The Computer for the 21st Century. Scientific American Special Issue on Communications, Computers, and Networks.

Wigginton, M., \& Harris, J. (2002). Intelligent Skins. Oxford:Architectural Press.

Wong, J., Li, H., \& Wang, S. (2005). Intelligent building research: a review. Automation in Construction, 14(1), 143-159. 


\section{Appendices}

\section{Appendix A.}

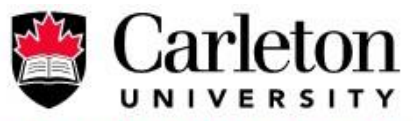

Canada's Capital University

\section{Participant Recruitment Email}

Subject: Would you like to participate in an online interdisciplinary design charrette?

Hi there,

My name is Eric Wolfe and I am a master's student from the Carleton University School of Industrial Design working on a research project entitled 'Knowledge Sharing Strategies for Smart Architecture Development: Facilitating interdisciplinary collaborative design.' under the supervision of Prof. Stephen Field. This research project aims to investigate strategies that may be employed by smart architecture project teams to promote interdisciplinary knowledge sharing among project collaborators.

This study consists of one 5-minute questionnaire, one 30-minute online design charrette, and one 30minute online card sorting session.

To be eligible for this study, you must have:

- A minimum of 5 years professional experience as an Architect, Civil or Mechanical Engineer, Industrial Designer, or Information Technologist.

- $\quad$ English language proficiency.

Design charrette and card sorting session participants will be compensated with a \$10 Tim Horton's gift card.

*Note that consent for audio recording of the design charrette and card sorting sessions are mandatory.

CURE-B Clearance \# $113042 \quad$ Date of Clearance: August 30, 2020

The ethics protocol for this project has been reviewed and cleared by the Carleton University Research Ethics Board. Should you have any ethical concerns with the study, please contact the REB Chair, Carleton University Research Ethics Board-B (by phone: 613-520-2600 ext. 4085 or by email: ethics@carleton.ca). For all other questions about the study, please contact the researcher.

Please contact the researcher Eric Wolfe for more details on this study at ericwolfe@cmail.carleton.ca 


\section{Appendix B.}

\section{Carleton \\ U N I V E R I T Y}

Canada's Capital University

\section{Email Response to Participant Interest}

Subject: Response to interest in online interdisciplinary design charrettes.

Thank you for your interest in this research project,

If you would like to participate or have any questions, please take a moment to read through and fill out the attached consent form which contains additional information about the study. Completed consent forms may be sent to ericwolfe@cmail.carleton.ca

After having completed the form you may begin the preliminary questionnaire: *link here*

I have also provided some text below that you may modify as you see fit and forward to any colleagues who may also be interested in participating. Any help would be greatly appreciated!

Sincerely,

Eric Wolfe

"I was recently contacted by Eric Wolfe who is actively searching for professionals within the Architecture Civil and Mechanical Engineering, Industrial Design, and Information Technology industries to participate in collaborative design charrettes for a Master of Design (MDes) thesis at Carleton University.

His research topic concerns interdisciplinary knowledge sharing between smart architecture project collaborators and he has asked that I reach out to some people in the Architectural, Engineering, Industrial Design, or Information Technology fields on his behalf. This is an opportunity for participants to identify and discuss the effects of gaps in disciplinary knowledge between smart architecture project collaborators and how they might be overcome.

If you would be willing to participate, please contact ericwolfe@cmail.carleton.ca." 


\section{Appendix C.}

\section{Carleton \\ U N I V E R I T Y \\ Canada's Capital University}

\section{Informed Consent Form}

\section{Name and Contact Information of Researchers:}

Eric Wolfe, Carleton University, School of Industrial Design

Email: ericwolfe@cmail.carleton.ca

Supervisor and Contact Information:

Stephen Field, Carleton University, School of Industrial Design

Phone: 613-520-2600, ext. 8371

Email: stephen.field@carleton.ca

\section{Project Title}

Knowledge Sharing Strategies for Smart Architecture Development: Facilitating interdisciplinary collaborative design.

\section{Carleton University Project Clearance}

Clearance \#: 113042

Date of Clearance: August 31, 2020

\section{Invitation}

You have been invited to take part in this research project because of your professional experience within one of the Architecture, Civil or Mechanical Engineering, Industrial Design, or Information Technology fields. Please note that 5 years' experience working in one of these fields is required. The information in this form is intended to help you understand what we are asking of you so that you can decide whether you would like to participate. Your participation in this study is voluntary, and a decision not to participate will not be used against you in any way. As you read this form, and decide whether or not to participate, please take your time, ask any questions you may have, and consult with others as you wish.

\section{What is the purpose of the study?}

The incorporation of sensing, data collection, and actuation within the built environment has begun to necessitate the involvement of new disciplines within the architectural design process. Alongside architects, engineers, and industrial designers, professionals from technology domains are being called upon to collaborate and develop smart architecture. Insight into how knowledge sharing may be facilitated among smart architectural project stakeholders may help future project teams overcome the difficulties associated with gaps in disciplinary knowledge and allow innovation to occur. 


\section{What will I be asked to do?}

If you agree to take part in the study, we will ask you to:

- $\quad$ Complete a brief 5-minute preliminary questionnaire

- Download and install Microsoft Teams videoconferencing and Miro online collaboration software.

- Convene with researchers and other participants using the programs listed above at the mutually agreed upon date and time.

- $\quad$ Participate in a 45-minute collaborative interdisciplinary design charrette.

- $\quad$ Participate in a 45-minute card sorting session.

- Consent to the audio recording of videoconferences and video recording of digital collaboration boards.

\section{Risks}

We do not anticipate any risks to participants during the conduction of this study.

\section{Possible Benefits}

You may not receive any direct benefit from your participation in this study, however you may benefit from knowledge sharing exercises and gain a greater understanding of other disciplinary knowledge, goals, and values in relation to the development of smart architecture. You may also benefit from a greater knowledge of knowledge sharing tools and remote collaboration through participation in online design charrettes. Your participation will also allow researchers to better understand gaps in disciplinary knowledge and help participant communities identify design processes that may be improved through the employment of knowledge sharing strategies.

\section{Compensation/Incentives}

You will be given a $\$ 10$ eGift card to Tim Horton's for your participation in the study.

\section{No waiver of your rights}

By signing this form, you are not waiving any rights or releasing the researchers from any liability.

\section{Withdrawing from the study}

If you withdraw your consent during the course of the study, all information collected from you before your withdrawal will be discarded. After the study, you may still request that your data be removed from the study and deleted by notice given to the Principal Investigator (named above) within 14 days after participation.

\section{Confidentiality}

No information that discloses your identity will be released or published. Design exercise and focus group transcripts will be altered to remove all names and identifying information. Once design exercise and focus group data are transcribed and de-identified, video and audio data will be destroyed. You will be assigned a coded pseudonym so that your identity will not be directly associated with the data you have provided. All data, including coded information, will be kept in a password-protected file on a secure computer. Research data will only be accessible by the researcher and the research supervisor. Research records may be accessed by the Carleton University Research Ethics Board in order to ensure continuing ethics compliance. De-identified data may be kept and used in publications, presentations, or future 
research/teaching. Your data will be stored and protected by Qualtrics, Microsoft Teams, and Miro in the United States, but may be disclosed via a court order or data breach. Under confidentiality agreement, a transcription agency will help with the transcription of audio data.

\section{Data Retention}

Your de-identified data will be retained until research is complete and will afterwards be securely destroyed.

\section{New information during the study}

In the event that any changes could affect your decision to continue participating in this study, you will be promptly informed.

\section{Ethics review}

This project was reviewed and cleared by the Carleton University Research Ethics Board B. If you have any ethical concerns with the study, please contact Carleton University Research Ethics Board (by phone at 613-520-2600 ext. 4085 or by email at ethics@carleton.ca.

\section{Statement of consent - print and sign name}

I voluntarily agree to participate in this study.

I agree to the audio/video recording of research proceedings.

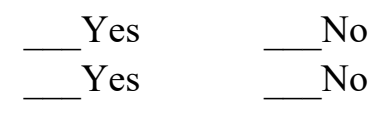

Signature of participant

Date

\section{Research team member who interacted with the participant}

I have explained the study to the participant and answered any and all of their questions. The participant appeared to understand and agree. I provided a copy of the consent form to the participant for their reference.

Signature of researcher

Date 


\section{Appendix D.}

\section{Carleton

Canada's Capital University

\section{Questionnaire}

Q1: Please select the discipline that best describes your field of work:

Architecture

Engineering

Industrial Design

Information Technology

Q2: How many years of professional experience do you have working within that discipline?

- Open field

The following questions have to do with knowledge sharing strategies commonly employed by architectural design teams.

These strategies may involve the use of tools such as knowledge management databases, building information models, virtual interaction and discussion boards, physical settings such as interdisciplinary co-location, and workgroups, social practices such as the formation of project sup-cultures through shared activities, or procedures that regulate the use of any of the above.

Q3: If any, what knowledge sharing strategies have you encountered in your career as a professional? (Select all that apply)

Knowledge management database

Building information models

Virtual interaction

Discussion boards

Co-location

Workgroups

Shared activities

Procedures

Other: 
Q4: When faced with a design problem that requires collaboration with other disciplines, I would (prefer to use) to gain knowledge from these disciplines. (Select all that apply)

Knowledge management database

Building information models

Virtual interaction

Discussion boards

Co-location

Workgroups

Shared activities

Procedures

Other: 


\section{Appendix E.}

\section{Questionnaire Responses}

\begin{tabular}{|l|l|}
\hline Questionnaire Q1 & \\
\hline Architect & 4 \\
\hline Architectural Technologist & 1 \\
\hline Engineer & 1 \\
\hline Building Envelope Engineer & 1 \\
\hline Building Automation Product Strategist & 1 \\
\hline Energy Analyst & 1 \\
\hline
\end{tabular}

\begin{tabular}{|l|l|}
\hline Questionnaire Q2 & \\
\hline Architect 1 & 8 \\
\hline Architect 2 & 16 \\
\hline Architect 3 & 22 \\
\hline Architect 4 & 16 \\
\hline Architectural Technologist & 8 \\
\hline Engineer & 12 \\
\hline Building Envelope Engineer & 32 \\
\hline Building Automation Product Strategist & 30 \\
\hline Energy Analyst & 6 \\
\hline
\end{tabular}

\begin{tabular}{|l|l|}
\hline Questionnaire Q3 - Team 1 & \\
\hline Knowledge Management Database & 1 \\
\hline Building Information Modeling & 1 \\
\hline Online Video Communication & 2 \\
\hline Online Discussion Board & 1 \\
\hline Co-Location & 0 \\
\hline Workgroups & 2 \\
\hline Pilot Projects & 1 \\
\hline Shared Activities: Charrettes/Workgroups & 3 \\
\hline Established Interaction Schemes & 2 \\
\hline Other & 1 \\
\hline
\end{tabular}




\begin{tabular}{|l|l|}
\hline Questionnaire Q3 - Team 2 & \\
\hline Knowledge Management Database & 1 \\
\hline Building Information Modeling & 2 \\
\hline Online Video Communication & 3 \\
\hline Online Discussion Board & 2 \\
\hline Co-Location & 2 \\
\hline Workgroups & 2 \\
\hline Pilot Projects & 2 \\
\hline Shared Activities: Charrettes/Workgroups & 2 \\
\hline Established Interaction Schemes & 0 \\
\hline Other & 0 \\
\hline
\end{tabular}

\begin{tabular}{|l|l|}
\hline Questionnaire Q3 - Team 3 & \\
\hline Knowledge Management Database & 2 \\
\hline Building Information Modeling & 2 \\
\hline Online Video Communication & 3 \\
\hline Online Discussion Board & 2 \\
\hline Co-Location & 2 \\
\hline Workgroups & 2 \\
\hline Pilot Projects & 1 \\
\hline Shared Activities: Charrettes/Workgroups & 2 \\
\hline Established Interaction Schemes & 0 \\
\hline Other & 2 \\
\hline
\end{tabular}

\begin{tabular}{|l|l|}
\hline Questionnaire Q4 - Team 1 & \\
\hline Knowledge Management Database & 1 \\
\hline Building Information Modeling & 1 \\
\hline Online Video Communication & 3 \\
\hline Online Discussion Board & 1 \\
\hline Co-Location & 0 \\
\hline Workgroups & 2 \\
\hline Pilot Projects & 0 \\
\hline Shared Activities: Charrettes/Workshops & 2 \\
\hline Established Interaction Schemes & 1 \\
\hline Other & 1 \\
\hline
\end{tabular}




\begin{tabular}{|l|l|}
\hline Questionnaire Q4 - Team 2 & \\
\hline Knowledge Management Database & 1 \\
\hline Building Information Modeling & 1 \\
\hline Online Video Communication & 2 \\
\hline Online Discussion Board & 1 \\
\hline Co-Location & 2 \\
\hline Workgroups & 2 \\
\hline Pilot Projects & 0 \\
\hline Shared Activities: Charrettes/Workshops & 3 \\
\hline Established Interaction Schemes & 1 \\
\hline Other & 0 \\
\hline
\end{tabular}

\begin{tabular}{|l|l|}
\hline Questionnaire Q4 - Team 3 & \\
\hline Knowledge Management Database & 2 \\
\hline Building Information Modeling & 2 \\
\hline Online Video Communication & 3 \\
\hline Online Discussion Board & 0 \\
\hline Co-Location & 1 \\
\hline Workgroups & 1 \\
\hline Pilot Projects & 1 \\
\hline Shared Activities: Charrettes/Workshops & 1 \\
\hline Established Interaction Schemes & 0 \\
\hline Other & 2 \\
\hline
\end{tabular}




\section{Appendix F.}

\section{Carleton \\ U N I V E R I T Y}

Canada's Capital University

\section{Design Brief and Miro Tutorial}

Project team members will receive discipline-specific project and knowledge sharing goals to be upheld prior to the commencement of the charrette.

\section{Architect}

Collaborate with other members of the project team to produce a creative response to the design brief. Help conceptualize, visualize, and organize ideas, concepts, forms, and materials.

Ensure that design brief response addresses human factors principles including but not limited to occupant need for visual and thermal comfort.

\section{Designer}

Collaborate with other members of the project team to produce a creative response to the design brief. Help conceptualize, visualize, and organize ideas, concepts, forms, and materials.

Ensure that design brief response addresses human factors principles including but not limited to occupant need for visual and thermal comfort.

\section{Engineer}

Collaborate with other members of the project team to produce a creative response to the design brief. Help conceptualize, visualize, and organize ideas, structures, mechanical systems, and materials. Ensure that design brief response will safely and reliably address all functional requirements.

\section{Technologist}

Collaborate with other members of the project team to produce a creative response to the design brief. Help conceptualize and organize ideas, software, and hardware solutions Ensure that design brief response will safely and reliably address all functional requirements.

The project team will work together over the course of 30 minutes to develop a response to the charrette brief using knowledge sharing strategies derived from questionnaire responses. Charrettes will be used to test the ability of strategies to assist project team members in collaboration and interdisciplinary knowledge sharing. Strategies may include tool-based approaches such as knowledge management databases, virtual interaction, discussion boards, or building information models, or setting based approaches such as co-location or workgroup. 


\section{Test Proceedings}

- First of all thank you for taking the time to participate in the study this afternoon

- Before we begin I know we're all joining each other from a couple of different spots across the country, so if you all don't mind I'd like for everyone to give maybe a short introduction and a little insight into the work that they do

- I'll also quickly give a refresher on the exercise you'll be doing, it's a condensed version of what's commonly called a 'charrette.'

- It involves you the design team and a design problem to be addressed within a limited time frame (in this case 30 minutes).

- As the design team, you may respond to the brief using any combination of notes, diagrams or sketches using the online collaboration board.

- Once the allotted time has elapsed, I'll ask for you to present your response and speak briefly about the process you've used to produce it.

- Finally l'Il just give a quick run-through of the brief and tools available on the board.

Miro features the digital equivalents of tools you might expect to find in the room if this exercise were to be held in person.

In the side bar on the left edge of the window you'll find in order from top to bottom:

- The cursor tool which will allow you to select and move an item

- A template feature, which we will not need here

- A sticky note tool

- A shape creator tool

- An arrow creator tool

- A pen / marker / eraser and lasso tool which will allow you to select and move multiple items at once

- The rest of the tools including those in the ellipsis menu won't really serve any purpose either

The bar on the bottom edge of your window will not be used in this exercise either, save for the timer tool which I will start when it's time to begin.

Before we do so are there any questions I can answer before I set and start the timer? 


\section{SCENARIO 1: RESIDENTIAL}

Your interdisciplinary project team has been assembled remotely to conceptualize a smart shading system to be implemented as part of a high-rise apartment building located in Ottawa, Canada.

The system is being workshopped as a method of dynamically regulating and optimizing building temperature across all apartment units. While part of a vast network, individual shading systems must interface with the occupants of each unit and be able to balance the preferences of each unit against a building-wide temperature control plan. Shading systems must be implemented along all exterior openings and allow for the full, partial, or non-shading of each individual unit.

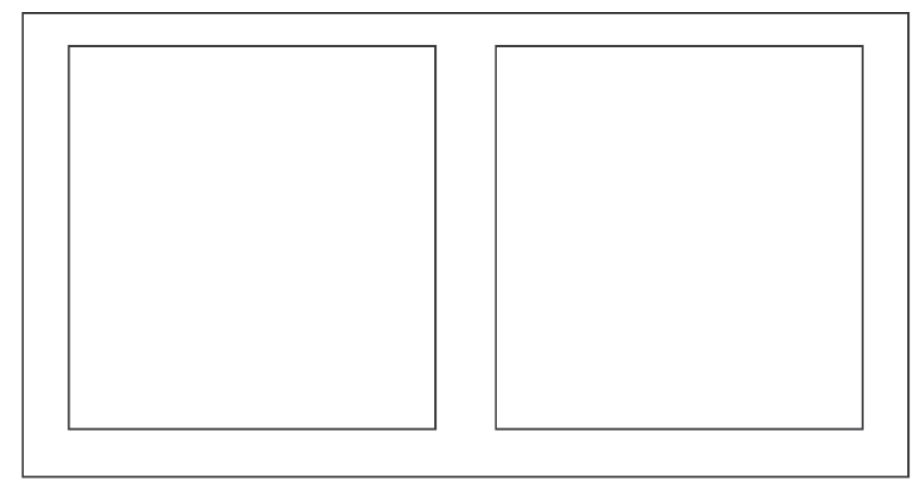

Exterior Wall Elevation

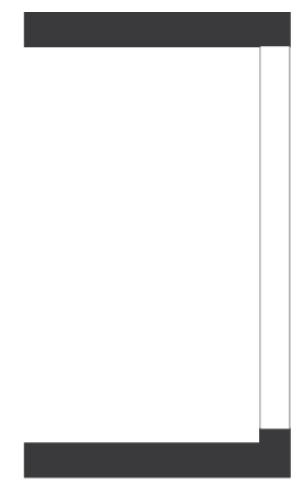

Exterior Wall Section
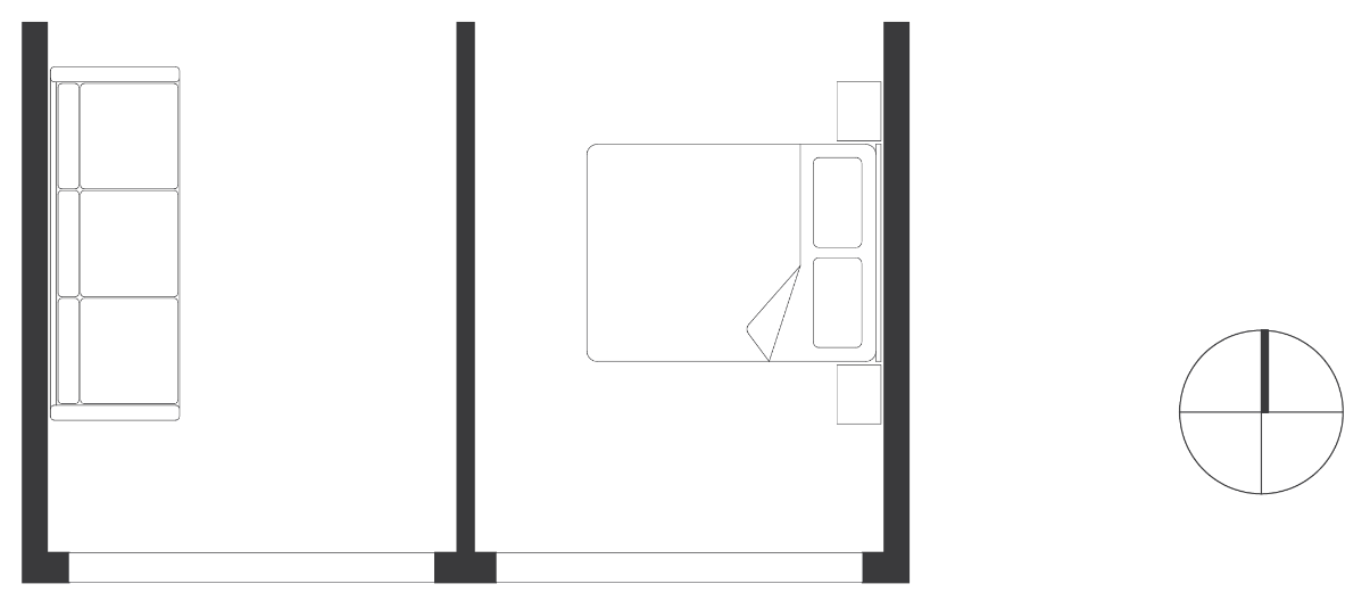

Plan 


\section{SCENARIO 2: COMMERCIAL}

Your interdisciplinary project team has been assembled remotely to conceptualize a smart shading system to be implemented as part of a high-rise commercial building located in Ottawa, Canada.

The system is being workshopped as a method of dynamically regulating and optimizing building temperature across all commercial units. While part of a vast network, individual shading systems must interface with the occupants of each unit and be able to balance the preferences of each unit against a building-wide temperature control plan. Shading systems must be implemented along all exterior openings and allow for the full, partial, or non-shading of each individual unit.

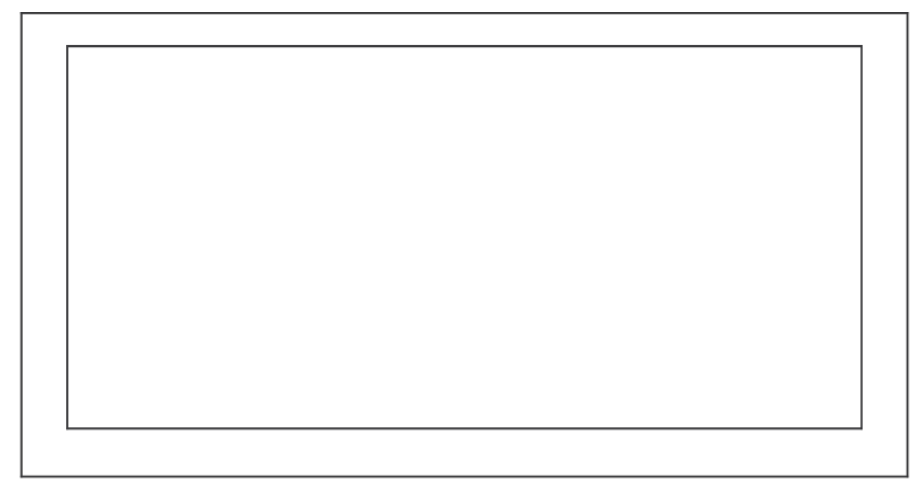

Exterior Wall Elevation

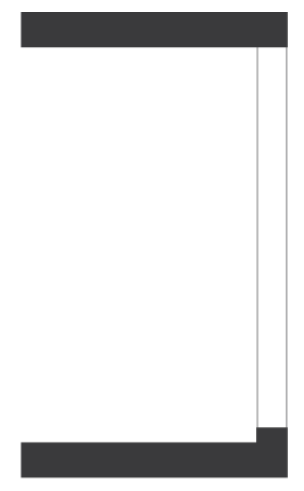

Exterior Wall Section

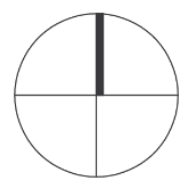

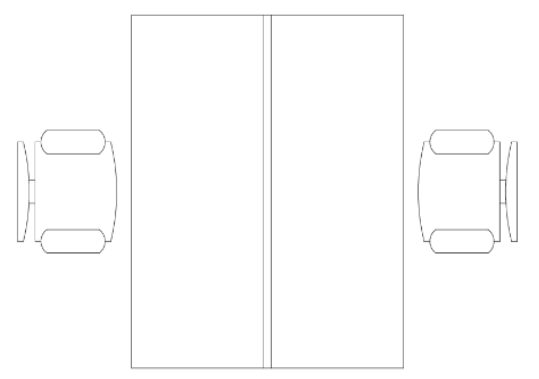

Plan 


\section{SCENARIO 3: HOSPITALITY}

Your interdisciplinary project team has been assembled remotely to conceptualize a smart shading system to be implemented as part of a healthcare facility located in Ottawa, Canada.

The system is being workshopped as a method of dynamically regulating and optimizing building temperature across all individual units. While part of a vast network, individual shading systems must interface with the occupants of each unit and be able to balance the preferences of each unit against a building-wide temperature control plan. Shading systems must be implemented along all exterior openings and allow for the full, partial, or non-shading of each individual unit.

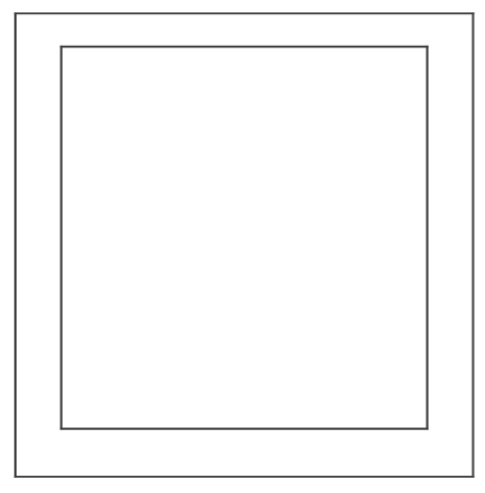

Exterior Wall Elevation

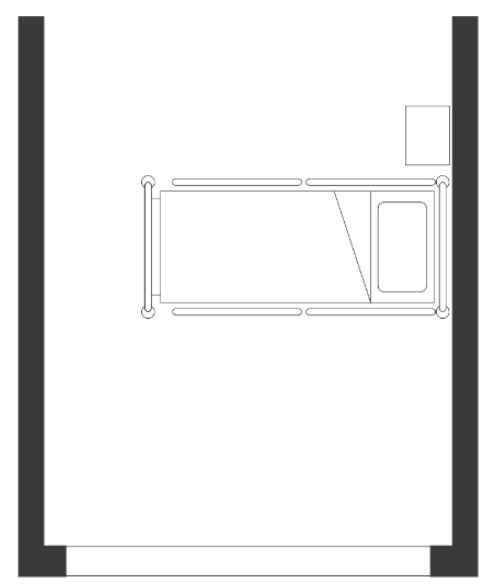

Plan

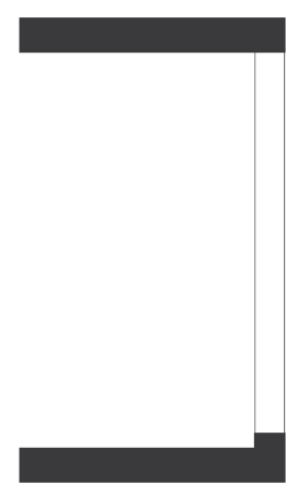

Exterior Wall Section

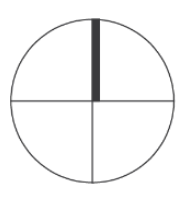


Appendix G.

Carleton

Canada's Capital University

\section{Miro Charrette Collaboration Board}
miro
Charrette Exercise
$\uparrow n$

Your interdisciplinary project team has been assembled remotely to conceptualize a smart shading system to be implemented as part of a high-rise apartment building located in Ottawa, Canada.

The system is being workshopped as a method of dynamically regulating and optimizing building temperature across all apartment units. While part of a vast network, individual shading systems must interface with the occupants of each unit and be able to balance the preferences of each unit against a building-wide temperature control plan. Shading systems must be implemented along all exterior openings and allow for the full, partial, or non shading of each individual unit.

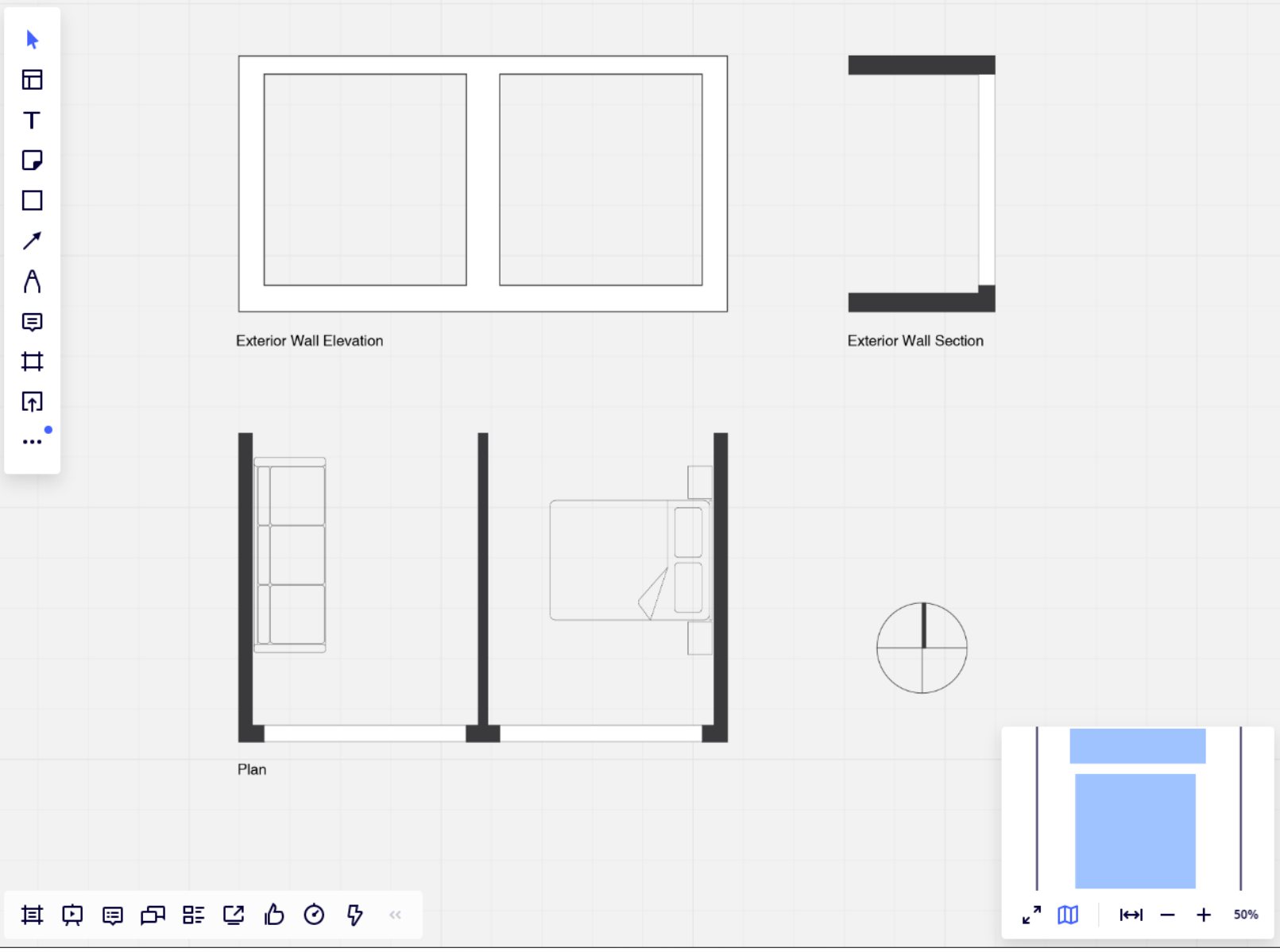




\section{Appendix $\mathrm{H}$.}

\section{Carleton

Canada's Capital University

\section{Card Sort}

Card sorting sessions will allow participants to discuss their experience using knowledge sharing strategies throughout the design charrette. Researchers will observe and record how participants conceptualize knowledge sharing throughout both the charrette and their experience as professionals.

\section{Briefing:}

The activity we would like you to do is called a "Card Sort." Your group will be given a set of index cards containing common knowledge sharing strategies and be asked to sort them. We would like you all to sort the cards into groups that, to you, belong together.

\section{After the sort has been completed:}

Now that your group has finished sorting the cards into categories, we would like you to briefly describe why cards have been placed together.

\section{Content:}

Knowledge sharing strategies:

- Tools: knowledge management databases, building information models, virtual interaction, and discussion boards

- $\quad$ Physical Settings: co-location, workgroups

- $\quad$ Social Practices: formation of project sub-cultures, shared activities

- $\quad$ Procedures

Artifacts produced through the employment of knowledge sharing strategies: •

Models, mock-ups, sketches, diagrams, notes

\section{Possible Sorting Categories (To be determined by participants):}

- Usage of strategies by project stage

- Usage of strategies in response to a particular type of design problem

- Strategies commonly employed by or between specific disciplinary user groups

- $\quad$ Perceived effectiveness of strategies 


\section{Appendix I.}

Carleton

Canada's Capital University

Card Sorting Deck

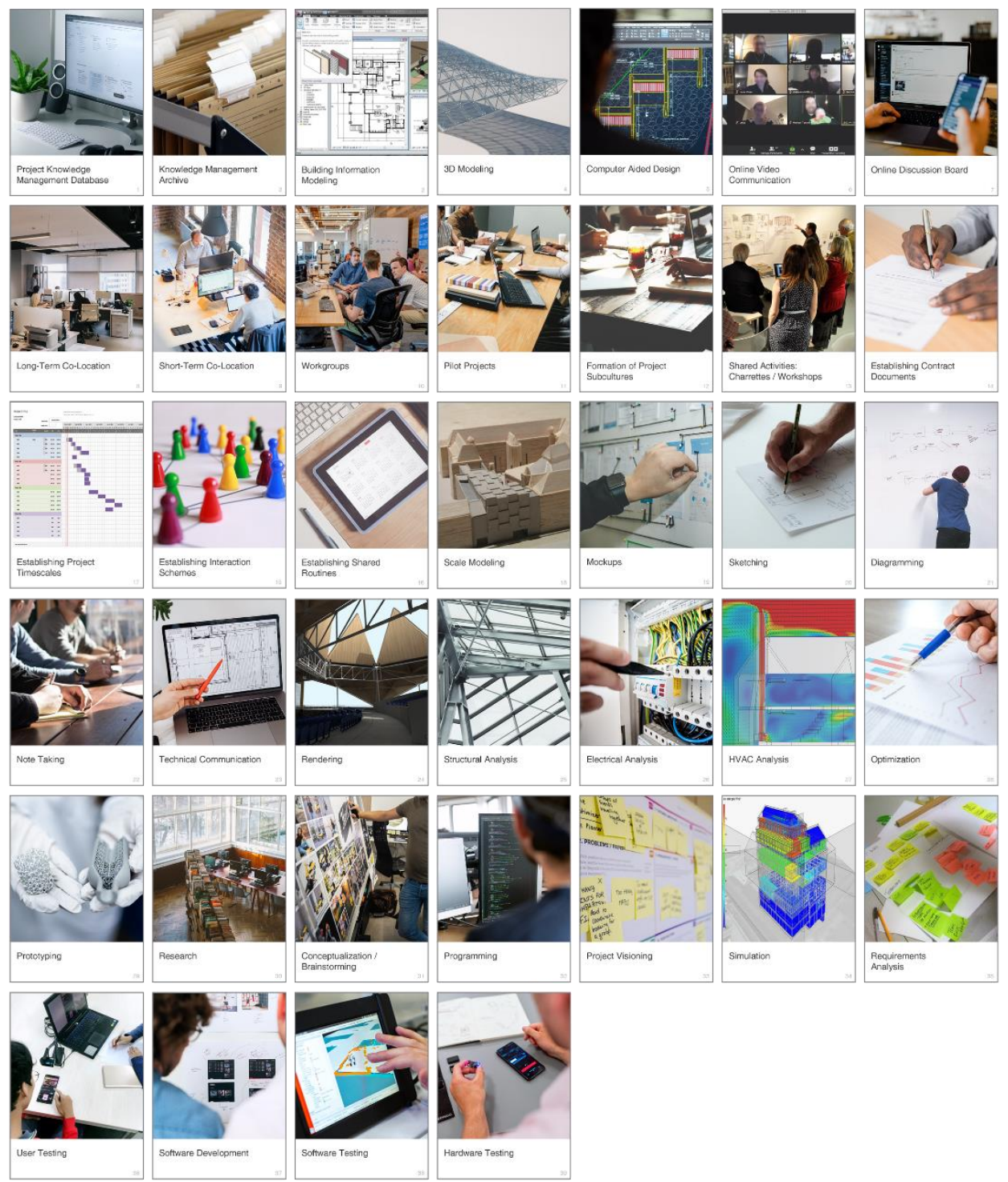


Appendix J.

Carleton

Canada's Capital University

\section{Miro Card Sorting Board}

miro

Card Sorting Exercise मे $\uparrow \curvearrowleft$

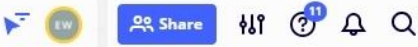

目

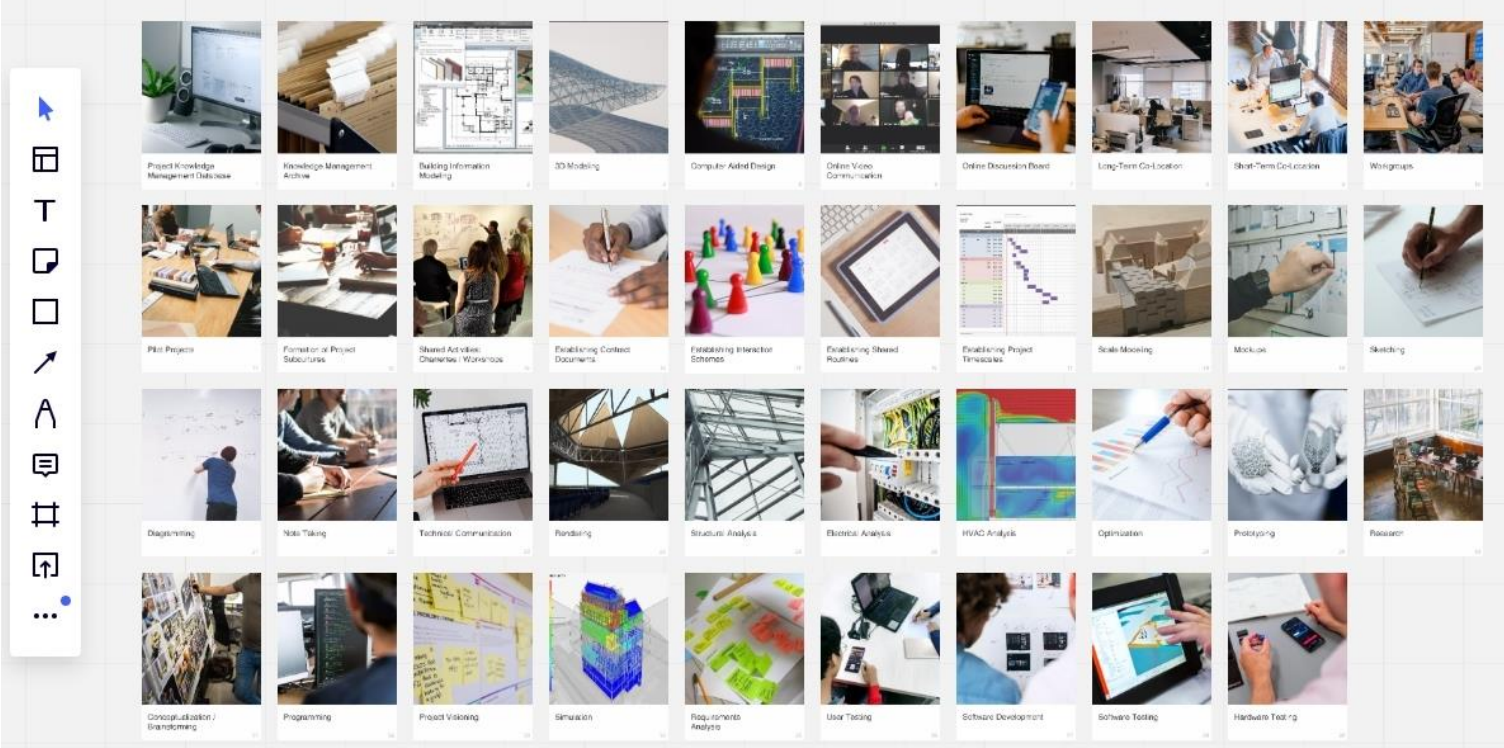

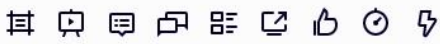




\section{Appendix K.}

\section{Carleton

\section{Debriefing Script}

First of all, I would like to thank you all for your participation throughout both the design charrette and focus group discussions.

Our research has sought primarily to understand the impact of knowledge sharing strategies on collaboration throughout interdisciplinary smart architectural design projects. The charrette you completed was designed to assess the ability of (a particular strategy) to help you and the other project team members share and acquire the knowledge necessary to answer the project brief.

Previous research has shown that integrating knowledge sharing strategies within design processes foster a greater understanding of disciplinary knowledge, goals, and values among project team members. Less is known however about the employment or effectiveness of such strategies within smart architectural design processes and the integration of sensing and actuation within the built environment. Research on this project began in an effort to understand this problem space given the calls for increased interdisciplinary collaboration within smart architecture development.

Before distributing questionnaires, conducting charrettes or card sorting sessions, our research team had hypothesized that bringing collaborators together to work in a shared physical setting (when that was still possible) would not alone be enough to prompt charrette participants to establish and bring knowledge sharing strategies into practice on their own. Through the introduction of a clearly defined procedure for establishing knowledge sharing, we expected that collaboration between interdisciplinary participants might be more efficient and lead to better design outcomes.

Through questionnaires and card sorting sessions, we asked you to provide some insight into strategies you may have encountered in your professional career and how they may have affected project processes and outcomes.

Your participation throughout these exercises will help our research team develop insights into how knowledge sharing might be facilitated among smart architectural project stakeholders and help future interdisciplinary project teams develop solutions to complex design problems

If you would like to receive a copy of this research once completed or have any remaining concerns, questions, or comments about the experiment, please feel free to contact me (Eric Wolfe) at: ericwolfe@cmail.carleton.ca, or Stephen Field at: stephen.field@carleton.ca 613-520-2600, ext. 8371. If you have any ethical concerns with the study, please contact the Carleton University Research Ethics Board-B (by phone at 613-520-2600 ext. 4085 or via email at ethics@carleton.ca).

Once again, thank you for your participation. 


\section{Appendix L.}

\section{Carleton \\ U N I VER S I T Y}

\section{Canada's Capital University}

\section{Card Sorting Results}

\begin{tabular}{|c|c|c|c|c|}
\hline Card no & Card name & Sort 1 & Sort 2 & Sort 3 \\
\hline 1 & Project Knowledge Management Database & Project Management & Schematic Design & Project Management \\
\hline 2 & Knowledge Management Archive & Project Management & Post-Construction & Project Management \\
\hline 3 & Building Information Modeling & Design Tools & Schematic Design & Detailed Design \\
\hline 4 & 3D Modeling & Design Tools & Design Development & Detailed Design \\
\hline & Computer Aided Design & Design Tools & Construction Documents & Detailed Design \\
\hline 6 & Online Video Communication & Client Interaction & Pre-Design / Concept Design & Collaboration \& Communication \\
\hline 7 & Online Discussion Board & Design Tools & Concept Design & Collaboration \& Communication \\
\hline 8 & Long-Term Co-Location & Project Management & Concept Design & Collaboration \& Communication \\
\hline 9 & Short-Term Co-Location & Project Management & Concept Design & Collaboration \& Communication \\
\hline 10 & Workgroups & Design Process (Building) & Post-Construction & Collaboration \& Communication \\
\hline 11 & Pilot Projects & Project Management & Concept Design & Prototyping \& Testing \\
\hline 12 & Formation of Project Subcultures & Project Management & Schematic Design & Collaboration \& Communication / Visioning \\
\hline 13 & Shared Activities: Charrettes / Workshops & Design Process (Building) & Pre-Design / Design Development & Collaboration \& Communication \\
\hline 14 & Establishing Contract Documents & Project Management & Contract Administration & Project Management \\
\hline 15 & Establishing Interaction Schemes & Client Interaction & Contract Administration & Collaboration \& Communication \\
\hline 16 & Establishing Shared Routines & Client Interaction & Contract Administration & Collaboration \& Communication \\
\hline 17 & Establishing Project Timescales & Project Management & Pre-Design & Project Management \\
\hline 18 & Scale Modeling & Design Tools & Schematic Design & Prototyping \& Testing \\
\hline 19 & Mockups & Design Tools & Contract Administration & Prototyping \& Testing \\
\hline 20 & Sketching & Design Tools & Concept Design & Visioning \\
\hline 21 & Diagramming & Client Interaction & Concept Design & Visioning \\
\hline 22 & Note Taking & Design Tools & Pre-Design & Collaboration \& Communication \\
\hline 23 & Technical Communication & Client Interaction & Design Development & Collaboration \& Communication \\
\hline 24 & Rendering & Design Tools & Design Development & Visioning \\
\hline 25 & Structural Analysis & Design Process (Building) & Design Development & Detailed Design \\
\hline 26 & Electrical Analysis & Design Process (Building) & Design Development & Detailed Design \\
\hline 27 & HVAC Analysis & Design Process (Building) & Design Development & Detailed Design \\
\hline 28 & Optimization & Design Process (Building) & Construction Documents & Detailed Design \\
\hline 29 & Prototyping & Design Process (Software) & Design Development & Prototyping \& Testing \\
\hline 30 & Research & Design Process (Building) & Pre-Design & Visioning \\
\hline 31 & Conceptualization / Brainstorming & Design Process (Building) & Pre-Design & Visioning \\
\hline 32 & Programming & Design Process (Software) & Pre-Design & Prototyping \& Testing \\
\hline 33 & Project Visioning & Client Interaction & Pre-Design & Visioning \\
\hline 34 & Simulation & Design Tools & Design Development & Detailed Design \\
\hline 35 & Requirements Analysis & Design Process (Building) & Concept Design & Visioning \\
\hline 36 & User Testing & Design Process (Software) & Post-Construction & Prototyping \& Testing \\
\hline 37 & Software Development & Design Process (Software) & Unsorted & Prototyping \& Testing \\
\hline 38 & Software Testing & Design Process (Software) & Unsorted & Prototyping \& Testing \\
\hline 39 & Hardware Testing & Design Process (Software) & Unsorted & Prototyping \& Testing \\
\hline 40 & Managing Subcontractors and Tradespeople & Project Management & Contract Administration & Project Management \\
\hline 41 & Sourcing Materials and Equipment & Project Management & Design Development & Project Management \\
\hline 42 & Monitoring Project Budget & Project Management & Construction Documents & Project Management \\
\hline 43 & Monitoring Project Timescales & Project Management & Construction Documents & Project Management \\
\hline 44 & Applying for Building Permits & Project Management & Construction Documents & Project Management \\
\hline
\end{tabular}




\section{Appendix M.}

\section{Carleton \\ U N I V E R S T Y}

Canada's Capital University

Card Sorting Exploratory Analysis

\begin{tabular}{|c|c|c|c|c|}
\hline Card no & Card name & Sort 1 & Sort 2 & Sort 3 \\
\hline 1 & 1 Project Knowledge Management Database & Project Management & Schematic Design & Project Management \\
\hline 2 & 2 Knowledge Management Archive & Project Management & Post-Construction & Project Management \\
\hline 3 & 3 Building Information Modeling & Design Tools & Schematic Design & Detailed Design \\
\hline 4 & 4 3D Modeling & Design Tools & Design Development & Detailed Design \\
\hline 5 & 5 Computer Aided Design & Design Tools & Construction Documents & Detailed Design \\
\hline 6 & 6 Online Video Communication & Client Interaction & Pre-Design / Concept Design & Collaboration \& Communication \\
\hline 7 & 7 Online Discussion Board & Design Tools & Concept Design & Collaboration \& Communication \\
\hline 8 & 8 Long-Term Co-Location & Project Management & Concept Design & Collaboration \& Communication \\
\hline 9 & 9 Short-Term Co-Location & Project Management & Concept Design & Collaboration \& Communication \\
\hline 10 & Workgroups & Design Process (Building) & Post-Construction & Collaboration \& Communication \\
\hline 11 & 1 Pilot Projects & Project Management & Concept Design & Prototyping \& Testing \\
\hline 12 & 2 Formation of Project Subcultures & Project Management & Schematic Design & Collaboration \& Communication / Visioning \\
\hline 13 & 3 Shared Activities: Charrettes / Workshops & Design Process (Building) & Pre-Design / Design Development & Collaboration \& Communication \\
\hline 14 & 4 Establishing Contract Documents & Project Management & Contract Administration & Project Management \\
\hline 15 & 5 Establishing Interaction Schemes & Client Interaction & Contract Administration & Collaboration \& Communication \\
\hline 16 & 6 Establishing Shared Routines & Client Interaction & Contract Administration & Collaboration \& Communication \\
\hline 17 & 7 Establishing Project Timescales & Project Management & Pre-Design & Project Management \\
\hline 18 & 8 Scale Modeling & Design Tools & Schematic Design & Prototyping \& Testing \\
\hline 19 & 9 Mockups & Design Tools & Contract Administration & Prototyping \& Testing \\
\hline 20 & Sketching & Design Tools & Concept Design & Visioning \\
\hline 21 & 1 Diagramming & Client Interaction & Concept Design & Visioning \\
\hline 22 & 2 Note Taking & Design Tools & Pre-Design & Collaboration \& Communication \\
\hline 23 & 3 Technical Communication & Client Interaction & Design Development & Collaboration \& Communication \\
\hline 24 & 4 Rendering & Design Tools & Design Development & Visioning \\
\hline 25 & 5 Structural Analysis & Design Process (Building) & Design Development & Detailed Design \\
\hline 26 & 5 Electrical Analysis & Design Process (Building) & Design Development & Detailed Design \\
\hline 27 & 7 HVAC Analysis & Design Process (Building) & Design Development & Detailed Design \\
\hline 28 & Optimization & Design Process (Building) & Construction Documents & Detailed Design \\
\hline 29 & Prototyping & Design Process (Software) & Design Development & Prototyping \& Testing \\
\hline 30 & Research & Design Process (Building) & Pre-Design & Visioning \\
\hline 31 & Conceptualization / Brainstorming & Design Process (Building) & Pre-Design & Visioning \\
\hline 32 & Programming & Design Process (Software) & Pre-Design & Prototyping \& Testing \\
\hline 33 & 3 Project Visioning & Client Interaction & Pre-Design & Visioning \\
\hline 34 & Simulation & Design Tools & Design Development & Detailed Design \\
\hline 35 & Requirements Analysis & Design Process (Building) & Concept Design & Visioning \\
\hline 36 & 5 User Testing & Design Process (Software) & Post-Construction & Prototyping \& Testing \\
\hline 37 & 7 Software Development & Design Process (Software) & Unsorted & Prototyping \& Testing \\
\hline 38 & 3 Software Testing & Design Process (Software) & Unsorted & Prototyping \& Testing \\
\hline 39 & Hardware Testing & Design Process (Software) & Unsorted & Prototyping \& Testing \\
\hline 40 & Managing Subcontractors and Tradespeople & Project Management & Contract Administration & Project Management \\
\hline 41 & Sourcing Materials and Equipment & Project Management & Design Development & Project Management \\
\hline 42 & Monitoring Project Budget & Project Management & Construction Documents & Project Management \\
\hline 43 & 3 Monitoring Project Timescales & Project Management & Construction Documents & Project Management \\
\hline 44 & Applying for Building Permits & Project Management & Construction Documents & Project Management \\
\hline
\end{tabular}

